\title{
A Stochastic Measure of International Competitiveness*
}

\author{
by \\ Kenneth W. Clements, H. Y. Izan and Yihui Lan ${ }^{\#}$ \\ Business School \\ The University of Western Australia
}

\begin{abstract}
$\underline{\text { Abstract }}$
Government agencies around the world produce indexes that purport to measure international competitiveness. The most common version is the real effective exchange rate, which is some form of weighted average of the real exchange rates of the country's trading partners. Such indexes convey a false sense of accuracy as they ignore the volatility among the component real exchange rates of the partners. As long as all real rates do not move in an equiproportionate fashion, in a fundamental sense real effective exchange rates are subject to estimation uncertainty. We demonstrate show how this uncertainty can be measured and used to enhance current practice.
\end{abstract}

\footnotetext{
${ }^{*}$ We would like to acknowledge the research assistance of Lukas Weber and the help of Luci Ellis in providing data. This research was supported in part by the ARC.

${ }^{\#}$ Corresponding author. Email: ylan@ecel.uwa.edu.au.
} 


\section{Introduction}

Suppose the economy experiences a period of considerable monetary turmoil involving a surge of inflation and a substantial depreciation of the exchange rate. Following this period, can it be said in any meaningful sense that the "international competitiveness" of the economy as a whole has changed -- has it "improved" or "worsened"? The conventional answer to this question involves the use of one of two measures, (i) the internal real exchange rate, the relative price of traded goods in terms of nontraded; or (ii) the external real exchange rate, the price-level adjusted nominal exchange rate. The first measure assesses the competitiveness of the economy's traded goods sector in comparison with the rest of the economy (as represented by nontraded goods), while the second measure makes this comparison for the economy as a whole vis-à-vis the trading partner. As in practice there are multiple trading partners, some form of averaging over partners is needed to map multiple bilateral external real exchange rates into one multilateral rate; typically a type of weighted geometric mean is employed for this purpose. ${ }^{1}$ Official agencies in many countries now publish multilateral real exchange rates of this form, which tend to be known as "real effective exchange rates" (REERs). Accordingly, one way to answer the above question is to refer to the change in the value of the REER to determine whether international competitiveness has improved or worsened.

There are surely many imperfections with the REER as a reliable indicator of competitiveness. One such imperfection that should be highlighted stems from its key building block, purchasing power parity theory, which postulates that as a long-run proposition, the nominal exchange rate is proportional to relative price levels, the ratio of prices at home $(\mathrm{P})$ relate to those abroad $\left(\mathrm{P}^{*}\right)^{2}$ That is, $\mathrm{S}=(1 / \alpha)\left(\mathrm{P} / \mathrm{P}^{*}\right)$, where $\mathrm{S}$ is the nominal exchange rate (the domestic-currency cost of a unit of foreign exchange) and $\alpha$ is a proportionality constant. According to PPP theory when foreign prices remain unchanged, a rise in prices at home is associated with an equiproportional depreciation of the home country's currency, so that $\left(\mathrm{P} / \mathrm{P}^{*}\right) / \mathrm{S}=\mathrm{P} / \mathrm{SP} *$ remains unchanged at the value $\alpha$. The nominal exchange rate adjusted by the price levels at home and abroad, $\mathrm{P} / \mathrm{SP} *$, which is the bilateral real exchange rate, evidently involves a comparison of the price level at home

\footnotetext{
${ }^{1}$ As in practice there are multiple traded and nontraded goods, some form of averaging over goods is also needed to define a unique internal real exchange rate. In this respect, the two versions of the real exchange rate are conceptually similar. For further discussions of the conceptual and empirical issues associated with different measures of international competitiveness and real exchange rates, see, e.g., Dwyer and Lowe (1993), Edwards (1989), Harberger (1986, 2004), Hinkle and Montiel (1999).

${ }^{2}$ Another problem with the REER as a measure of international competitiveness is that it concentrates exclusively on exchange rates and prices, to the neglect of other factors such as macroeconomic policy changes that impinge on trade; changes in the exchange-rate system and arrangements pertaining to international trade; changes in the regulatory and institutional environment; and productivity changes.
} 
with that abroad, where both are expressed in terms of the domestic currency. This definition of the real exchange rate implies that an increase (decrease) entails a real appreciation (depreciation) of the domestic currency. If we use this measure as the basis for a measure of international competitiveness, the assumption is that it tends over the longer term to some constant value $\alpha$, which plays the role of the "equilibrium real exchange rate". Accordingly, when the real rate differs from $\alpha$, we could identify this as a "disequilibrium" situation; and in terms of changes over time, an increase (decrease) in the real rate could be described as a reduction (enhancement) in competitiveness. $^{3}$

The theory of PPP provides a sharp prediction regarding the relationship between the exchange rate and relative prices. As such sharp predictions are a rarity in economics, it is not surprising that considerable controversy surrounds PPP theory, and we shall discuss four important areas of disputation. First, does PPP indeed hold over the long run? Second, if PPP is valid as a theory pertaining to the long run, then just how long is the long run? Clearly PPP theory would be of more practical usefulness (and more interesting) if the long run were a couple of quarters, rather than a couple of decades. Third, what exactly are the prices -- P and $\mathrm{P}^{*}$-- to which PPP refers? Finally, suppose we observe that the real rate is high in one period relative to some earlier period, but relative to some other earlier period, the real rate is lower. Do we conclude that competitiveness has improved or worsened? The answer to this question depends on in which of the two earlier periods the real rate was closer to its long-run equilibrium value $\alpha$. We can thus label this controversy the "base-period issue". We now briefly discuss each of the four controversies in turn.

Does PPP hold? Over the last 30 years there is much heated debate regarding whether or not PPP holds and by the early 1980s professional confidence in PPP theory dipped to possibly an alltime low after the publication of the paper "The Collapse of Purchasing Power Parities during the 1970s" by Frenkel (1981). But that was far from constituting the last word on the topic, and since then research on PPP theory has been increasing dramatically. ${ }^{4}$ There is now general consensus that PPP is not a theory of short-term exchange rate determination, but it does offer a long-run equilibrium relationship between relative prices and exchange rates, at least for the major currencies. In other words, the deviation from parity, or the real exchange rate, displays mean reversion over time and ultimately settles down at some well-defined equilibrium value. For

\footnotetext{
${ }^{3}$ Note that the bilateral real exchange rate $\mathrm{P} / \mathrm{SP}^{*}$ can be interpreted as a comparison of the unit costs $(\mathrm{P})$ of domestic producers with their revenue per unit $\mathrm{SP}^{*}$, and thus reveal something about domestic profitability. This interpretation might seem to be have somewhat different foundations, but as the identification of SP* with revenue per unit of domestic producers depends on PPP holding, such is not the case.

${ }^{4}$ According to Lan (2004), published research on PPP has grown at an average annual rate of about 15 percent, which is substantially higher than many other prominent areas of economics.
} 
surveys of these matters, see Froot and Rogoff (1995), Rogoff (1996), Sarno and Taylor (2002) and Taylor and Taylor (2004).

How long is the long run? With the growing support for PPP, the more recent focus of research has moved to the issue of what constitutes the length of the long run, that is, the period over which exchange rates fully adjust to shocks to relative prices. The general consensus reported in the literature is that the long run is estimated at about 3-5 years. As such a period could be considered too long to be plausible from an economic viewpoint, several possible explanations have been advanced for this finding, including non-linear adjustment (Michael et al., 1997), temporal aggregation (Taylor, 2001) and heterogeneity and aggregation bias (Imbs et al., 2002). Another approach is to control for the cross-country heterogeneity of consumption baskets by using the relative prices of an identical basket, the Big Mac hamburger (published by The Economist magazine). Interestingly, the length of the long run based on Big Mac prices is about 1-2 years, which is considerably lower than those based on conventional price indices. ${ }^{5}$

What prices? It is by no means clear from PPP theory what sort of prices should be used to implement the theory. Some have advocated the use of goods that enter into international trade, while others prefer broader-based price indexes, such as the CPI, which include both traded and nontraded components. Additionally, there is now a substantial literature that applies PPP to the prices of Big Mac hamburgers around the world, as mentioned above. Frenkel (1978) argues that the choice of the nature of the prices reflects deeper issues regarding the meaning of PPP theory. The use of traded goods prices reflects international arbitrage considerations, while those who advocate the use of broader price indexes tend to regard PPP as a building block of the open economy's overall monetary structure, which entails the transmission of inflation from traded to nontraded goods via substitution in consumption and production, and via the formation of expectations.

The base-period issue. Usually indexes of real exchange rates are scaled such that they take the value of 100 in some base period; and then subsequent values of the index are assessed with reference to this base value in determining whether or not there has been a real depreciation or appreciation of the currency. This amounts to assuming that in this base period the real exchange rate was at its long-run equilibrium value of $\alpha$. Such a decision is not innocuous and the issue has not received sufficient attention by agencies that publish these indexes.

Once the above difficulties regarding the bilateral real rates have been resolved as best they can, the individual rates then have to be aggregated over countries to form a multilateral index of competitiveness. As mentioned before, the REER is some type of weighted average of the real

\footnotetext{
${ }^{5}$ See Cumby (1996), Lan (2004), and Ong (2003).
} 
exchange rates of the country's major trading partners. Typically, a geometric weighted mean is used, with weights reflecting the economic importance of the partners, so that for example the weights are specified as proportional to exports, imports, total trade or GDPs. The REER index thus created tells us that in comparison to the base period, whether the economy has become more or less competitive. Conventional analysis usually ends here. In this paper we demonstrate that ending at this point is premature as it ignores valuable information contained in the data already employed in the construction of the REER. This information relates to the volatility of the underlying bilateral real rates, which can be used to add valuable measures of the degree of certainty that can be attached to the resulting REER. We construct stochastic index numbers of international competitiveness, which yield point estimates of changes in the REER as well as associated standard errors that reflect estimation uncertainty. The source of the standard errors is the underlying volatility of the component real exchange rates. ${ }^{6}$

The organisation of the paper is as follows. In Section 2 we use two examples to illustrate the basic workings of the stochastic approach as applied to international competitiveness. In Section 3 we present the details of the application of the stochastic approach to the REER index, while Sections 4 and 5 deal with the related topics of modelling heteroscedasticity and developing a procedure to identify optimal sub-periods during which the country weights can be regarded as being fixed. In Section 6, we implement the stochastic indexes for Australia, and their use in assessing the change in international competitiveness is illustrated in Section 7. Concluding remarks are given in Section 8.

\section{Two Examples}

To illustrate the basic idea of the paper, in this section we use two numerical examples in the following context. Let $\mathrm{P}_{\mathrm{t}}$ be the price index in the home country in period $t, \mathrm{P}_{\mathrm{ct}}^{*}$ be the index in trading partner $\mathrm{c}$, and $\mathrm{S}_{\mathrm{ct}}$ be the nominal exchange rate between the two countries. We can then define the corresponding bilateral real exchange rate as $r_{c t}=P_{t} / S_{c t} P_{c t}^{*}$. Furthermore, write $w_{c}$ for the weight accorded to country $\mathrm{c}$ that reflects the relative importance of $\mathrm{c}$ to the home country, and $\mathrm{D}$ for the $\log$-change operator, such that $\mathrm{Dx}_{\mathrm{t}}=\log \mathrm{x}_{\mathrm{t}}-\log \mathrm{x}_{\mathrm{t}-1}$; as an approximation $100 \times \mathrm{Dx}$ is the percentage change in $\mathrm{x}$ from the period $\mathrm{t}-1$ to $\mathrm{t}$. If the home country has $\mathrm{n}$ trading

\footnotetext{
${ }^{6}$ The two most prominent approaches to index-number theory are (i) Fisher's (1922) test approach (see Balk, 1995, for a comprehensive survey), and (ii) the economic theory of indexes (see Diewert, 1981, for a comprehensive survey). Obscure for about half a century, the stochastic approach to index numbers has been revived in recent times. Besides accounting for estimation uncertainty, the stochastic approach is versatile in that it can generate a number of familiar index formulae, as emphasised by Diewert (2002). For surveys of the stochastic approach, see Clements et al. (2005), which answers criticisms by Diewert (1995) of the approach, and Selvanathan and Prasada Rao (1994).
} 
partners, $\sum_{\mathrm{c}=1}^{\mathrm{n}} \mathrm{w}_{\mathrm{c}}=1$ and we can formulate the change in this country's REER as the following Divisia-type index:

$$
\mathrm{DR}_{\mathrm{t}}=\sum_{\mathrm{c}=1}^{\mathrm{n}} \mathrm{w}_{\mathrm{c}} \mathrm{Dr}_{\mathrm{ct}} \text {. }
$$

This is a weighted average of the changes in the bilateral real rates in the $\mathrm{n}$ partner countries, $\mathrm{Dr}_{1 \mathrm{t}}, \ldots, \mathrm{Dr}_{\mathrm{nt}}$, where the weights $\mathrm{w}_{1}, \ldots, \mathrm{w}_{\mathrm{n}}$ measure the relative importance of each country to the home country. This means that the more important trading partners are more heavily weighted in the index. Note also that the logarithmic nature of index (2.1) means that it possesses the homogeneity property that if all of the $\mathrm{n}$ bilateral rates change equiproportionally, then the index also changes by the same proportionate amount; that is, if $\operatorname{Dr}_{\mathrm{ct}}=\beta$, a constant for $\mathrm{c}=1, \ldots, \mathrm{n}$, then $\mathrm{DR}_{\mathrm{t}}=\beta$. Both these properties make perfect economic sense.

In the first example, suppose there are $n=3$ partner countries, each of which has the same importance to the home country so that $\mathrm{w}_{1}=\mathrm{w}_{2}=\mathrm{w}_{3}=1 / 3$. Suppose further that the home country's currency appreciates in real terms against each of other three currencies by approximately 10 percent, which implies that the change in each bilateral real rate is $\mathrm{Dr}_{\mathrm{ct}}=.10$. In this equiproportional case, it is clear that equation (2.1) yields a change in the index of $\mathrm{DR}_{t}=0.10$, and as there is no dispersion of the component real rates, the standard deviation is zero, as set out in column 3 of Table 1. The more interesting nonproportionate case is considered in column 4. Here the change in the REER, $\mathrm{DR}_{\mathrm{t}}$, is again approximately 10 percent, but now there is considerable variability of the underlying real rates, with a 20 percent real appreciation against country 1,10 percent against country 2 , while for country 3 the real rate is unchanged. The standard deviation of

TABLE 1

THE DISPERSION OF REAL EXCHANGE RATES

\begin{tabular}{cccc}
\hline \hline & & \multicolumn{2}{c}{$\begin{array}{c}\text { Bilateral real exchange rate } \\
(\text { Log-change } \times 100)\end{array}$} \\
\cline { 3 - 4 } Country & $\begin{array}{c}\text { Weight } \\
\text { (Percent) } \\
(1)\end{array}$ & $\begin{array}{c}\text { Case } 1 \\
(3)\end{array}$ & $\begin{array}{c}\text { Case } 2 \\
(4)\end{array}$ \\
\hline 1 & 33.3 & 10 & 20 \\
2 & 33.3 & 10 & 10 \\
3 & 33.3 & 10 & 0 \\
Mean & & 10 & 10 \\
Standard deviation & & 0 & 8.2 \\
\hline
\end{tabular}


these three changes is 8.2 percent. While the REER change is exactly the same in the two cases, it is clear that the underlying volatility is fundamentally different. This implies that we should have less certainty regarding the value of the REER change when the component real rates move in a disproportionate manner, as will now be demonstrated.

The REER change can be considered to be an estimate of the unknown population mean $\mu$ of the changes in the $n$ bilateral rates; thus we write $\hat{\mu}$ for this estimate of $\mu$ and $\hat{\sigma}$ for the estimated standard deviation. Then the standard error of the mean in column 4 of the table is $\hat{\sigma} / \sqrt{\mathrm{n}}=8.2 / \sqrt{3}=4.7\left(\right.$ all $\left.\times 10^{-2}\right)$. If we wish to test the hypothesis that $\mu=\mu_{0}$, then under the assumption that the individual real rates are iid and normal, the statistic $\left(\hat{\mu}-\mu_{0}\right) \sqrt{\mathrm{n}} / \hat{\sigma}$ follows a $t$ distribution with $(n-1)=2$ degrees of freedom. Accordingly, if we are interested in whether or not the country's competitiveness has deteriorated over the period, we would test the hypothesis that it remained unchanged, so that $\mu=0$, against the alternative $\mu>0$. Using the data of column 4 of Table 1 , the test statistic associated with this hypothesis is $(10-0) \sqrt{3} / 8.2=2.11$. As this is less than the critical value at the 5 percent level of $t_{2}$ of 2.92 (using a one-tale test), we are unable to reject the hypothesis of constant competitiveness. Another way of expressing the result is in terms of the 95-percent confidence interval for the change in competitiveness, which is $\hat{\mu} \pm 2.92(\hat{\sigma} / \sqrt{n})$ or $10 \pm 13.7\left(\right.$ all $\left.\times 10^{-2}\right)$. Accordingly, we can be 95 percent confident that the interval $[23.7,-3.7]$ contains the population parameter $\mu$; the large size of the interval reflects both the small sample and the extent of dispersion of the underlying real rates.

The above example shows that in the case in which there is no variability among the individual real exchange rates, there is no uncertainty that the REER index has risen by 10 percent, so there has been an unambiguous deterioration in the country's international competitiveness. But in the more realistic case of disproportionate movement of the real exchange rates, while the point estimate of the change in the REER is the same (10 percent), the underlying volatility leads to estimation uncertainty of the change in competitiveness. In fact, in the example, this uncertainty is so large that we are unable to reject the hypothesis that competitiveness was unchanged.

That the above considerations are of practical importance is illustrated by the second example based on real world data. Here we use Australia as the home country with $n=26$ trading partners; and allow for unequal weights by employing trade weights. We evaluate the change in the REER, defined by equation (2.1), for the transition from $t-1=1994 Q 4$ to $t=1995 Q 1$, which yields $\mathrm{DR}_{\mathrm{t}}=-2.3 \times 10^{-2}$, so that competitiveness for Australia improves by about 2.3 percent over this 
period. ${ }^{7}$ This change in competitiveness is represented by the horizontal line in panel A of Figure 1. Also included in this figure are the real exchange rate changes for the 26 countries $\operatorname{Dr}_{\mathrm{ct}}$, with two adjustments. First, as $\mathrm{DR}_{\mathrm{t}}$ is a weighted mean, we multiply each $\mathrm{Dr}_{\mathrm{ct}}$ by the respective weight $\mathrm{w}_{\mathrm{c}}$. Second, to make the term $\mathrm{w}_{\mathrm{c}} \times \mathrm{Dr}_{\mathrm{ct}}$ of the same order as $\mathrm{DR}_{\mathrm{t}}$, we multiply the former by 26 , as then the unweighted average over the 26 countries of $26 \times \mathrm{w}_{\mathrm{c}} \times \mathrm{Dr}_{\mathrm{ct}}$ equals $\mathrm{DR}_{\mathrm{t}}$. The weighted standard deviation corresponding to the weighted mean $(2.1)$ is $\sqrt{\sum_{c=1}^{\mathrm{n}} \mathrm{w}_{\mathrm{c}}\left(\mathrm{Dr}_{\mathrm{ct}}-\mathrm{DR}_{\mathrm{t}}\right)^{2}}$, which

FIGURE 1

TWO EPISODES OF CHANGES IN REAL EXCHANGE RATES
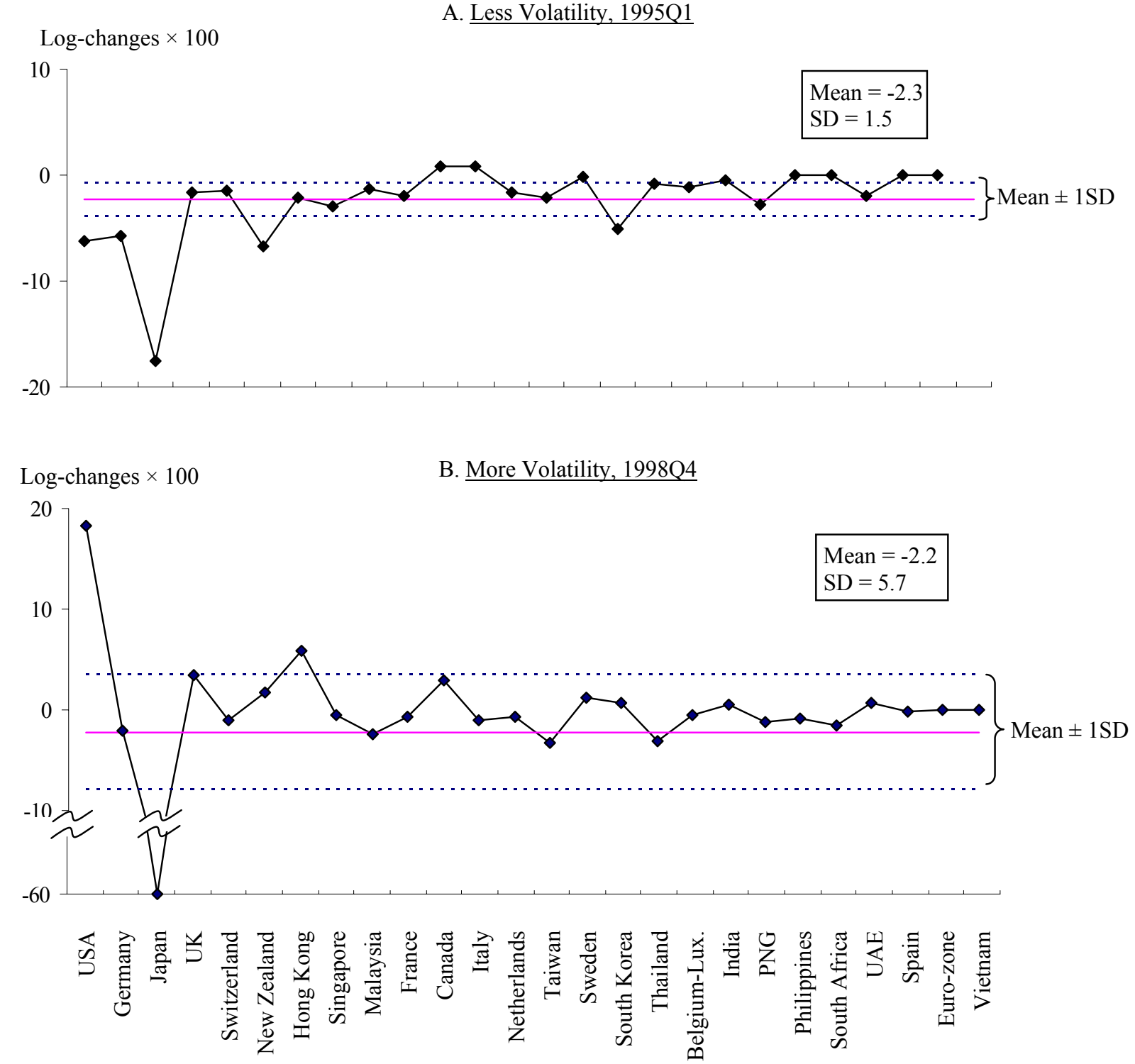

${ }^{7}$ Details of the underlying data will be given subsequently in the paper. 
equals $1.5 \times 10^{-2}$ for this example with $\mathrm{n}=26$. The figure also contains the one-standard-deviation band around the mean. Next, we apply exactly the same approach to the transition from 1998Q3 to 1998Q4, and panel B of the figure contains the results. As can be seen, the mean is close to what it was in the earlier period (about -2 percent), but now there is considerably more dispersion as the standard deviation is 5.7 percent, more than three times the previous value. Even if we omit the two outlying observations for the US and Japan, the standard deviation is $2.9 \times 10^{-2}$, which is still substantially higher than in the first period. ${ }^{8}$ The conclusion is that while competitiveness improves by approximately the same amount in the two periods, because of the higher volatility of the underlying real rates we can have much less certainty about the result for the second period. This becomes even clearer if we test the hypothesis of constant competitiveness in the two periods. For the two cases, the $\mathrm{t}$-values are $-2.3 \times \sqrt{26} / 1.5=-7.82$ and $-2.2 \times \sqrt{26} / 5.7=-1.97$. Accordingly, the hypothesis of no change can be safely rejected for 1995Q1, but we are unable to do so for 1998Q4.

Although the examples above are simple, they still illustrate the key point of the paper: $A s$ current measures of international competitiveness are deterministic and neglect estimation error, they give a false sense of accuracy. In what follows, we elaborate this basic idea within the context of the stochastic approach to index numbers.

\section{3. $\quad$ A Stochastic REER Index}

In this section we apply the stochastic approach to index-number theory to real exchange rates. As before, let $r_{c t}$ be the bilateral real exchange rate between country $c(c=1, \ldots, n)$ and the base (or numéraire) country, and let $\operatorname{Dr}_{\mathrm{ct}}=\log \mathrm{r}_{\mathrm{ct}}-\log \mathrm{r}_{\mathrm{c}, \mathrm{t}-1}$ be its log-change $(\mathrm{t}=1, \ldots, \mathrm{T})$. Suppose that each $\operatorname{Dr}_{\mathrm{ct}}$ is made up of three components, (i) a time component $\alpha_{t}$, (ii) a country component $\beta_{\mathrm{c}}$, and (iii) a zero-mean random component $\varepsilon_{\mathrm{ct}}$ :

$$
\operatorname{Dr}_{\mathrm{ct}}=\alpha_{\mathrm{t}}+\beta_{\mathrm{c}}+\varepsilon_{\mathrm{ct}}
$$

As $\quad \alpha_{t}$ plays the role of the common trend in all $n$ exchange rates, it can be thought of as isolating the influence of changes stemming from the numéraire country. Accordingly, $\alpha_{t}$ is interpreted as the change in the multilateral real exchange rate for this country, or more simply, the change in the REER index.

\footnotetext{
${ }^{8}$ When these two countries are omitted, weights of the remaining 24 countries are renormalised such that they have a unit sum.
} 
The change in the $c^{\text {th }}$ exchange rate relative to the multilateral rate is $\operatorname{Dr}_{c t}-\alpha_{t}=\beta_{c}+\varepsilon_{c t}$, so that $\beta_{\mathrm{c}}=\mathrm{E}\left(\mathrm{Dr}_{\mathrm{ct}}-\alpha_{\mathrm{t}}\right)$ is the expected value of this relative change. In other words, $\beta_{\mathrm{c}}$ is the expectation of the change in the deflated exchange rate of country c. Accordingly, as $\beta_{c}$ excludes the impact of the numéraire country, this component reflects the trend change in the exchange rate of c stemming from developments that occur outside the home country. Such a trend change could be associated with long-term productivity developments as discussed by Balassa (1964) and Samuelson (1964). To identify model (3.1) we assume that a country-share weighted-average of the country components is zero, $\sum_{\mathrm{c}}^{\mathrm{n}} \mathrm{w}_{\mathrm{c}} \beta_{\mathrm{c}}=0$, with $\mathrm{w}_{\mathrm{c}}$ the $\mathrm{c}^{\text {th }}$ country share. Thus the differential productivity changes, or other developments leading to long-term changes in real exchange rates, average out to zero over all countries. Finally, the random term in equation (3.1) measures the impact of all other factors, and is assumed to be heteroschedastic but independent across countries.

If we multiply both sides of (3.1) by $\sqrt{\mathrm{w}_{\mathrm{c}}}$ and then apply least squares, we obtain (Clements and Izan, 1987)

$$
\hat{\alpha}_{t}=\sum_{c=1}^{n} w_{c} \operatorname{Dr}_{c t}, \quad \hat{\beta}_{c}=\frac{1}{T} \sum_{t=1}^{T}\left(D_{c t}-\hat{\alpha}_{t}\right)
$$

Thus the estimator of $\alpha_{t}$ is a country-share weighted average of the changes in the $n$ bilateral rates. This has the sensible property that more weight is accorded to the currencies of those countries that are more economically important to the numéraire country. This expression for $\hat{\alpha}_{t}$ is exactly the same as index (2.1). The estimator $\hat{\beta}_{\mathrm{c}}$ is the sample mean of the changes in the deflated exchange rate of country c. Thus it can be seen that expressions (3.2) have attractively simple interpretations.

\section{4. $\quad$ Modelling Heteroschedasticity}

To compute the standard errors of the estimators of the index (3.2), one could use conventional least-squares theory, on the basis of homoscedasticity. An alternative, to be followed here, is to use a heteroscedastic-consistent covariance matrix. ${ }^{9}$ This section uses Monte Carlo simulation techniques to evaluate several alternative versions of the heteroscedasticity-consistent covariance matrix in the context of the stochastic index model.

\footnotetext{
${ }^{9}$ Clements and Izan (1987) use the first approach, while Crompton (2000) and Selvanathan and Selvanathan (2004) use the second. Note that when Selvanathan and Selvanathan (2004) set out White's (1980) heteroscedasticity-consistent covariance matrix, they erroneously omit from their equation (10) a scalar, $\mathrm{n}$.
} 
We write model (3.1) for $\mathrm{c}=1, \ldots, \mathrm{n}$ and $\mathrm{t}=1, \ldots, \mathrm{T}$ by defining $\mathbf{y}=\left[\begin{array}{lll}\mathbf{y}_{1}^{\prime} & \mathbf{y}_{2}^{\prime} & \cdots \\ \mathbf{y}_{\mathrm{n}}^{\prime}\end{array}\right]^{\prime}$, with $\mathbf{y}_{\mathrm{c}}=\left[\begin{array}{llll}\mathrm{y}_{\mathrm{c} 1} & \mathrm{y}_{\mathrm{c} 2} & \cdots & \mathrm{y}_{\mathrm{cT}}\end{array}\right]^{\prime}$ and $\mathrm{y}_{\mathrm{ct}}=\sqrt{\mathrm{w}_{\mathrm{c}}} \operatorname{Dr}_{\mathrm{ct}} ; \mathbf{X}_{\mathrm{c}}=\sqrt{\mathrm{w}_{\mathrm{c}}} \mathbf{I}$ with $\mathbf{I}$ the identity matrix of order $\mathrm{T} ; \mathbf{A}=-\mathbf{X}_{1}^{-1}\left[\begin{array}{lllll}\mathbf{X}_{2} \mathbf{X}_{2} \mathbf{l} & \mathbf{X}_{3} \mathbf{X}_{3} \mathbf{l} & \cdots & \mathbf{X}_{\mathrm{n}} \mathbf{X}_{\mathrm{n}} \mathbf{l}\end{array}\right]$, with $\mathbf{\imath}$ a vector of unit elements; and

$$
\mathbf{Z}=\left[\begin{array}{c:cccc}
\mathbf{X}_{1} & & & \mathbf{A} & \\
\hdashline \mathbf{X}_{2} & \mathbf{X}_{2} \mathbf{l} & \mathbf{0} & \cdots & \mathbf{0} \\
\mathbf{X}_{3} & \mathbf{0} & \mathbf{X}_{3} \mathbf{l} & \cdots & \mathbf{0} \\
\vdots & \vdots & \vdots & \ddots & \vdots \\
\mathbf{X}_{\mathrm{n}} & 0 & \cdots & \mathbf{0} & \mathbf{X}_{\mathrm{n}} \mathbf{l}
\end{array}\right]
$$

After multiplying both sides of equation (3.1) by $\sqrt{\mathrm{w}_{\mathrm{c}}}$ and substituting out the identification constraint $\sum_{\mathrm{c}} \mathrm{w}_{\mathrm{c}} \beta_{\mathrm{c}}=0$, the model can be written in vector form as

$$
\mathbf{y}=\mathbf{Z} \gamma+\xi
$$

where $\gamma=\left[\alpha_{1} \cdots \alpha_{\mathrm{T}} \vdots \beta_{1} \cdots \beta_{\mathrm{n}-1}\right]^{\prime}$ and $\xi=\left[\xi_{11} \cdots \xi_{1 \mathrm{~T}} \vdots \cdots \vdots \xi_{\mathrm{n} 1} \cdots \xi_{\mathrm{nT}}\right]^{\prime}$, with $\xi_{\mathrm{ct}}=\sqrt{\mathrm{w}_{\mathrm{c}}} \varepsilon_{\mathrm{ct}}$.

The heteroscedastic-consistent covariance matrix estimator (HCCME) of the coefficient vector $\gamma$ in model (4.1) is

$$
\operatorname{Var}(\boldsymbol{\gamma})=\left(\mathbf{Z}^{\prime} \mathbf{Z}\right)^{-1} \mathbf{Z}^{\prime} \hat{\mathbf{\Omega}} \mathbf{Z}\left(\mathbf{Z}^{\prime} \mathbf{Z}\right)^{-1}
$$

Here, $\hat{\boldsymbol{\Omega}}$ is an $\mathrm{nT} \times \mathrm{nT}$ diagonal matrix with typical diagonal element $\mathrm{a}_{\mathrm{ct}}^{2} \hat{\xi}_{\mathrm{ct}}^{2}$, where $\hat{\xi}_{\mathrm{ct}}$ is the OLS residual. Following Davison and Flachaire (2001) and Flachaire (2001, 2003), we refer to the White (1980) version of (4.2), corresponding to $\mathrm{a}_{\mathrm{ct}}^{2}=1$, as $\mathrm{HC}_{0}$. MacKinnon and White (1985) consider other possible forms of the HCCME, with $\mathrm{a}_{\mathrm{ct}}$ defined as

$$
\mathrm{HC}_{1}: \mathrm{a}_{\mathrm{ct}}=\sqrt{\frac{\mathrm{nT}}{\mathrm{nT}-(\mathrm{n}+\mathrm{T}-1)}}, \quad \mathrm{HC}_{2}: \mathrm{a}_{\mathrm{ct}}=\frac{1}{\sqrt{1-\mathrm{h}_{\mathrm{ct}}}}, \quad \mathrm{HC}_{3}: \mathrm{a}_{\mathrm{ct}}=\frac{1}{1-\mathrm{h}_{\mathrm{ct}}},
$$

where $\mathrm{h}_{\mathrm{ct}}$ is $(\mathrm{c} \times \mathrm{t})^{\mathrm{th}}$ element on the main diagonal of the $\mathrm{nT} \times \mathrm{nT}$ matrix $\mathbf{Z}\left(\mathbf{Z}^{\prime} \mathbf{Z}\right)^{-1} \mathbf{Z}^{\prime}$. MacKinnon and White show that in finite samples, all the above forms of the HCCME can be seriously biased, especially in the presence of observations with high leverage. Moreover, Chesher and Jewitt (1987) show that the extent of bias is related to the structure of regressors in the model. 
In conventional cases, the residual bootstrap method can be used to provide finite-sample inferences regarding the coefficients $\gamma$. However, this method generally fails for the case of heteroscedasticity of unknown form, since such heteroscedasticity cannot be mimicked in the bootstrap distribution. One way to get around the problem is to use the wild bootstrap (see, e.g., Davison and Flachaire, 2001, Flachaire, 2003, and Godfrey and Orme, 2002). The simulations in Cribari-Neto and Zarkos (1999) and Flachaire (2001) show that if the generated wild bootstrap errors are the products of the OLS residuals, the term $\mathrm{a}_{\mathrm{ct}}$ defined in (4.3) above and a probability distribution with mean of zero and variance of one, then (i) the wild bootstrap estimators and the HCCME estimators based on the same $a_{c t}$ exhibit similar finite-sample behaviour; (ii) the wild bootstrap estimators are substantially worse due to experimental errors; and (iii) the $\mathrm{HC}_{2}$ of (4.3) has smallest bias and mean squared error. Flachaire (2001) proves that for a fixed number of observations and under the above-mentioned wild bootstrap data-generating process, the wild bootstrap covariance matrix estimator is equal to the HCCME (4.2).

In order to determine which covariance estimator performs the best when the regressors are of the form $\mathbf{Z}$, we carry out Monte Carlo simulation experiments. As our data are two-dimensional (countries $\times$ time), we shall consider the $2 \times 2$ structure of heteroscedasticity set out in panel A of Table 2. As can be seen, we split the time period into two sub-periods, each with an equal number of observations. Similarly we split the $n$ countries equally, and then consider the various combinations of homo/heteroscedasticity. While the 50:50 split is somewhat arbitrary, it serves to keep the analysis manageable and at least can provide a guide to more complex cases. For the simulations, we specify the scedasticity function as

TABLE 2

THE STRUCTURE OF HETEROSCEDASTICITY

\begin{tabular}{|c|c|c|}
\hline \multirow{2}{*}{ Time periods } & \multicolumn{2}{|c|}{ Countries } \\
\hline & First group & Second group \\
\hline \multicolumn{3}{|c|}{ A. Schematic Structure } \\
\hline First half & $\begin{array}{l}\text { Countries: Homoscedastic } \\
\text { Time: } \quad \text { Homoscedastic }\end{array}$ & $\begin{array}{l}\text { Countries: Heteroscedastic } \\
\text { Time: } \quad \text { Homoscedastic }\end{array}$ \\
\hline Second half & $\begin{array}{ll}\text { Countries: Homoscedastic } \\
\text { Time: } \quad \text { Heteroscedastic }\end{array}$ & $\begin{array}{ll}\text { Countries: Heteroscedastic } \\
\text { Time: } \quad \text { Heteroscedastic }\end{array}$ \\
\hline \multicolumn{3}{|c|}{ B. Parametric restrictions in equation (4.4) } \\
\hline First half & $\eta_{1}=1, \quad \eta_{2}=1$ & $\eta_{1} \geq 1, \quad \eta_{2}=1$ \\
\hline Second half & $\eta_{1}=1, \quad \eta_{2} \geq 1$ & $\eta_{1} \geq 1, \quad \eta_{2} \geq 1$ \\
\hline
\end{tabular}




$$
\xi_{c t}= \begin{cases}\mathrm{u}_{\mathrm{ct}} & \mathrm{c}<\mathrm{n} / 2, \mathrm{t}<\mathrm{T} / 2 \\ \eta_{2} \mathrm{u}_{\mathrm{ct}} & \mathrm{c}<\mathrm{n} / 2, \mathrm{t} \geq \mathrm{T} / 2 \\ \eta_{1} \mathrm{u}_{\mathrm{ct}} & \mathrm{c} \geq \mathrm{n} / 2, \mathrm{t}<\mathrm{T} / 2 \\ \eta_{1} \eta_{2} \mathrm{u}_{\mathrm{ct}} & \mathrm{c} \geq \mathrm{n} / 2, \mathrm{t} \geq \mathrm{T} / 2,\end{cases}
$$

where, following Long and Ervin (2000), $\mathrm{u}_{\mathrm{ct}}$ is alternatively drawn from a $\mathrm{z}, \chi_{5}^{2}$, or $\mathrm{t}_{5}$ distribution. The values of $\eta_{i}$ in equation (4.4) are specified in panel B of Table 2.

The following simulation procedure is adopted:

- $\quad$ First, we specify the values of relevant variables. We set the number of countries $\mathrm{n}=15$ and specify the number of time periods $\mathrm{T}$ as set out in Table 3. Cases 1, 2 and 3, respectively, correspond to the number of periods less than, equal to, and greater than the number of countries. The reason for this is that in the next section, we classify the whole sample period into a number of sub-periods that unavoidably involve these three situations. We set the coefficients $\alpha_{t}$ and $\beta_{c}$ at $\widetilde{\alpha}_{t}$ and $\widetilde{\beta}_{c}$, the values of which are given in Table 3 . The values of the country shares, $\widetilde{\mathrm{w}}_{\mathrm{c}}$, are also given in Table 3 .

TABLE 3

PARAMETRIC SETUP FOR HETEROSCEDASTICITY SIMULATIONS

\begin{tabular}{|c|c|c|c|c|c|c|c|c|c|}
\hline \multirow[b]{2}{*}{$\mathrm{c}, \mathrm{t}$} & \multicolumn{3}{|c|}{ Case 1: $T=4$ and $n=15$} & \multicolumn{3}{|c|}{ Case 2: $T=15$ and $n=15$} & \multicolumn{3}{|c|}{ Case 3: $T=42$ and $n=15$} \\
\hline & $\tilde{\alpha}_{t}$ & $\tilde{\beta}_{\mathrm{c}}$ & $\tilde{\mathrm{w}}_{\mathrm{c}}$ & $\tilde{\alpha}_{t}$ & $\tilde{\beta}_{\mathrm{c}}$ & $\tilde{\mathrm{w}}_{\mathrm{c}}$ & $\tilde{\alpha}_{t}$ & $\tilde{\beta}_{\mathrm{c}}$ & $\tilde{\mathrm{w}}_{\mathrm{c}}$ \\
\hline 1 & -1.0 & -1.9746 & 8.26 & -1.0 & -1.9746 & 8.26 & -1.0 & -1.9746 & 8.26 \\
\hline 2 & -1.1 & 1.5061 & 1.62 & -1.1 & 1.5061 & 1.62 & -1.1 & 1.5061 & 1.62 \\
\hline 3 & -1.2 & -0.1292 & 10.46 & -1.2 & -0.1292 & 10.46 & -1.2 & -0.1292 & 10.46 \\
\hline 4 & -1.3 & 0.7370 & 3.07 & -1.3 & 0.7370 & 3.07 & -1.3 & 0.7370 & 3.07 \\
\hline 5 & - & 0.7233 & 3.25 & -1.4 & 0.7233 & 3.25 & -1.4 & 0.7233 & 3.25 \\
\hline 6 & - & 0.6372 & 7.18 & -1.5 & 0.6372 & 7.18 & -1.5 & 0.6372 & 7.18 \\
\hline 7 & - & 0.1995 & 14.10 & -1.6 & 0.1995 & 14.10 & -1.6 & 0.1995 & 14.10 \\
\hline 8 & - & -0.9154 & 6.93 & -1.7 & -0.9154 & 6.93 & -1.7 & -0.9154 & 6.93 \\
\hline 9 & - & -3.0734 & 2.94 & -1.8 & -3.0734 & 2.94 & -1.8 & -3.0734 & 2.94 \\
\hline 10 & - & 1.8308 & 14.51 & -1.9 & 1.8308 & 14.51 & -1.9 & 1.8308 & 14.51 \\
\hline 11 & - & -0.7895 & 1.79 & -2.0 & -0.7895 & 1.79 & -2.0 & -0.7895 & 1.79 \\
\hline 12 & - & -0.7480 & 10.51 & -2.1 & -0.7480 & 10.51 & -2.1 & -0.7480 & 10.51 \\
\hline 13 & - & -0.8016 & 7.79 & -2.2 & -0.8016 & 7.79 & -2.2 & -0.8016 & 7.79 \\
\hline 14 & - & 0.5999 & 2.00 & -2.3 & 0.5999 & 2.00 & -2.3 & 0.5999 & 2.00 \\
\hline 15 & - & -0.4475 & 5.59 & -2.4 & -0.4475 & 5.59 & -2.4 & -0.4475 & 5.59 \\
\hline 16 & - & - & - & - & - & - & -2.5 & - & - \\
\hline$\vdots$ & - & - & - & - & - & - & $\vdots$ & - & - \\
\hline 42 & - & - & - & - & - & - & -4.1 & - & - \\
\hline
\end{tabular}

Note: All entries are to be divided by 100 . 
- Second, we generate the disturbances according to equation (4.4) with four combinations of $\eta_{1}$ and $\eta_{2}$, (i) $\eta_{1}=1, \eta_{2}=1$; (ii) $\eta_{1}=1, \eta_{2}=5$; (iii) $\eta_{1}=5$, $\eta_{2}=1$; and (iv) $\eta_{1}=5, \eta_{2}=5$. The choice of $\eta_{i}>1$ ensures a certain level of heteroscedasticity in the error variance.

- Third, we carry out 1,000 simulation trials. In each of the $s=1, \ldots, 1000$ trials, we generate an $\mathrm{n} \times \mathrm{T}$ random error vector $\left[\xi_{\mathrm{ct}}^{(\mathrm{s})}\right]$ according to (4.4) and then define $\varepsilon_{\mathrm{ct}}^{(\mathrm{s})}=\xi_{\mathrm{ct}}^{(\mathrm{s})} / \sqrt{\widetilde{\mathrm{w}}_{\mathrm{c}}}$. The dependent variable is then computed as $\operatorname{Dr}_{\mathrm{ct}}^{(\mathrm{s})}=\tilde{\alpha}_{\mathrm{t}}+\tilde{\beta}_{\mathrm{c}}+\varepsilon_{\mathrm{ct}}^{(\mathrm{s})}$. This equation is transformed into vector form (4.1) and the OLS estimates of its coefficients in trial $s$ are denoted by $\hat{\alpha}_{t}^{(s)}$ and $\hat{\beta}_{c}^{(s)}$. We then compute the four versions of the heteroscedasticity-corrected covariance matrix of coefficient estimates, $\mathrm{HC}_{\mathrm{m}}$ $(\mathrm{m}=0, \ldots, 3)$ using the residuals $\hat{\xi}_{\mathrm{ct}}^{(\mathrm{s})}=\tilde{\mathrm{w}}_{\mathrm{c}} \times \hat{\varepsilon}_{\mathrm{ct}}^{(\mathrm{s})}=\tilde{\mathrm{w}}_{\mathrm{c}}\left[\mathrm{Dq}_{\mathrm{ct}}^{(\mathrm{s})}-\hat{\alpha}_{\mathrm{t}}^{(\mathrm{s})}-\hat{\beta}_{\mathrm{c}}^{(\mathrm{s})}\right]$.

- Fourth, the results from the simulations are summarised. Let $\hat{\gamma}^{(\mathrm{s})}$ be the vector of estimates of all coefficients in trial s, $\left[\hat{\alpha}_{1}^{(\mathrm{s})}, \ldots, \hat{\alpha}_{\mathrm{T}}^{(\mathrm{s})}: \hat{\beta}_{1}^{(\mathrm{s})}, \ldots, \hat{\beta}_{\mathrm{n}-1}^{(\mathrm{s})}\right]^{\prime}$, and let $\hat{\gamma}_{\mathrm{k}}^{(\mathrm{s})}$ be the $\mathrm{k}^{\text {th }}$ element of $\hat{\gamma}^{(\mathrm{s})}$. We summarise the results from 1,000 trials by computing the mean and root-mean-squared error (RMSE) of $\gamma_{\mathrm{k}}^{(\mathrm{s})}$ :

$$
\bar{\gamma}_{\mathrm{k}}=\frac{1}{1,000} \sum_{\mathrm{s}=1}^{1000} \gamma_{\mathrm{k}}^{(\mathrm{s})}, \quad \quad \mathrm{RMSE}_{\mathrm{k}}=\sqrt{\frac{1}{1,000} \sum_{\mathrm{s}=1}^{1000}\left[\gamma_{\mathrm{k}}^{(\mathrm{s})}-\bar{\gamma}_{\mathrm{k}}\right]^{2}},
$$

and the mean-squared error of the standard error of $\gamma_{\mathrm{k}}^{(\mathrm{s})}$, based on $\mathrm{HC}_{\mathrm{m}}$ :

$$
\mathrm{MSE}_{\mathrm{mk}}=\sqrt{\frac{1}{1,000} \sum_{\mathrm{s}=1}^{1000}\left[\operatorname{diag}\left(\mathrm{HC}_{\mathrm{mk}}^{(\mathrm{s})}\right)\right]^{2}}
$$

where $\operatorname{diag}\left(\mathrm{HC}_{\mathrm{mk}}^{(\mathrm{s})}\right)$ is the $\mathrm{k}^{\text {th }}$ diagonal element of the $\mathrm{m}^{\text {th }}$ HCCME at trial $\mathrm{s}$.

- Finally we analyse the sampling variability. We need to compare the standard error based on $\mathrm{HC}_{\mathrm{m}}$ of each of the $\mathrm{T}+\mathrm{n}-1$ estimated coefficients with the corresponding true sampling variability as measured by the RMSEs. A simple way to make this comparison is to average over the $\mathrm{T}+\mathrm{n}-1$ coefficients:

$$
\Delta_{\mathrm{m}}=\sqrt{\frac{1}{\mathrm{~T}+\mathrm{n}-1} \sum_{\mathrm{k}=1}^{\mathrm{T}+\mathrm{n}-1}\left[\mathrm{MSE}_{\mathrm{mk}}-\mathrm{RMSE}_{\mathrm{k}}\right]^{2}} .
$$

We use the Breusch-Pagan (1979) test to see whether the error terms $\xi_{\mathrm{ct}}$ defined by equation (4.4) are heteroscedastic. As can be seen from columns 3, 8 and 13 of Table 4, when $\eta_{1}=\eta_{2}=1$, no matter which error structure is used, the error terms are always homoscedastic. For the remaining three combinations of $\eta_{1}$ and $\eta_{2}$, if the base error terms $u_{\text {it }}$ are distributed as $\chi^{2}$ or $\mathrm{t}$, then the $\xi_{\mathrm{ct}}$ are heteroscedastic in all 1,000 experiments in panels B and C of Table 4 . 
TABLE 4

COMPARISON OF FOUR VERSIONS OF STANDARD ERRORS

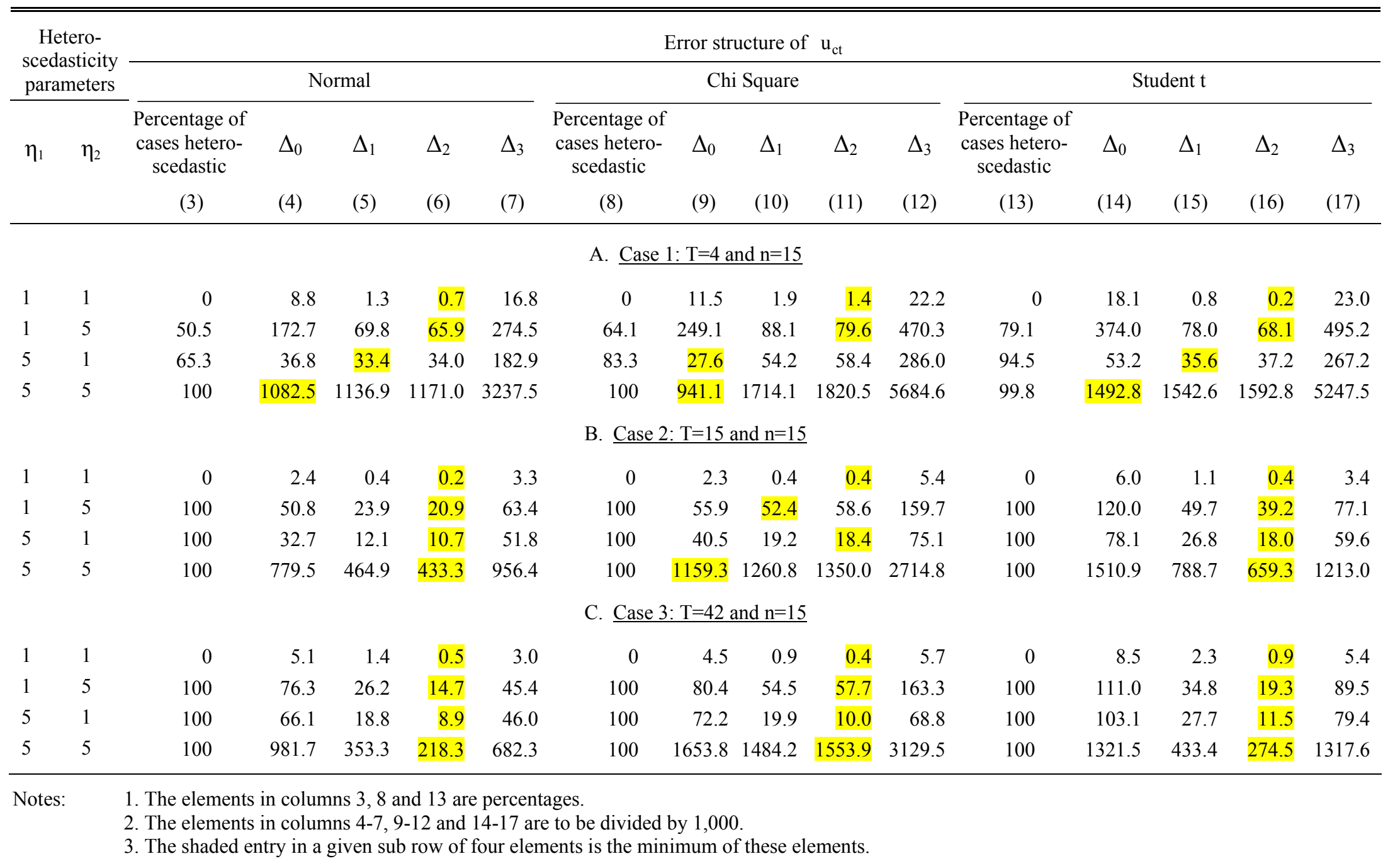


But when the number of time periods falls (with the number of countries fixed), we see from panel A that the Breusch-Pagan test identifies a smaller number of cases of heteroscedasticity when $\eta_{1} \neq \eta_{2} \neq 1$.

The simulation results show that the estimates of $\widetilde{\alpha}_{t}$ and $\widetilde{\beta}_{c}$ (not reported) are very close to their true values shown in Table 3, indicating unbiasedness. The value of $\Delta_{\mathrm{m}}$ for $\mathrm{m}=0, \ldots, 3$ are contained in columns 4-7, 9-12 and 14-17 of Table 4. As can be seen from panel A, the $\Delta_{2}$ values are smallest (indicated by the shaded cells) in 50 percent of the cases. This percentage is 83 and 100, respectively, in panels $\mathrm{B}$ and $\mathrm{C}$. On the basis of this evidence, it would seem to be reasonable to conclude that for model (4.1) $\mathrm{HC}_{2}$ is the best-performing estimator of the covariance matrix. This result is consistent with those reported in the literature for other models (see, e.g, Chesher and Jewitt, 1987).

\section{Optimal Sub-Periods}

According to equation (3.2), the least-squares estimator of the REER change is a countryshare weighted of the $\mathrm{n}$ bilateral rates, $\sum_{\mathrm{c}=1}^{\mathrm{n}} \mathrm{w}_{\mathrm{c}} \mathrm{Dr}_{\mathrm{ct}}$. As the country weights are time-invariant here, this approach should be interpreted as referring to sub-periods during which these shares can be treated as approximately constants. In a similar vein, in the REER index published by the Reserve Bank of Australia (RBA), discussed in Appendix 1, the weights are constant within subperiods. In this section we present and evaluate a procedure to divide up the whole period into an "optimal" number of sub-periods within which the weights are constants.

Let $\mathrm{w}_{\mathrm{ct}}$ be the weight of country $\mathrm{c}$ in period $\mathrm{t}$. As we wish to identify the time at which the weights change substantially, we consider a scalar function of the weight vector, $\mathrm{g}(\mathrm{t})=\mathrm{g}\left(\mathrm{w}_{1 \mathrm{t}}, \ldots, \mathrm{w}_{\mathrm{nt}}\right)$. This function should reflect not only the average distance of the weights from their previous values, but also the economic importance to the home country of each country's distance. One function that has these characteristics is

$$
\mathrm{g}\left(\mathrm{w}_{1 \mathrm{t}}, \ldots, \mathrm{w}_{\mathrm{nt}}\right)=\sqrt{\sum_{\mathrm{c}=1}^{\mathrm{n}} \mathrm{w}_{\mathrm{ct}}\left(\mathrm{w}_{\mathrm{ct}}-\mathrm{w}_{\mathrm{c}, \mathrm{t}-1}\right)^{2}}
$$

In words, this is the square root of the weighted sum of squared changes in the country shares. If $\mathrm{g}(\mathrm{t})$ takes a large value in comparison with its average, then we shall declare that period t represents a "break point" signifying the start of a new sub-period with a new set of weights. To operationalise this idea, we use the average of $g(t)$ from $t_{0}$ to $t-1$, 
$\overline{\mathrm{g}}\left(\mathrm{t}_{0}, \mathrm{t}-1\right)=\left[1 /\left(\mathrm{t}-\mathrm{t}_{0}-1\right)\right] \sum_{\tau=\mathrm{t}_{0}}^{\mathrm{t}-1} \mathrm{~g}(\tau)$. Thus if $\mathrm{g}(\mathrm{t})-\overline{\mathrm{g}}\left(\mathrm{t}_{0}, \mathrm{t}-1\right)>\mathrm{d}$, where $\mathrm{d}$ is some pre-specified number, we conclude that period $t$ is the starting point of a new sub-period; if the reverse is true, then $\mathrm{t}$ remains part of the pre-existing sub-period. As the volatility of the weights increases, for a given value of $d$ we expect the procedure to identify more sub-periods. Additionally, as the value of $\mathrm{d}$ increases, the number of sub-periods is expected to fall.

Next, we use a Monte Carlo simulation to investigate the performance of our criterion. Suppose there are 10 countries and 6 sub-periods each of which consists of 20 observations, so that the total number of observations is $6 \times 20=120$. The pre-determined mean weights are presented in Table 5. The simulation is carried out as follows. In each sub-period, we generate $6 \times 20$ random weights which have the property of meandering around the values in each cell in Table 5, $\mathrm{m}_{\mathrm{ij}}$, in the range $\left[\mathrm{m}_{\mathrm{ij}}-\mathrm{u}(0,1) * \mathrm{~h}, \mathrm{~m}_{\mathrm{ij}}+\mathrm{u}(0,1) * \mathrm{~h}\right]$, where $\mathrm{u}(0,1)$ is a random variable drawn from a uniform distribution over the range $(0,1)$, and $\mathrm{h}$ is a constant. The distance of a realised share from its mean is thus $\pm \mathrm{u}(0,1)^{*} \mathrm{~h}$, so that the larger is $\mathrm{h}$, the higher is the variability of the weights. Each set of generated weights is renominalised such that it has a unit sum. Then we specify positive values of $\mathrm{d}$ and $\mathrm{h}$ and for each $2 \leq \mathrm{t} \leq 120$, and compute the difference between $\mathrm{g}(\mathrm{t})$ and $\overline{\mathrm{g}}\left(\mathrm{t}_{0}, \mathrm{t}-1\right)$. This procedure is repeated 1,000 times.

For given values of the threshold and variability parameters $d$ and $h$, the procedure identifies the optimal number of sub-periods. We summarise the results by giving in Table 6 the means and standard deviations of the number of sub-periods identified for various values of $\mathrm{d}$ and h. For example, as the standard deviation is zero, the entry in the top left corner reveals that for $\mathrm{h}=.001$ and $\mathrm{d}=.005$, the procedure identifies the number of sub-periods as 6 in all 1,000 trials. Accordingly, as 6 is the true number of sub-periods, here the performance of the procedure could not be better. Several comments can be made about the other results in Table 6. First, as we go down a given column we see that for a given $\mathrm{h}$, as $\mathrm{d}$ rises the mean number of sub-periods falls,

TABLE 5

MEAN WEIGHTS FOR THE SIMULATION

\begin{tabular}{lccccccccccc}
\hline \hline \multirow{2}{*}{ Sub-period } & \multicolumn{10}{c}{ Mean weight of country } \\
\cline { 2 - 11 } & 1 & 2 & 3 & 4 & 5 & 6 & 7 & 8 & 9 & 10 \\
\hline 1 & 0.24 & 0.26 & 0.10 & 0.15 & 0.12 & 0.03 & 0.03 & 0.025 & 0.025 & 0.02 \\
2 & 0.27 & 0.23 & 0.12 & 0.13 & 0.09 & 0.07 & 0.02 & 0.025 & 0.025 & 0.02 \\
3 & 0.28 & 0.20 & 0.17 & 0.12 & 0.08 & 0.075 & 0.02 & 0.025 & 0.01 & 0.02 \\
4 & 0.31 & 0.25 & 0.11 & 0.08 & 0.07 & 0.095 & 0.035 & 0.02 & 0.01 & 0.02 \\
5 & 0.35 & 0.245 & 0.09 & 0.09 & 0.06 & 0.075 & 0.045 & 0.015 & 0.01 & 0.02 \\
6 & 0.38 & 0.27 & 0.06 & 0.06 & 0.08 & 0.10 & 0.01 & 0.01 & 0.01 & 0.02 \\
\hline
\end{tabular}


TABLE 6

THE OPTIMAL NUMBER OF SUB-PERIODS, SIMULATION RESULTS

\begin{tabular}{cccccccc}
\hline \hline \multirow{2}{*}{$\begin{array}{c}\text { Threshold } \\
\text { parameter d }\end{array}$} & \multicolumn{7}{c}{ Variability parameter $\mathrm{h}$} \\
\cline { 2 - 8 }$(1)$ & 0.001 & 0.002 & 0.003 & 0.004 & 0.005 & 0.006 & 0.007 \\
$(2)$ & $(3)$ & $(4)$ & $(5)$ & $(6)$ & $(7)$ & $(8)$ \\
\hline \multirow{2}{*}{0.005} & 6.0 & 6.7 & 11.4 & 19.0 & 25.3 & 28.8 & 30.0 \\
& $(0.0)$ & $(0.8)$ & $(1.3)$ & $(2.7)$ & $(2.1)$ & $(1.5)$ & $(1.0)$ \\
0.010 & 6.0 & 6.00 & 6.0 & 6.7 & 8.7 & 12.2 & 16.2 \\
& $(0.0)$ & $(0.0)$ & $(0.2)$ & $(0.9)$ & $(1.7)$ & $(2.3)$ & $(2.7)$ \\
0.015 & 6.0 & 6.0 & 6.0 & 6.0 & 6.1 & 6.7 & 7.8 \\
& $(0.0)$ & $(0.0)$ & $(0.0)$ & $(0.1)$ & $(0.4)$ & $(0.9)$ & $(1.5)$ \\
0.020 & 6.0 & 6.0 & 5.9 & 5.9 & 5.9 & 5.8 & 5.9 \\
& $(0.0)$ & $(0.0)$ & $(0.1)$ & $(0.3)$ & $(0.4)$ & $(0.5)$ & $(0.7)$ \\
0.025 & 5.5 & 5.2 & 5.0 & 4.9 & 4.9 & 4.7 & 4.8 \\
& $(0.6)$ & $(0.8)$ & $(0.8)$ & $(0.9)$ & $(0.9)$ & $(0.9)$ & $(0.9)$ \\
0.030 & 2.0 & 2.1 & 2.3 & 2.6 & 2.9 & 3.1 & 3.3 \\
& $(0.0)$ & $(0.3)$ & $(0.5)$ & $(0.7)$ & $(0.9)$ & $(0.9)$ & $(1.0)$ \\
\hline
\end{tabular}

Note: Figures in parentheses are standard deviations of the number of sub-periods.

as expected. Second, for smaller values of $d(d=0.005,0.010$, and 0.015$)$, the mean number of sub-periods rises with $h$, as expected. But for $d=0.020$ and 0.025 , there is a tendency for the opposite to occur. For $\mathrm{d}=0.030$, the number of sub-periods increases with $\mathrm{h}$, as before. This interaction between $\mathrm{h}$ and $\mathrm{d}$ is unexpected. Third, the first four entries in column 2 and the middle two entries in column 3 show that when $h$ and $d$ are both small, the number of sub-periods can be correctly identified with high probability. The results are further elaborated in Figure 2 which provides the underlying distributions of the optimal number of sub-periods; the corresponding entries in Table 6 are the means and standard deviations of these distributions. As a final way of illustrating the results, in panel A of Figure 3 we plot the probability of correctly identifying the true number of sub-periods against $h$ and $d$. This shows that this probability never falls as $\mathrm{h}$ falls; and that except for a relatively minor region labelled ABCDE, the probability also never falls as $\mathrm{d}$ falls. Panel B presents this region in the $(\mathrm{d}, \mathrm{h})$ plane; as this region is about 7 percent of the $(\mathrm{d}, \mathrm{h})$ space displayed in Panel B, clearly there is no substantial problem.

As the criterion seems to work satisfactorily, we now apply it to identify optimal sub-periods for the REER index using the Australian data for the period of 1970Q1-2002Q2. ${ }^{10}$ As the weights span over 129 quarters, it seems not unreasonable to divide the whole period into 5 to 6 sub-periods. We shall use the procedure to identify the starting and ending points of each of these sub-periods by

\footnotetext{
${ }^{10}$ See Appendix 1 for details of the data. The RBA uses four sets of weights to calculate four versions of its REER index -- exports, imports, trade (exports plus imports) and G7-GDP. From this point on, we will present in the text the results for trade weights; those pertaining to the other three sets of weights are contained in Appendixes 2 to 5 .
} 


\section{FIGURE 2}

RELATIVE FREQUENCY DISTRIBUTIONS OF NUMBER OF SUB-PERIODS, SIMULATION RESULTS
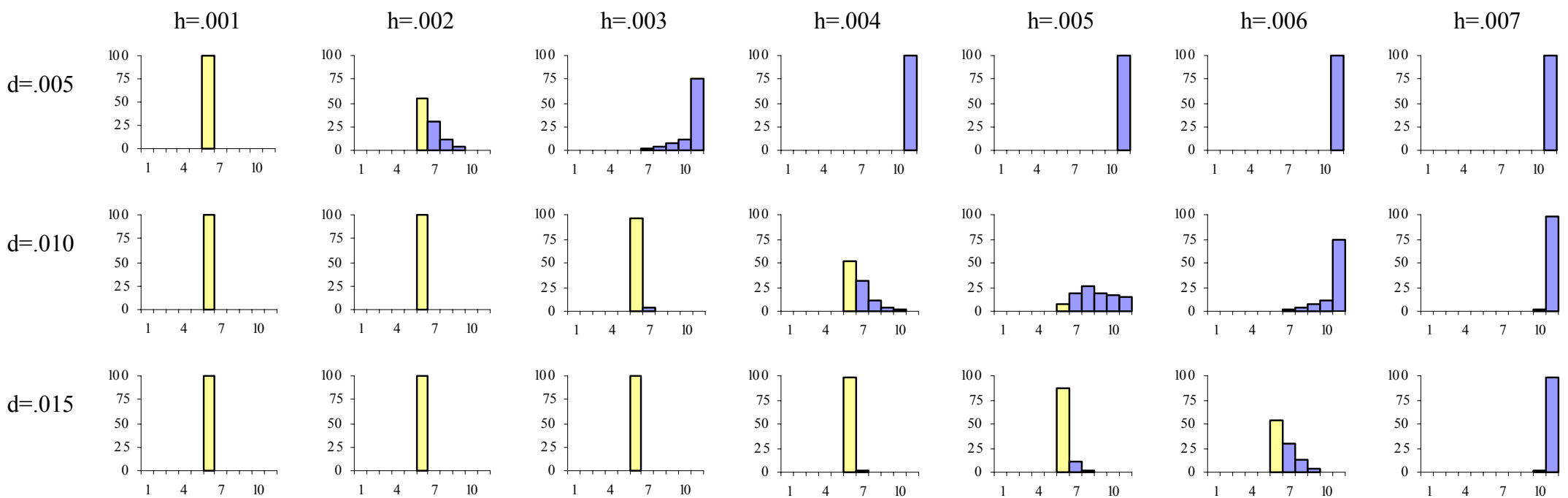

$\mathrm{d}=.020$
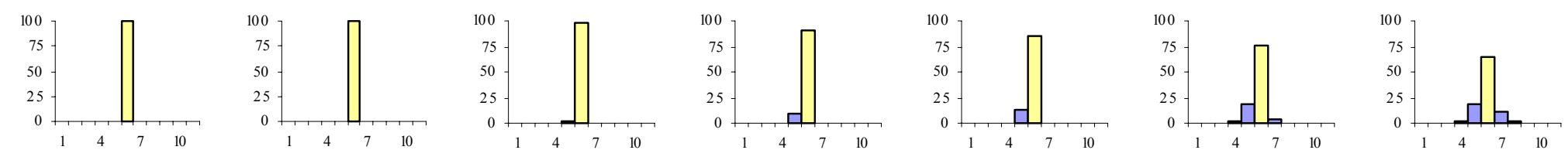

$\mathrm{d}=.025$
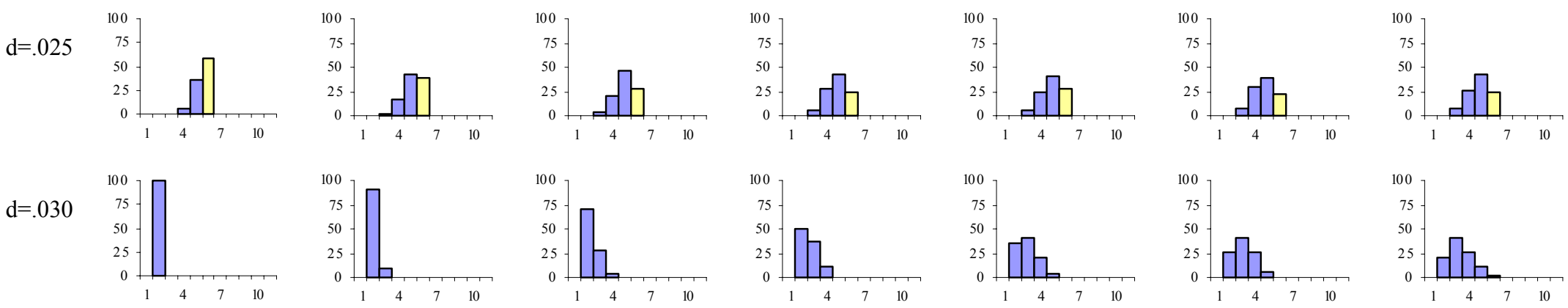

Note: The lightly-shaded columns correspond to the true number of sub-periods, 6 . 
FIGURE 3

IDENTIFYING THE CORRECT NUMBER OF SUB-PERIODS

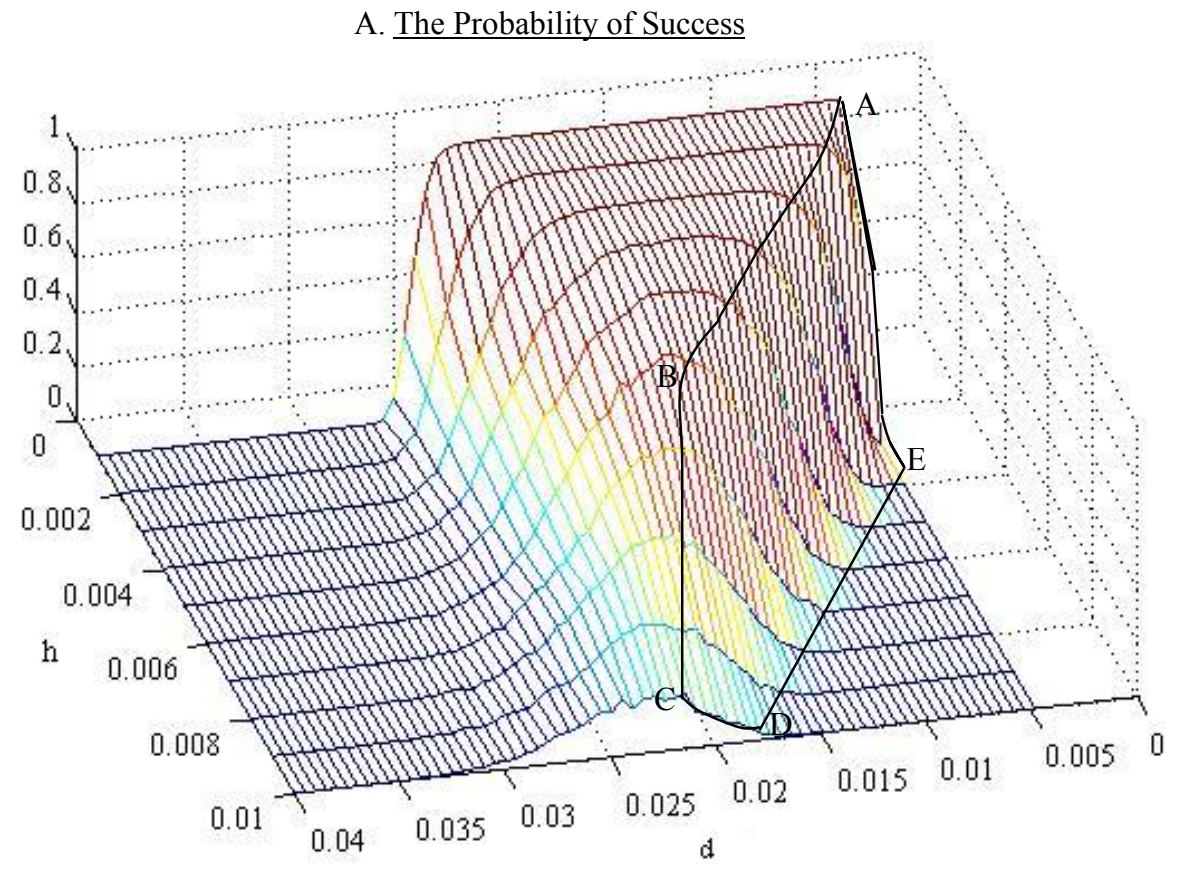

B. The Non-Performing Region

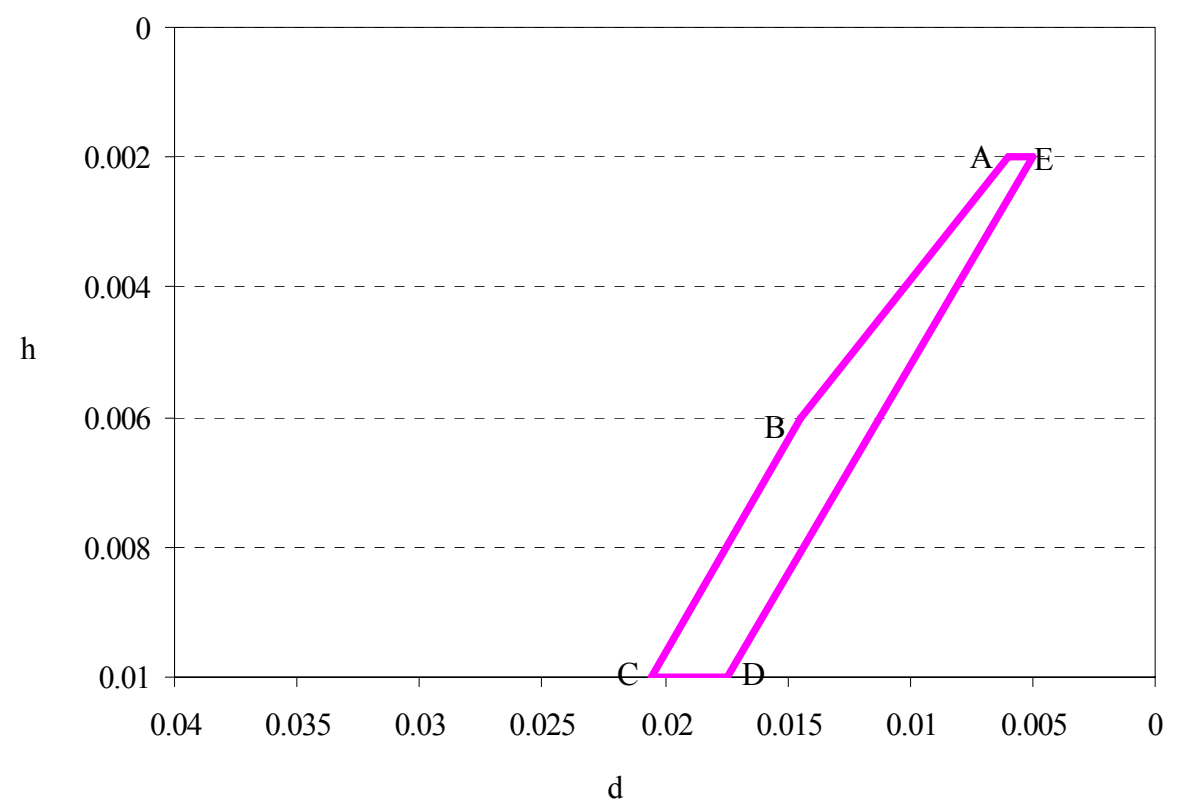

a trial-and-error approach to determine the value of the only unknown parameter $\mathrm{d}$. It can be seen from the second row of Table 7 that the procedure yields 6 sub-periods when $d=0.018$. Accordingly, we shall use the sub-periods identified by that row. 
TABLE 7

IDENTIFICATION OF SUB-PERIODS

\begin{tabular}{|c|c|c|c|c|c|c|c|}
\hline \multicolumn{2}{|c|}{$\begin{array}{l}\text { Threshold } \\
\text { parameter d }\end{array}$} & \multicolumn{2}{|c|}{$\begin{array}{l}\text { Number } \\
\text { of sub- } \\
\text { period }\end{array}$} & \multicolumn{4}{|c|}{$\begin{array}{c}\text { Time line } \\
\text { (Observation numbers of the start of each sub-period) }\end{array}$} \\
\hline 1. & 0.015 & 9 & 1 & $|20| 26$ & $|52| 55$ & $|68| 72 \mid 76$ & 117 \\
\hline 2. & 0.018 & 6 & 1 & 20 & $|52| 55$ & 76 & 117 \\
\hline 3. & 0.020 & 5 & 1 & & $|52| 55$ & 76 & 117 \\
\hline 4. & 0.025 & 4 & 1 & & 52 & 76 & 117 \\
\hline 5. & 0.003 & 2 & 1 & & & & 117 \\
\hline
\end{tabular}

Note: The whole period is from 1970Q1 (observation number 1) to 2002Q2 (observation number 130).

\section{Implementation of the Index}

We estimate model (3.1) with quarterly Australian data of real exchange rates for 26 countries over the period 1970Q1-2002Q2. Consumer prices are used to transform nominal into real exchange rates. Before estimation, we divide the whole sample period into optimal sub-periods using the criterion described in Section 5. Based on the Monte Carlo evidence in Section 4, we use the $\mathrm{HC}_{2}$ version of covariance matrix (4.2) to adjust for heteroscedasticity.

The preliminary estimation results are contained in Appendix 3. There are two points to note from these results: (i) Regarding the estimated changes in the REER index, the $\alpha_{t}$ estimates, about 40 percent are significant at the 5 percent level. (ii) While most of the country-specific components, $\beta_{c}$, are insignificant, it seems that high-growth countries tend to have negative estimates of $\beta_{c}$ and vice versa. As discussed in Section 3, the value of $\beta_{c}$ could reflect the longer-term developments of productivity and income in country c. To explore the relationship between exchange-rate changes and income growth, in Appendix 4 we adopt the methodology of Divisia moments. The evidence generally supports the productivity-bias hypothesis that fast (slow) growing countries tend to have appreciating (depreciating) currencies. When country c's currency appreciates (depreciates) relative to the average of all exchange-rate changes, then its $\beta_{\mathrm{c}}$ is negative (positive). We thus group countries according to the combination of exchange-rate and income changes as follows. Let $\mathrm{DR}_{\mathrm{t}}=\sum_{\mathrm{c}=1}^{\mathrm{n}} \mathrm{w}_{\mathrm{c}} \mathrm{Dr}_{\mathrm{ct}}$ be the Divisia (or weighted) mean of the $\mathrm{n}$ exchange-rate changes, so that $\mathrm{Dr}_{\mathrm{ct}}^{\prime}=\mathrm{Dr}_{\mathrm{ct}}-\mathrm{DR}_{\mathrm{t}}$ is the relative change in the exchange rate of country c. Furthermore, let $\mathrm{Dy}_{\mathrm{ct}}$ be the log-change in real GDP for c, DY $\mathrm{t}_{\mathrm{t}}=\sum_{\mathrm{c}=1}^{\mathrm{n}} \mathrm{w}_{\mathrm{c}} \mathrm{Dy} \mathrm{y}_{\mathrm{ct}}$ be the 
Divisia mean growth rate and $\mathrm{Dy}_{\mathrm{ct}}^{\prime}=\mathrm{Dy}_{\mathrm{ct}}-\mathrm{DY}_{\mathrm{t}}$ be the growth in $\mathrm{c}$ relative to the mean. We then classify countries into three groups:

$\left\{\begin{array}{l}\text { (i) Fast growing countries with appreciating currencies: } \mathrm{Dy}_{\mathrm{ct}}^{\prime}>0, \mathrm{Dr}_{\mathrm{ct}}^{\prime}<0 ; \\ \text { (ii) Slow growing countries with depreciating currencies: } \mathrm{Dy}_{\mathrm{ct}}^{\prime}<0, \mathrm{Dr}_{\mathrm{ct}}^{\prime}>0 \text {; } \\ \text { (iii) Other: } \mathrm{Dy}_{\mathrm{ct}}^{\prime}<0, \mathrm{Dr}_{\mathrm{ct}}^{\prime}<0 \text {; or } \mathrm{Dy}_{\mathrm{ct}}^{\prime}>0, \mathrm{Dr}_{\mathrm{ct}}^{\prime}>0 .\end{array}\right.$

For the reasons discussed above, we expect the bulk of countries to be contained in groups (i) and (ii).

To reduce the number of unknown $\beta_{\mathrm{c}}$, we assume that each country in a given group possesses the same $\beta_{\mathrm{c}}$, to be denoted by $\beta_{\mathrm{F}}, \beta_{\mathrm{S}}$ and $\beta_{\mathrm{O}}(\mathrm{F}=$ fast, $\mathrm{S}=$ slow, $\mathrm{O}=\mathrm{other})$. We can then rewrite model (3.1) as

$$
\operatorname{Dr}_{\mathrm{ct}}=\alpha_{\mathrm{t}}+\beta_{\mathrm{F}} \mathrm{D}_{\mathrm{Fct}}+\beta_{\mathrm{S}} \mathrm{D}_{\mathrm{Sct}}+\beta_{\mathrm{O}} \mathrm{D}_{\mathrm{Oct}}+\varepsilon_{\mathrm{ct}}
$$

where $\mathrm{D}_{\mathrm{Fct}}, \mathrm{D}_{\mathrm{Sct}}, \mathrm{D}_{\mathrm{Oct}}$ are dummy variables with $\mathrm{D}_{\mathrm{Fct}}=1$ for fast-growing countries with appreciating currencies, 0 otherwise; $\mathrm{D}_{\mathrm{Sct}}=1$ for slow-growing countries with depreciating currencies, 0 otherwise; and $\mathrm{D}_{\mathrm{Oct}}=1-\mathrm{D}_{\mathrm{Fct}}-\mathrm{D}_{\mathrm{Sct}}$. Note that the identification constraint $\sum_{\mathrm{c}=1}^{\mathrm{n}} \mathrm{w}_{\mathrm{c}} \beta_{\mathrm{c}}=0$ becomes $\mathrm{w}_{\mathrm{F}} \beta_{\mathrm{F}}+\mathrm{w}_{\mathrm{S}} \beta_{\mathrm{S}}+\mathrm{w}_{\mathrm{O}} \beta_{\mathrm{O}}=0$, where $\mathrm{w}_{\mathrm{F}}, \mathrm{w}_{\mathrm{S}}$ and $\mathrm{w}_{\mathrm{O}}$ are the respective shares of the three groups of countries. We proceed in exactly the same way as before to estimate (6.2) by weighting by $\sqrt{\mathrm{w}_{\mathrm{c}}}$ and then computing heteroscedasticity-consistent standard errors using $\mathrm{HC}_{2}$. Columns 5 and 10 of Table 8 contain the estimated $\alpha_{t}$ and Figure 4 gives histograms of these estimates and their t-values.

To visualise the stochastic REER, we present in Figure 5 a "fan chart" of the changes, ${ }^{11}$ which plots the point estimates together with $\pm \mathrm{k}$ standard-error bands, where $\mathrm{k}=0.5,1,1.5$ and 2 . The bands for the late 1970s and early 1980s are quite wide, reflecting the higher variability of the component real exchange rates associated with high oil prices, high and variable inflation and a volatile world economy during that period.

From the estimates of $\alpha_{t}$, we can compute the corresponding stochastic index in levels as follows. Denote the level of the index in the reference quarter by $R_{r}$, whose value is set to 100. Then for subsequent quarters, $\log \left(\mathrm{R}_{\mathrm{r}+1} / \mathrm{R}_{\mathrm{r}}\right)=\alpha_{\mathrm{r}+1}$ and $\log \left(\mathrm{R}_{\mathrm{r}+2} / \mathrm{R}_{\mathrm{r}+1}\right)=\alpha_{\mathrm{r}+2}, \ldots$, etc. By successive substitution we obtain the logarithmic index for $M$ quarters after $r$ as

11 The fan chart was invented by the Band of England for reporting its probability forecasts of inflation and output growth (Britton et al., 1998, Wallis, 1999). 
TABLE 8

THE REER INDEX

(Standard errors in parentheses)

\begin{tabular}{|c|c|c|c|c|c|c|c|c|c|c|}
\hline \multirow{2}{*}{$\begin{array}{l}\text { Observation } \\
\text { number } \\
\text { (1) }\end{array}$} & \multirow[b]{2}{*}{$\begin{array}{l}\text { Year } \\
(2)\end{array}$} & \multirow[b]{2}{*}{$\begin{array}{c}\text { Quarter } \\
\text { (3) }\end{array}$} & \multicolumn{3}{|c|}{ REER index } & \multirow{2}{*}{$\begin{array}{c}\text { Observation } \\
\text { number } \\
(6)\end{array}$} & \multirow[b]{2}{*}{$\begin{array}{r}\text { Year } \\
(7)\end{array}$} & \multirow[b]{2}{*}{$\begin{array}{c}\text { Quarter } \\
\text { (8) }\end{array}$} & \multicolumn{2}{|c|}{ REER index } \\
\hline & & & & $\begin{array}{l}\text { evel } \\
4)\end{array}$ & $\begin{array}{c}\text { Change } \alpha_{t} \\
\text { (5) }\end{array}$ & & & & $\begin{array}{l}\text { Level } \\
(9)\end{array}$ & $\begin{array}{c}\text { Change } \alpha_{t} \\
\text { (10) }\end{array}$ \\
\hline 1 & 1970 & (1) & 150.46 & $(7.58)$ & & 49 & 1982 & (1) & $139.63(5.95)$ & $-1.59(1.04)$ \\
\hline 2 & & (2) & 149.72 & $(7.61)$ & $-0.50(0.45)$ & 50 & & (2) & $138.90(5.94)$ & $-0.53(1.06)$ \\
\hline 3 & & (3) & 148.66 & $(7.66)$ & $-0.71(0.37)$ & 51 & & (3) & $136.01(5.96)$ & $-2.10(1.48)$ \\
\hline 4 & & (4) & 148.32 & (7.67) & $-0.23(0.34)$ & 52 & & (4) & $134.67(6.01)$ & $-1.00(0.46)$ \\
\hline 5 & 1971 & (1) & 147.80 & $(7.69)$ & $-0.35(0.40)$ & 53 & 1983 & (1) & $132.06(5.96)$ & $-1.95(1.93)$ \\
\hline 6 & & (2) & 147.41 & $(7.71)$ & $-0.27(0.44)$ & 54 & & (2) & $125.01(6.28)$ & $-5.48(0.47)$ \\
\hline 7 & & (3) & 148.17 & $(7.66)$ & $0.51(0.33)$ & 55 & & (3) & $129.62(6.00)$ & $3.62(1.12)$ \\
\hline 8 & & (4) & 150.16 & $(7.54)$ & $1.34(0.83)$ & 56 & & (4) & $134.26(5.77)$ & $3.52(0.63)$ \\
\hline 9 & 1972 & (1) & 147.68 & $(7.62)$ & $-1.67(1.27)$ & 57 & 1984 & (1) & $137.76(5.61)$ & $2.57(0.44)$ \\
\hline 10 & & (2) & 146.64 & $(7.68)$ & $-0.70(0.20)$ & 58 & & (2) & $134.29(5.75)$ & $-2.55(0.33)$ \\
\hline 11 & & (3) & 148.12 & $(7.58)$ & $1.00(0.73)$ & 59 & & (3) & $130.97(5.69)$ & $-2.50(2.03)$ \\
\hline 12 & & (4) & 148.77 & $(7.55)$ & $0.44(0.27)$ & 60 & & (4) & $135.06(5.48)$ & $3.08(0.86)$ \\
\hline 13 & 1973 & (1) & 162.61 & $(6.86)$ & $8.89(1.30)$ & 61 & 1985 & (1) & $125.06(5.79)$ & $-7.70(1.55)$ \\
\hline 14 & & (2) & 164.94 & $(6.71)$ & $1.42(1.51)$ & 62 & & (2) & $110.10(6.50)$ & $-12.74(1.08)$ \\
\hline 15 & & (3) & 166.35 & $(6.62)$ & $0.85(0.95)$ & 63 & & (3) & $112.80(6.27)$ & 2.42 (1.09) \\
\hline 16 & & (4) & 176.77 & $(6.22)$ & $6.08(0.68)$ & 64 & & (4) & $105.86(6.35)$ & $-6.35(2.22)$ \\
\hline 17 & 1974 & (1) & 179.99 & $(6.10)$ & $1.81(0.65)$ & 65 & 1986 & (1) & $105.89(6.19)$ & $0.03(1.51)$ \\
\hline 18 & & (2) & 174.87 & $(6.24)$ & $-2.89(1.15)$ & 66 & & (2) & $104.75(6.07)$ & $-1.09(1.56)$ \\
\hline 19 & & (3) & 180.15 & $(6.00)$ & $2.98(1.48)$ & 67 & & (3) & 90.27 (6.88) & $-14.87(1.36)$ \\
\hline 20 & & (4) & 160.70 & $(6.72)$ & $-11.43(0.53)$ & 68 & & (4) & $97.05(6.04)$ & $7.23(2.07)$ \\
\hline 21 & 1975 & (1) & 163.74 & $(6.56)$ & $1.87(1.07)$ & 69 & 1987 & (1) & $98.41 \quad(5.87)$ & $1.40(0.96)$ \\
\hline 22 & & (2) & 164.73 & $(6.52)$ & $0.60(0.52)$ & 70 & & (2) & $102.29(5.57)$ & $3.86(0.98)$ \\
\hline 23 & & (3) & 162.28 & $(6.57)$ & $-1.50(1.21)$ & 71 & & (3) & $103.86(5.34)$ & 1.53 (1.29) \\
\hline 24 & & (4) & 167.44 & $(6.36)$ & $3.13(0.54)$ & 72 & & (4) & $98.76(5.52)$ & $-5.03(1.02)$ \\
\hline 25 & 1976 & (1) & 168.42 & $(6.32)$ & $0.58(0.38)$ & 73 & 1988 & (1) & $99.76(5.44)$ & $1.00(0.51)$ \\
\hline 26 & & (2) & 167.96 & $(6.30)$ & $-0.27(1.12)$ & 74 & & (2) & $107.76(5.02)$ & $7.72(0.48)$ \\
\hline 27 & & (3) & 169.16 & $(6.25)$ & $0.71(0.64)$ & 75 & & (3) & $116.78(4.34)$ & 8.04 (1.89) \\
\hline 28 & & (4) & 158.50 & $(6.66)$ & $-6.51(0.51)$ & 76 & & (4) & $120.17(4.12)$ & $2.86(1.09)$ \\
\hline 29 & 1977 & (1) & 148.60 & $(7.08)$ & $-6.45(0.86)$ & 77 & 1989 & (1) & $124.19(3.92)$ & $3.29(0.87)$ \\
\hline 30 & & (2) & 148.71 & (7.04) & $0.08(0.96)$ & 78 & & (2) & $117.47(4.04)$ & $-5.56(1.08)$ \\
\hline 31 & & (3) & 147.11 & (7.11) & $-1.08(0.60)$ & 79 & & (3) & $116.98(4.01)$ & $-0.42(0.76)$ \\
\hline 32 & & (4) & 145.67 & $(7.10)$ & $-0.99(1.53)$ & 80 & & (4) & $119.80(3.89)$ & $2.38(0.48)$ \\
\hline 33 & 1978 & (1) & 143.37 & $(7.19)$ & $-1.59(0.95)$ & 81 & 1990 & (1) & $117.68(3.83)$ & $-1.79(1.21)$ \\
\hline 34 & & (2) & 140.08 & $(7.26)$ & $-2.32(1.68)$ & 82 & & (2) & $119.66(3.67)$ & $1.67(1.02)$ \\
\hline 35 & & (3) & 135.07 & $(7.31)$ & $-3.64(2.43)$ & 83 & & (3) & $121.55(3.50)$ & $1.57(1.08)$ \\
\hline 36 & & (4) & 133.65 & $(7.38)$ & $-1.06(0.51)$ & 84 & & (4) & $113.34(3.31)$ & $-7.00(1.99)$ \\
\hline 37 & 1979 & (1) & 133.01 & $(7.30)$ & $-0.48(1.68)$ & 85 & 1991 & (1) & $113.93(3.26)$ & $0.52(0.59)$ \\
\hline 38 & & (2) & 132.53 & $(7.19)$ & $-0.36(1.91)$ & 86 & & (2) & $116.96(3.05)$ & $2.62(1.01)$ \\
\hline 39 & & (3) & 132.30 & $(7.12)$ & $-0.18(1.43)$ & 87 & & (3) & 119.19 (2.97) & $1.89(0.42)$ \\
\hline 40 & & (4) & 131.87 & $(6.95)$ & $-0.32(2.19)$ & 88 & & (4) & $115.53(2.91)$ & $-3.12(1.11)$ \\
\hline 41 & 1980 & (1) & 130.60 & $(6.96)$ & $-0.97(1.11)$ & 89 & 1992 & (1) & $110.60(3.01)$ & $-4.36(0.48)$ \\
\hline 42 & & (2) & 130.35 & $(6.91)$ & $-0.19(1.19)$ & 90 & & (2) & $111.57(2.91)$ & $0.88(0.73)$ \\
\hline 43 & & (3) & 131.58 & $(6.80)$ & $0.94(1.07)$ & 91 & & (3) & $104.46(3.01)$ & $-6.59(0.82)$ \\
\hline 44 & & (4) & 132.03 & $(6.73)$ & $0.34(1.06)$ & 92 & & (4) & $102.05(2.62)$ & $-2.33(1.65)$ \\
\hline 45 & 1981 & (1) & 134.68 & $(6.56)$ & $1.99(0.91)$ & 93 & 1993 & (1) & $101.95(2.44)$ & $-0.09(0.98)$ \\
\hline 46 & & (2) & 137.77 & $(6.29)$ & $2.27(1.72)$ & 94 & & (2) & 99.80 (1.64) & $-2.14(1.87)$ \\
\hline 47 & & (3) & 144.03 & $(5.84)$ & $4.44(2.09)$ & 95 & & (3) & 95.95 (1.32) & $-3.93(1.03)$ \\
\hline 48 & & (4) & 141.87 & $(5.91)$ & $-1.51(0.79)$ & 96 & & (4) & $96.50(1.22)$ & $0.57(0.49)$ \\
\hline
\end{tabular}


TABLE 8 (continued)

THE REER INDEX

(Standard errors in parentheses)

\begin{tabular}{|c|c|c|c|c|c|c|c|c|c|}
\hline \multirow{2}{*}{$\begin{array}{c}\text { Observation } \\
\text { number } \\
\text { (1) }\end{array}$} & \multirow{2}{*}{$\begin{array}{l}\text { Year } \\
(2)\end{array}$} & \multirow{2}{*}{$\begin{array}{c}\text { Quarter } \\
\text { (3) }\end{array}$} & \multicolumn{2}{|c|}{ REER index } & \multirow{2}{*}{$\begin{array}{c}\text { Observation } \\
\text { number } \\
\text { (6) }\end{array}$} & \multirow{2}{*}{$\begin{array}{l}\text { Year } \\
\text { (7) }\end{array}$} & \multirow{2}{*}{$\begin{array}{c}\text { Quarter } \\
\text { (8) }\end{array}$} & \multicolumn{2}{|c|}{ REER index } \\
\hline & & & $\begin{array}{l}\text { Level } \\
\text { (4) }\end{array}$ & $\begin{array}{c}\text { Change } \alpha_{t} \\
\text { (5) }\end{array}$ & & & & $\begin{array}{l}\text { Level } \\
(9)\end{array}$ & $\begin{array}{c}\text { Change } \alpha_{t} \\
(10)\end{array}$ \\
\hline 97 & 1994 & (1) & $1.86(1.11)$ & $5.41(0.32)$ & 114 & & (2) & $100.95(5.16)$ & $-5.17(1.66)$ \\
\hline 98 & & (2) & $101.71(0.77)$ & $-0.15(0.81)$ & 115 & & (3) & $97.55(5.04)$ & $-3.43(0.78)$ \\
\hline 99 & & (3) & $101.01(0.49)$ & $-0.69(0.61)$ & 116 & & (4) & $95.41 \quad(5.58)$ & $-2.22(2.74)$ \\
\hline 100 & & (4) & $102.38(0.35)$ & $1.35(0.34)$ & 117 & 1999 & (1) & $99.25(6.18)$ & 3.95 (2.14) \\
\hline 101 & 1995 & (1) & $100.00(0.00)$ & $-2.35(0.35)$ & 118 & & (2) & $104.27(6.53)$ & $4.93(0.63)$ \\
\hline 102 & & (2) & $92.60(2.10)$ & $-7.69(2.27)$ & 119 & & (3) & $103.32(6.59)$ & $-0.91(1.21)$ \\
\hline 103 & & (3) & $97.74(3.07)$ & $5.41 \quad(2.16)$ & 120 & & (4) & $100.80(6.62)$ & $-2.47(1.56)$ \\
\hline 104 & & (4) & $100.96(3.49)$ & $3.24(1.47)$ & 121 & 2000 & (1) & $100.44(6.63)$ & $-0.36(0.70)$ \\
\hline 105 & 1996 & (1) & $103.42(3.73)$ & $2.41(1.01)$ & 122 & & (2) & $95.19(6.33)$ & $-5.36(0.75)$ \\
\hline 106 & & (2) & $108.79(3.95)$ & $5.06(0.39)$ & 123 & & (3) & $94.65(6.31)$ & $-0.58(0.53)$ \\
\hline 107 & & (3) & $108.60(3.97)$ & $-0.18(0.45)$ & 124 & & (4) & $90.00(6.03)$ & $-5.03(0.59)$ \\
\hline 108 & & (4) & $110.36(4.13)$ & $1.61(0.80)$ & 125 & 2001 & (1) & $91.16(6.32)$ & $1.28(1.79)$ \\
\hline 109 & 1997 & (1) & $112.33(4.48)$ & $1.77(1.38)$ & 126 & & (2) & $90.75(6.31)$ & $-0.46(0.54)$ \\
\hline 110 & & (2) & $110.74(4.52)$ & $-1.43(0.85)$ & 127 & & (3) & $90.76(6.32)$ & $0.01 \quad(0.41)$ \\
\hline 111 & & (3) & $107.35(4.50)$ & $-3.10(0.99)$ & 128 & & (4) & $91.33(6.37)$ & $0.63(0.40)$ \\
\hline 112 & & (4) & $105.64(4.76)$ & $-1.61(1.65)$ & 129 & 2002 & (1) & $94.52(6.68)$ & $3.43(1.12)$ \\
\hline 113 & 1998 & (1) & $106.30(5.14)$ & $0.62(1.75)$ & 130 & & (2) & $97.61(6.96)$ & $3.22(0.95)$ \\
\hline & & & & & & & & & -0.34 \\
\hline & & & ercentage of $\alpha_{t}$ & gnificant at th & he $5 \%$ level & & & & 45 \\
\hline
\end{tabular}

Note: All entries in columns 5 and 10 are to be divided by 100 .

FIGURE 4

HISTOGRAMS OF ESTIMATED $\alpha_{t}$ AND t-RATIOS
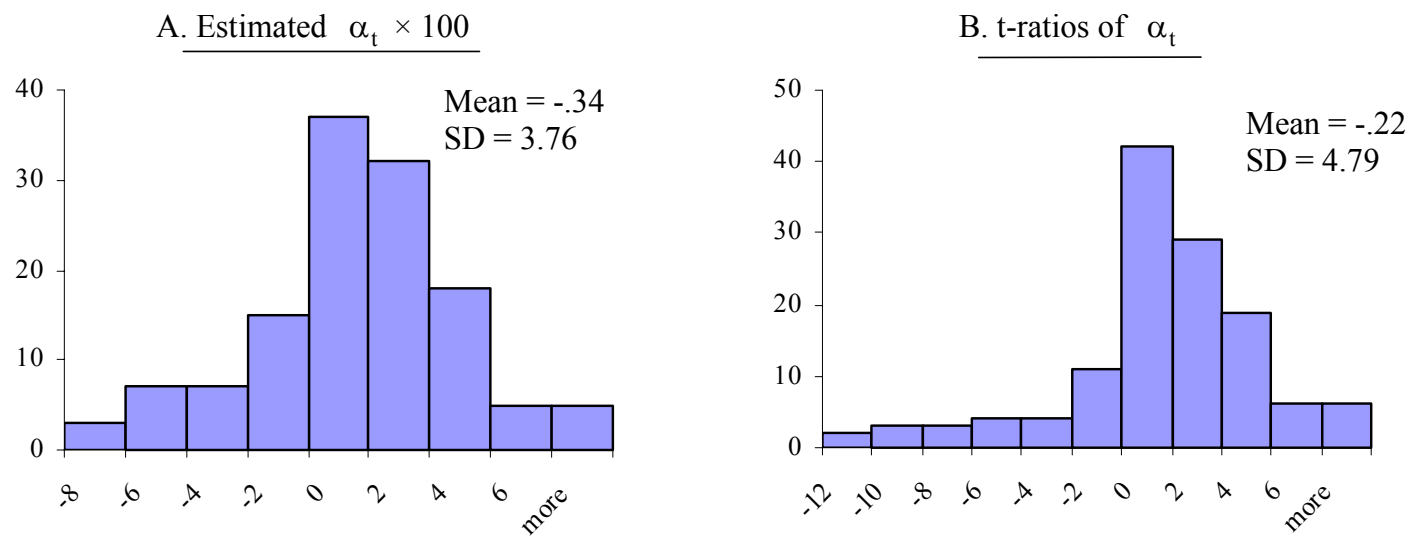

$\log R_{r+M}=\log R_{r}+\sum_{m=r+1}^{r+M} \alpha_{m}$, so that $R_{r+M}=100 \times \exp \left(\sum_{m=r+1}^{r+M} \alpha_{m}\right)$, where $M>0$.

Similarly, for periods prior to the reference quarter, the level of the index number is $\mathrm{R}_{\mathrm{r}+\mathrm{M}}=100 / \exp \left(\sum_{\mathrm{m}=\mathrm{r}+\mathrm{M}+1}^{\mathrm{r}} \alpha_{\mathrm{m}}\right)$, where $\mathrm{M}<0$. The results are presented in columns 4 and 9 of 
Log-changes $\times 100$

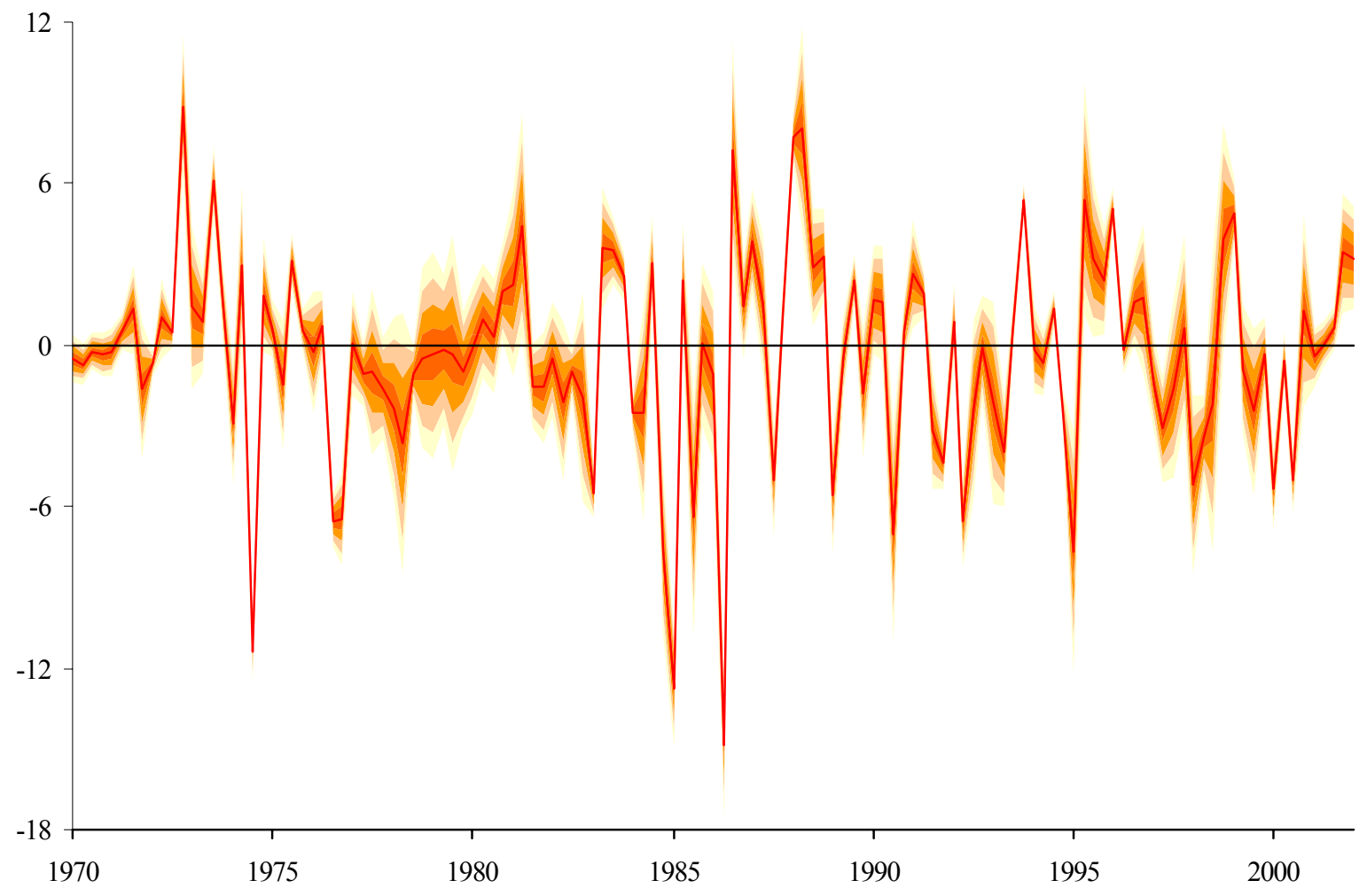

Table 8. The index $R_{r+M}$ is a nonlinear function of $M$ terms of the estimated $\alpha_{t}$, which we write as $\mathrm{f}\left(\boldsymbol{\alpha}_{\mathrm{r}+\mathrm{M}}\right)$, where $\boldsymbol{\alpha}_{\mathrm{r}+\mathrm{M}}$ is the relevant sub-set of the $\alpha_{t}$-estimates. We use the delta method to compute its asymptotic variance, $\operatorname{var}\left(\mathrm{R}_{\mathrm{r}+\mathrm{M}}\right)=\left(\partial \mathrm{f} / \partial \boldsymbol{\alpha}^{\prime}\right) \boldsymbol{\Sigma}_{\boldsymbol{\alpha}}(\partial \mathrm{f} / \partial \boldsymbol{\alpha})$, where $\boldsymbol{\Sigma}_{\boldsymbol{\alpha}}$ is the estimated $\mathrm{M} \times \mathrm{M}$ covariance matrix corresponding to $\boldsymbol{\alpha}_{\mathrm{r}+\mathrm{M}}$. Figure 6 plots in fan-chart format the levels of the index and the confidence bands. As can be seen, as the index value is set to 100 for 1995Q1, there is no uncertainty for this value, and as we get further away from this base period, the confidence bands tend to become successively wider, reflecting the cumulative estimation error.

Table 9 contains the country-specific estimates for the three groups of countries. It can be seen that the estimated $\beta_{c}$ for fast-growing countries with appreciating currencies are all negative, while those for slow-growing countries with depreciating currencies are all positive, as expected. More than half of these estimates are significant. The last row shows that the $\beta_{c}$-estimates for the "other" group of countries are all insignificantly different from zero. 


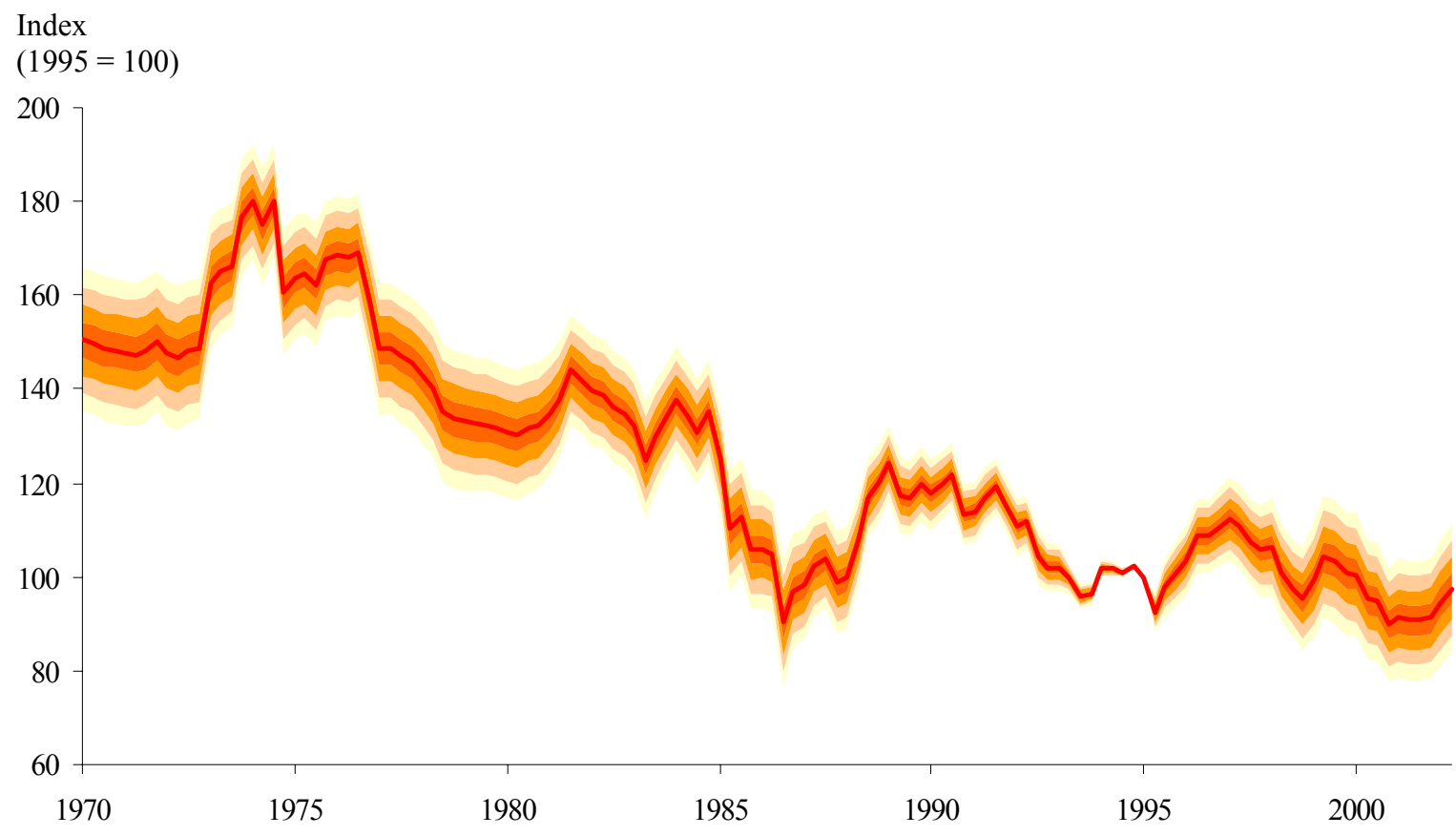

TABLE 9

ESTIMATES OF COUNTRY-GROUP COMPONENTS OF REER CHANGES

(Standard errors in parentheses)

\begin{tabular}{|c|c|c|c|c|c|c|c|c|}
\hline \multicolumn{2}{|c|}{ Country group with } & \multicolumn{6}{|c|}{ Sub-period } & \multirow{2}{*}{ Mean } \\
\hline $\begin{array}{l}\text { GDP } \\
\text { growth }\end{array}$ & $\begin{array}{l}\text { Exchange- } \\
\text { rate change }\end{array}$ & 1 & 2 & 3 & 4 & 5 & 6 & \\
\hline Fast & Appreciation & $-0.87(0.24)$ & $-0.12(0.46)$ & $-0.35(0.89)$ & $-1.19(0.45)$ & $-0.37(0.28)$ & $-0.81(0.34)$ & $-0.65(0.15)$ \\
\hline Slow & Depreciation & $0.92(0.22)$ & $0.46(0.29)$ & $1.67(0.92)$ & $0.98(0.41)$ & $0.24(0.28)$ & $0.63(0.28)$ & $0.70(0.13)$ \\
\hline \multicolumn{2}{|c|}{ All other } & $-0.57(0.37)$ & $-0.08(0.20)$ & $-0.40(0.26)$ & $0.04(0.34)$ & $-0.12(0.18)$ & $-0.18(0.37)$ & $-0.20(0.11)$ \\
\hline
\end{tabular}

Notes: 1. See Table 7 for the sub-periods.

2. The means of $\beta_{\mathrm{c}}$ in the last column are defined as $\bar{\beta}_{\mathrm{c}}=\sum_{\mathrm{i}=1}^{6} \mathrm{w}_{\mathrm{ic}} \beta_{\mathrm{ic}}$, where the weight $\mathrm{w}_{\mathrm{ic}}=\left[1 / \mathrm{SE}\left(\beta_{\mathrm{ic}}\right)\right] / \mathrm{k}$ in which $\mathrm{k}=\sum_{\mathrm{i}=1}^{6}\left[1 / \mathrm{SE}\left(\beta_{\mathrm{ic}}\right)\right]$. Assuming independence, the standard error of $\bar{\beta}_{\mathrm{c}}$ is thus $\sqrt{\sum_{\mathrm{i}=1}^{6} \mathrm{w}_{\mathrm{ic}}^{2}\left[\mathrm{SE}\left(\beta_{\mathrm{ic}}\right)\right]^{2}}=\sqrt{6 / \mathrm{k}^{2}}=\sqrt{6} / \mathrm{k}$, where $\mathrm{k}$ is as above.

\section{How Has Competitiveness Changed?}

In Section 2, we showed how to employ the information on the variability of individual real exchange rates to gauge the significance of changes in international competitiveness. In this section we apply this approach to illustrate how the indexes of Section 6 can be used to assess changes in competitiveness between any two periods. To provide the appropriate background for this analysis, 
we start with a discussion of the broad trends in competitiveness over the past three decades and introduce a simple decomposition.

Let $\mathrm{P}_{\mathrm{t}}$ be the price level at home at time $t, \mathrm{~S}_{\mathrm{t}}$ be the effective nominal exchange rate and $\mathrm{P}_{\mathrm{t}}^{*}$ be an index of foreign prices. ${ }^{12}$ We can then write the level of the real effective exchange rate as $\mathrm{R}_{\mathrm{t}}=\mathrm{P}_{\mathrm{t}} / \mathrm{S}_{\mathrm{t}} \mathrm{P}_{\mathrm{t}}^{*}=\left(1 / \mathrm{S}_{\mathrm{t}}\right) \times\left(\mathrm{P}_{\mathrm{t}} / \mathrm{P}_{\mathrm{t}}^{*}\right)$, which provides a decomposition of the real rate into a term involving the nominal rate $\left(1 / \mathrm{S}_{\mathrm{t}}\right)$, and a relative price term $\left(\mathrm{P}_{\mathrm{t}} / \mathrm{P}_{\mathrm{t}}^{*}\right)$. Figure 7 uses this decomposition for Australia and reveals several interesting features. First, there has been a substantial real depreciation of the Australian dollar over the last three decades, with most of the change taking place between 1975 and 1985. Second, changes in the real rate closely mirror those of the nominal rate, although $\mathrm{R}$ is a bit less volatile than $1 / \mathrm{S}$. Third, there is a long-term upward trend in relative prices $\mathrm{P} / \mathrm{P}^{*}$, a trend which is more pronounced in the first 15 years of the period. Fourth, the volatility of relative prices is substantially lower than that of the two exchange rates.

To explore these issues in more depth, consider the logarithmic change in the real rate

$$
\mathrm{DR}_{\mathrm{t}}=\mathrm{D}\left(1 / \mathrm{S}_{\mathrm{t}}\right)+\mathrm{D}\left(\mathrm{P}_{\mathrm{t}} / \mathrm{P}_{\mathrm{t}}^{*}\right)
$$

where, as before, $\mathrm{D}$ is the log-change operator, defined for any positive variable $\mathrm{x}$ as $D x_{t}=\log x_{t}-\log x_{t-1}=\log \left(x_{t} / x_{t-1}\right)$. We define the change in the effective nominal rate as

FIGURE 7

THE EVOLUTION OF THE REER INDEX AND ITS COMPONENTS

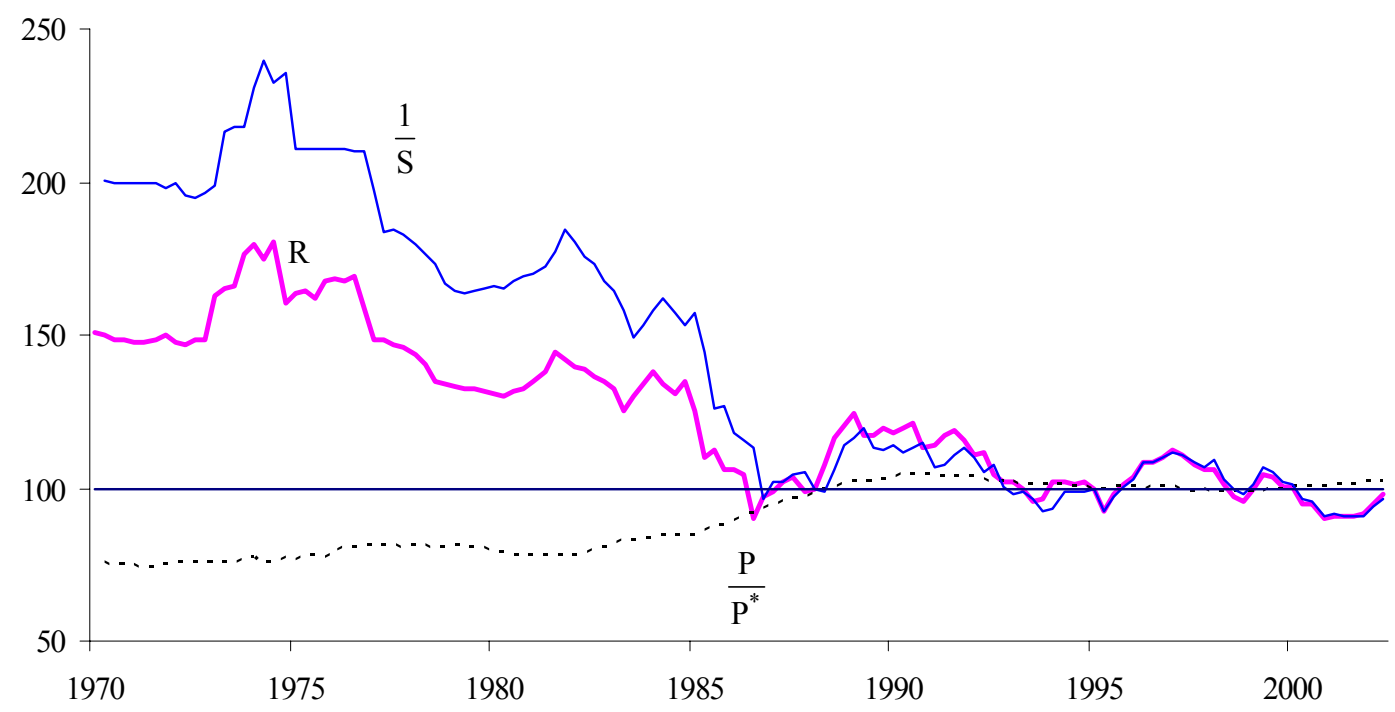

\footnotetext{
${ }^{12}$ Details of precise definitions are given below.
} 
a trade-weighted average of the changes in the $\mathrm{n}$ nominal rates, $\mathrm{DS}_{\mathrm{t}}=\sum_{\mathrm{c}=1}^{\mathrm{n}} \mathrm{w}_{\mathrm{c}} \mathrm{Ds}_{\mathrm{ct}}$, where $\mathrm{w}_{\mathrm{c}}$ is the trade share for county c. Similarly, the change in relative prices is the excess of the change in the CPI in Australian over a trade-weighted average of the changes in the CPIs in each of the $n$ trading partners; that is, $\mathrm{D}\left(\mathrm{P}_{\mathrm{t}} / \mathrm{P}_{\mathrm{t}}^{*}\right)=\mathrm{DP}_{\mathrm{t}}-\sum_{\mathrm{c}=1}^{\mathrm{n}} \mathrm{w}_{\mathrm{c}} \mathrm{DP}_{\mathrm{ct}}^{*}$. A useful property of log-changes is that they are additive in the following sense. If $\mathrm{x}_{1}$ and $\mathrm{x}_{\mathrm{T}}$ are the values of the variable $\mathrm{x}$ at the beginning and end of some period, then the log-change over the entire period is $\log \left(\mathrm{x}_{\mathrm{T}} / \mathrm{x}_{1}\right)$, which is equal to the sum of the corresponding one-period changes over the same period; that is, $\log \left(\mathrm{x}_{\mathrm{T}} / \mathrm{x}_{1}\right)=\sum_{\mathrm{t}=2}^{\mathrm{T}} \log \left(\mathrm{x}_{\mathrm{t}} / \mathrm{x}_{\mathrm{t}-1}\right)=\sum_{\mathrm{t}=2}^{\mathrm{T}} \mathrm{Dx}_{\mathrm{t}} \cdot{ }^{13} \quad$ Percentage changes do not share this attractive additive feature. We apply equation (7.1) to the Australian data with $n=26$ and then accumulate the quarterly changes to (mostly) five-year intervals. The results are contained in Table 10 and several comments can be made. ${ }^{14}$ First, as can be seen from the second last entry of column 2 , over the entire 33 -year period the log-change in the real exchange rate is -0.43 , which is equivalent to a depreciation of 35 percent. ${ }^{15}$ This is composed of a cumulative depreciation of the corresponding nominal rate of 53 percent (column 3), while domestic inflation was 37 percent above that in the

TABLE 10

A DECOMPOSITION OF THE REAL EXCHANGE RATE

(Log-changes $\times 100)$

\begin{tabular}{cccc}
\hline \hline Period & $\begin{array}{c}\text { Real } \\
\text { exchange rate } \\
\mathrm{R}\end{array}$ & $\begin{array}{c}\text { Nominal } \\
\text { exchange rate }\end{array}$ & $\begin{array}{c}\text { Relative prices } \\
\mathrm{P} / \mathrm{P}^{*}\end{array}$ \\
$(1)$ & $(2)$ & $\mathrm{S}$ & $(4)$ \\
\hline $1970-1975$ & 10.69 & 5.16 & 5.53 \\
$1976-1980$ & -23.76 & -21.25 & -2.51 \\
$1981-1985$ & -22.09 & -36.95 & 14.86 \\
$1986-1990$ & 6.83 & -9.95 & 16.77 \\
$1991-1995$ & -11.57 & -7.84 & -3.74 \\
$1996-2000$ & -11.49 & -10.19 & -1.30 \\
$2001-2002$ & 8.12 & 6.29 & 1.83 \\
Sum & -43.27 & -74.72 & 31.44 \\
Mean (quarterly) & -0.34 & -0.58 & 0.24 \\
\hline
\end{tabular}

\footnotetext{
${ }^{13}$ To construct the levels versions of $\mathrm{R}, 1 / \mathrm{S}$ and $\mathrm{P} / \mathrm{P}^{*}$ for Australia in Figure 7 with $\mathrm{n}=26$, we accumulate the quarterly changes, exponentiate and then set 1995Q1 $=100$.

14 To avoid rounding errors and ensure that equation (7.1) holds exactly, we define the change in relative prices residually, so that $\mathrm{D}\left(\mathrm{P}_{\mathrm{t}} / \mathrm{P}_{\mathrm{t}}^{*}\right)=\mathrm{DR}_{\mathrm{t}}-\mathrm{D}\left(1 / \mathrm{S}_{\mathrm{t}}\right)$.

${ }^{15}$ The relationship between the log-change $\alpha$ and the implied percentage change $\beta$ is $\{\exp (\alpha)-1\} \times 100=\beta$ percent. Application of this rule to the cumulative change in the real rate yields $\{\exp (-0.4327)-1\} \times 100=-35$ percent.
} 
trading partners on average (column 4). ${ }^{16}$ Second, there is considerable variability of the real exchange rate, with it appreciating in three sub-periods and depreciating in the other four. Third, in all sub periods except one, the real and nominal rates move in the same direction, and by the same order of magnitude. Finally, in the majority of sub-periods domestic inflation was not too different to that in the rest of the world; in the 1980s, however, Australian inflation was substantially higher, so much so that this decade accounts for almost all of the cumulative inflation difference over the entire three decades: The cumulative log-change in $\mathrm{P}_{\mathrm{t}} / \mathrm{P}_{\mathrm{t}}^{*}$ over the $1980 \mathrm{~s}$ is $14.86+16.77=31.63$, while that for the three decades is $31.44($ all $\times 100)$.

Next, we assess whether the real depreciation over the whole period of 35 percent leads to an improvement in Australia's international competitiveness that is significant in statistical sense, using the standard errors of the index reported in the previous section. Columns 3 and 4 of the first row of Table 11 give the estimates of the index numbers for 1970 and 2002. As can be seen from column 5, the index falls by 53 points. The test of the change in competitiveness involves a comparison of two unknown population means $\mathrm{R}_{0}$ and $\mathrm{R}_{1}$. If we wish to test the hypothesis that the country's competitiveness improved over the transition from period 0 to period 1 , then the null is $\mathrm{R}_{1}-\mathrm{R}_{0}=0$, while the alternative is $\mathrm{R}_{1}-\mathrm{R}_{0}<0$. Using a circumflex to denote an estimated mean and SE for the corresponding standard error, under normality the test statistic $\left(\hat{\mathrm{R}}_{1}-\hat{\mathrm{R}}_{0}\right) /\left(\sqrt{\mathrm{SE}_{\mathrm{R}_{1}}^{2}+\mathrm{SE}_{\mathrm{R}_{0}}^{2}}\right)$ follows a $\mathrm{t}$ distribution with 25 degrees of freedom. Using the data given in columns 3 and 4 of row 1 of Table 11, the value of this test statistic is -5.20 , as indicated in column 6. As this is greater than (in absolute value) the 5-percent critical value of -1.71 (using a one-tailed test), we are able to reject the hypothesis and conclude that international competitiveness improved between 1970 and 2002.

In 1997 the nominal value of the Australian dollar reached almost 80 US cents, while by 2001, it had depreciated to near 50 US cents. This deprecation occurred not only vis-à-vis the US dollar, but also relative to the currencies of many of Australia's other trading partners. Did this nominal depreciation translate into a real depreciation so that competitiveness was enhanced, or was it just offset by changes in price levels? If competitiveness improved, was the improvement significant? We shall examine this issue as a second illustration of the general approach. Applying the same $t$ test as above, we can see from row 2 of Table 11 that the index fell by 18 points over this period, and the t-value is -2.33 . As this exceeds (in absolute value) the 5 percent critical value, we can reject the hypothesis of constant competitiveness from 1997 to 2001.

\footnotetext{
${ }^{16}$ That is, $\{\exp (-0.7472)-1\} \times 100=-53$ percent; and $\{\exp (0.3144)-1\} \times 100=37$ percent.
} 
TABLE 11

TESTS OF CHANGES IN INTERNATIONAL COMPETITIVENESS

\begin{tabular}{|c|c|c|c|c|c|c|}
\hline \multicolumn{3}{|c|}{ Period } & \multicolumn{2}{|c|}{$\begin{array}{c}\text { REER index for } \\
\text { (Standard errors in parentheses) }\end{array}$} & \multirow{3}{*}{$\begin{array}{c}\text { Change in } \\
\text { competitiveness } \\
\mathrm{R}_{1}-\mathrm{R}_{0} \\
\text { (5) }\end{array}$} & \multirow{3}{*}{$\begin{array}{c}\mathrm{t} \text { statistic for testing } \\
\mathrm{H}_{0}: \mathrm{R}_{1}-\mathrm{R}_{0}=0 \\
\text { against } \mathrm{H}_{1}: \mathrm{R}_{1}-\mathrm{R}_{0}<0 \\
\text { (6) }\end{array}$} \\
\hline & 0 & 1 & $\mathrm{R}_{0}$ & $\mathrm{R}_{1}$ & & \\
\hline & (1) & (2) & (3) & (4) & & \\
\hline 1. & 1970 & 2002 & $149.3(7.6)$ & $96.1(6.8)$ & -53.2 & -5.20 \\
\hline 2. & 1997 & 2001 & $109.0(4.6)$ & $91.0(6.2)$ & -18.0 & -2.33 \\
\hline
\end{tabular}

Note: The numbers in columns 3 to 4 are the averages over the corresponding four quarters of the index numbers and the associated standard errors given in columns 4 and 9 of Table 8.

The material in this section demonstrates how the uncertainty measures of the real exchange rate index can be used to test for changes in international competitiveness, so that it is possible to analyse whether such changes are significant in statistical sense. This is one of the attractions of the stochastic approach to index numbers.

\section{8. $\quad$ Concluding Comments}

Official agencies in many countries now publish indexes of international competitiveness. Typically these take the form of a weighted average (of some type or other) of the real exchange rates between the country in question and its major trading partners. An important aspect of these indexes that has been neglected is that as they are an average of the underlying real exchange rates, they are subject to estimation uncertainty, except in the unlikely case in which all the real rates change equiproportionally. Accordingly, these indexes convey a false sense of accuracy as they ignore the volatility of the component real rates.

The recently-revived stochastic approach to index-number theory can be employed to solve this defect in current practice by providing the whole probability distribution of the index of international competitiveness, with the dispersion of the distribution reflecting the volatility of real rates. A stochastic index of international competitiveness can be thought of as representing the solution to a signal-extraction problem: The $\mathrm{n}$ real exchange rates ( $\mathrm{n}$ being the number of trading partners) are each made up of two components, the signal and noise, and the problem is to combine the real rates in such a manner so as to minimise the overall impact of noise in the system. This leads to the index emerging as the generalised least-squares (GLS) estimator of the common trend in the $\mathrm{n}$ real rates, so that the index has a number of attractive properties associated with GLS theory. The econometric framework provides not only a point estimate of the index, but also its 
standard error, which can be used to assess the confidence that can be placed in the estimate of international competitiveness.

In this paper we demonstrated the implementation of the stochastic approach to the measurement of international competitiveness. The application with Australian data contained several novel features including Monte Carlo simulation results on the modelling of heteroscedasticity in the context of the stochastic approach; the introduction of a procedure for determining the length of sub-periods during which the country weights of the index can be treated as remaining unchanged; the use of a "fan type" diagram to provide a new way to visualise stochastic index numbers, with colour-coded probabilities; and the use of the productivity-bias hypothesis of Balassa (1964) and Samuelson (1964) as a way to link the evolution of real exchange rates to country income.

One final point is worth making. The stochastic approach requires no more data than is currently employed in conventional competitiveness indexes. In a fundamental sense, conventional indexes are concerned with the first moment of the data, while stochastic indexes use both first and second moments, so that the volatility of the underlying data leads directly to estimation uncertainty as measured by the standard error of the index. 


\section{APPENDIX 1}

\section{THE RBA INDEX}

The Reserve Bank of Australia publishes a quarterly real exchange rate index. There are four versions of this index, each corresponding to a different set of weights, exports, imports, trade (exports plus imports) and G7-GDP. Let $w_{c}$ be the weight for country $c$ $(\mathrm{c}=1, \ldots, \mathrm{n})$ and $\mathrm{r}_{\mathrm{ct}}$ be the real exchange rate between $\mathrm{c}$ and Australia in quarter $\mathrm{t}$. The Bank defines its multilateral index as a weighted geometric mean of the $\mathrm{n}$ bilateral rates, the logarithm of which is

$$
\sum_{\mathrm{c}=1}^{\mathrm{n}} \mathrm{w}_{\mathrm{c}} \log \mathrm{r}_{\mathrm{ct}}
$$

The weights are held constant for certain sub-periods and then change in a discrete fashion. When the weights change, the RBA slices the index (Ellis, 2001). ${ }^{17}$

To evaluate the RBA index (A1.1), we obtained the nominal exchange rates and CPIs from Datastream, and Luci Ellis of the RBA generously provided us with the country weights. ${ }^{18}$ Figure A1 gives the indexes published by the RBA, as well as our "reproduced" versions. As can be seen, we reproduce the Bank's results reasonably closely. These indexes show that the Australia dollar has depreciated in real terms over the last three decades by something of the order of 30 percent.

\footnotetext{
${ }^{17}$ Splicing is carried out as follows. Assume that at time $t_{1}>t_{0}$ the weights change to $w_{c, t_{1}}$ from their previous values at time $t_{0}, w_{c, t_{0}}$. Then the spliced index at time $t_{1}$ is given by $\log \mathrm{R}_{\mathrm{t}_{1}}=\log \mathrm{R}_{\mathrm{t}_{0}}+\sum_{\mathrm{c}} \mathrm{W}_{\mathrm{c}, \mathrm{t}_{1}} \log \mathrm{r}_{\mathrm{c}, \mathrm{t}_{1}}-\sum_{\mathrm{c}} \mathrm{W}_{\mathrm{c}, \mathrm{t}_{1}} \log \mathrm{r}_{\mathrm{c}, \mathrm{t}_{0}}$.

18 The RBA trade weights originally included 29 countries, which represent 90 percent of Australia's international trade. In our initial explorations, it was found that the data on China, Saudi Arabia and Indonesia severely distorted the real exchange rate index. Thus we set the trade weights for these three countries to zero and renormalise the remaining weights to sum to one. The import and export weights use the same 26 countries as the trade weights. The G7-GDP weights are not affected as the three problematic countries are not part of the G7.
} 
FIGURE A1

FOUR REAL EXCHANGE INDEXES
A. Trade weights
$(1995 \mathrm{Q} 1=100)$
B. Import weights

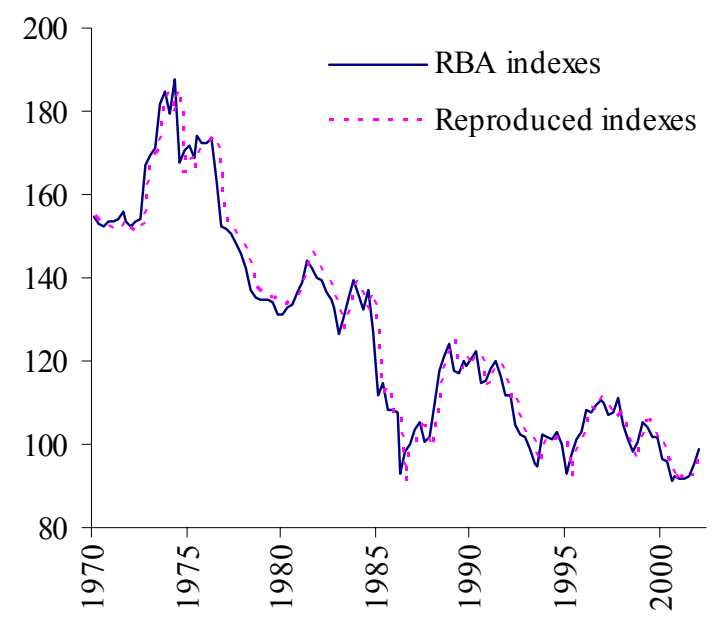

C. Export weights
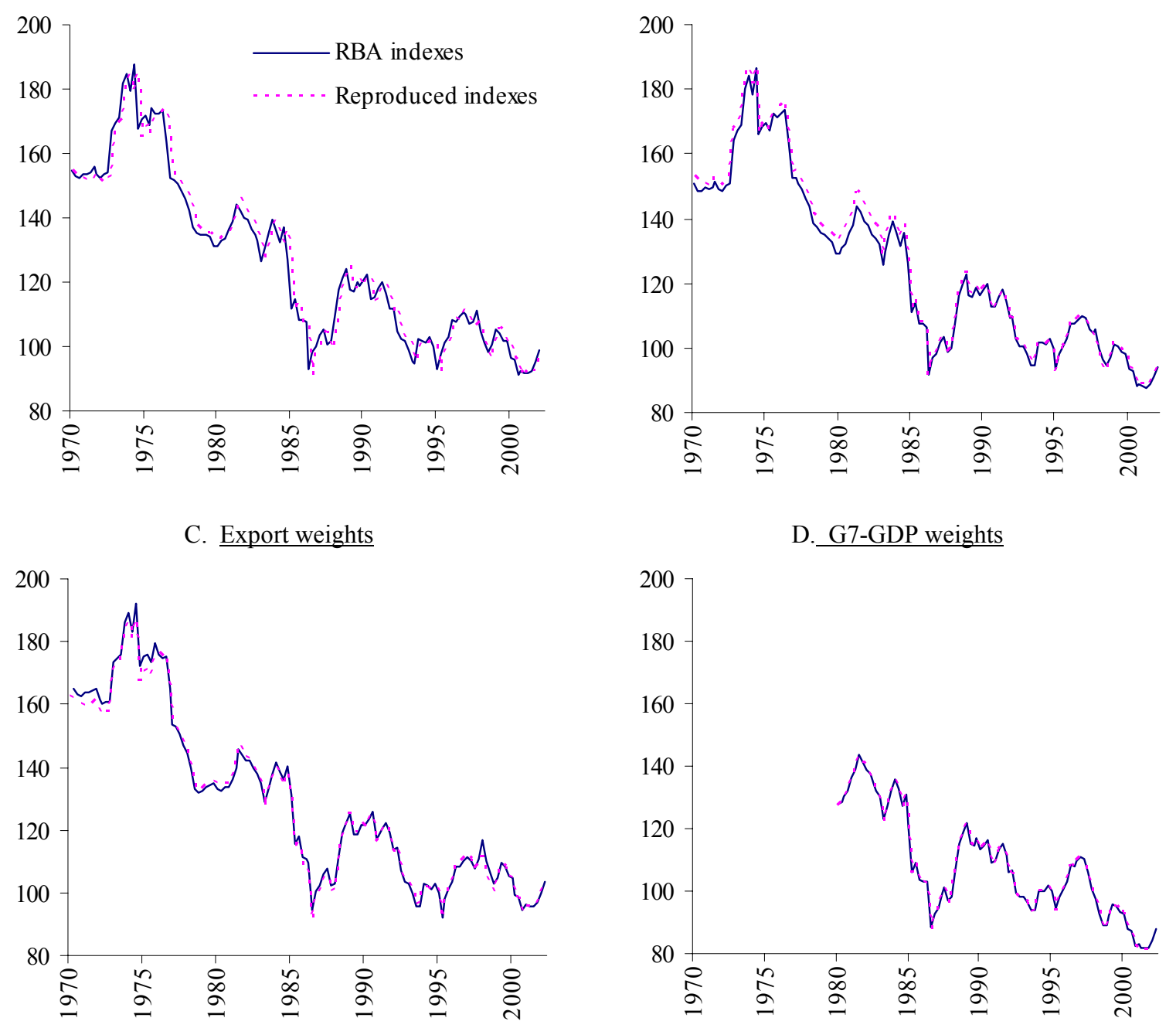

Source: The RBA indices are from the RBA website http://www.rba.gov.au/ (consulted in January 2003). 


\section{APPENDIX 2}

\section{OPTIMAL SUB-PERIODS FOR}

\section{THE FOUR SETS OF WEIGHTS}

To be consistent with the RBA approach, we use the same four sets of weights in the stochastic approach: trade, import, export and G7-GDP. Before estimation, we use the criterion described in Section 5 to divide the whole sample period into optimal sub-periods during which the weights are assumed to be constant.

For the first three sets of weights quarterly data are available, while for G7-GDP we only have annual data for 1980-2001. We "expand" the 22 annual GDP weights for each country into 88 quarterly weights by assuming that they are constant within each year. The trade, import and export weights refer to 129 quarters and we divide the whole period into 5 to 6 sub-periods. As the total number of quarters is smaller for GDP weights (88), it is not unreasonable to use 3 to 4 sub-periods in this case. We use the procedure of Section 5 to identify the optimal sub-periods for each of the four weighting schemes. The optimal subperiods are displayed in rows $2,7,11$ and 16 of Table A1. 
TABLE A1

IDENTIFICATION OF SUB-PERIODS

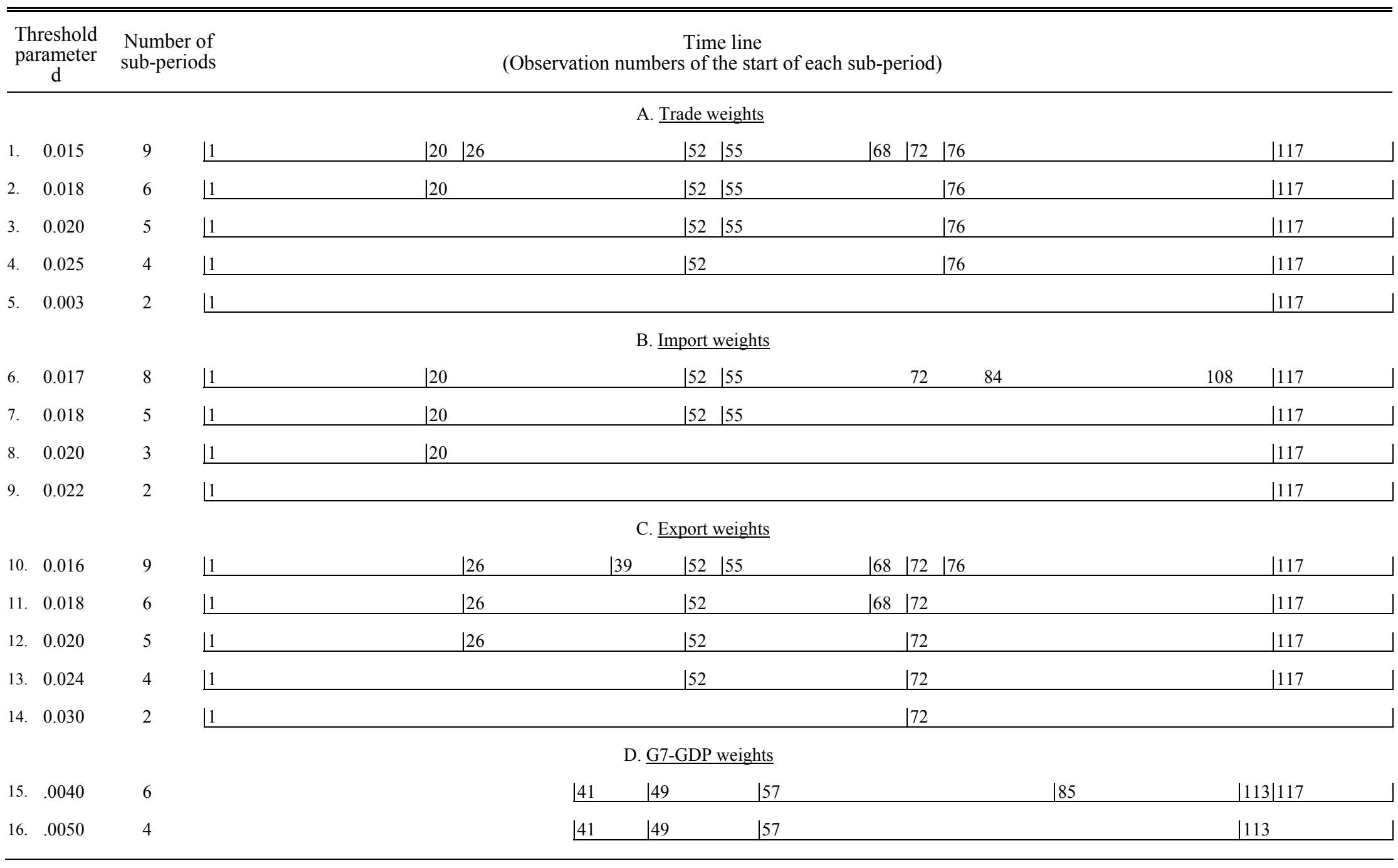

Note: 1. This table corresponds to Table 7.

2. The whole period is from 1970Q1 (observation number 1) to 2002Q2 (observation number 130). 


\section{APPENDIX 3 \\ PRELIMINARY ESTIMATES OF MODEL (3.1) \\ FOR FOUR SETS OF WEIGHTS}

This appendix presents the preliminary estimation results of equation (3.1), with the country-specific components $\beta_{c}$ satisfying the identification constraint $\sum_{c} w_{c} \beta_{c}=0$. These results are preliminary in that the country-specific parameters are otherwise unconstrained. Table A2 contains the preliminary estimates of the REER with the four sets of weights. It can be seen that with the trade weights, the point estimates are exactly the same as the final estimates reported in Table 8, where the countries are categorised into three groups. This is due to the orthogonality between the time component $\alpha_{t}$ and the country/group component $\beta_{c}$ in model (3.1). The four versions of indexes in levels are quite similar. Figures A2 and A3 give the histograms of the estimates and their t-values. The fan charts for changes and levels of the REER index are given in Figures A4 and A5.

The preliminary estimates of the country-specific parameters, $\beta_{c}$, are contained in Table A3 and we can see that most of them are insignificant. Figure A6 plots $\beta_{c}$ for each country and it can be seen that they tend to fluctuate considerably over time. Next to eliminate some detail, we plot in Figure A7 the estimated $\beta_{c}$ averaged over sub-periods (these averages are given in the last column of Table A3). As can be seen, the mean for Japan is consistently significantly negative, while that for PNG is consistently significantly positive. 
TABLE A2

PRELIMINARY ESTIMATES OF REER INDEX

(Standard errors in parentheses)

\begin{tabular}{|c|c|c|c|c|c|c|c|c|c|c|c|c|c|}
\hline \multirow{2}{*}{\multicolumn{2}{|c|}{$\begin{array}{l}\text { Observation } \\
\text { number }\end{array}$}} & \multirow{3}{*}{ Quarter } & \multicolumn{11}{|c|}{ Weights } \\
\hline & & & \multicolumn{3}{|c|}{ Trade } & \multicolumn{3}{|c|}{ Import } & \multicolumn{3}{|c|}{ Export } & \multicolumn{2}{|c|}{ G7-GDP } \\
\hline (1) & (2) & & & $\begin{array}{l}\text { Level } \\
\text { (4) }\end{array}$ & $\underset{\text { (5) }}{\text { Change }} \alpha_{t}$ & & $\begin{array}{l}\text { evel } \\
6)\end{array}$ & $\begin{array}{l}\text { Change } \alpha_{t} \\
\text { (7) }\end{array}$ & & vel & $\begin{array}{c}\text { Change } \alpha_{t} \\
\text { (9) }\end{array}$ & $\begin{array}{l}\text { Level } \\
(10)\end{array}$ & $\underset{\text { (11) }}{\text { Change }} \alpha_{t}$ \\
\hline 1 & 1970 & (1) & 150.46 & $(17.47)$ & & 146.63 & (17.94) & & 162.08 & $(11.80)$ & & & \\
\hline 2 & & (2) & 149.72 & $(17.44)$ & $-0.50(0.75)$ & 145.83 & $(17.92)$ & $-0.54(0.74)$ & 161.40 & $(11.79)$ & $-0.42(0.55)$ & & \\
\hline 3 & & (3) & 148.66 & $(17.45)$ & $-0.71(0.76)$ & 144.78 & (17.94) & $-0.72(0.74)$ & 160.27 & $(11.81)$ & $-0.70(0.60)$ & & \\
\hline 4 & & (4) & 148.32 & (17.39) & $-0.23(0.70)$ & 144.51 & $(17.87)$ & $-0.19(0.69)$ & 159.81 & (11.79) & $-0.29(0.49)$ & & \\
\hline 5 & 1971 & (1) & 147.80 & $(17.36)$ & $-0.35(0.83)$ & 143.87 & $(17.85)$ & $-0.44(0.83)$ & 159.28 & (11.79) & $-0.33(0.64)$ & & \\
\hline 6 & & (2) & 147.41 & $(17.33)$ & $-0.27(0.85)$ & 143.21 & $(17.86)$ & $-0.46(0.90)$ & 158.92 & $(11.77)$ & $-0.22(0.59)$ & & \\
\hline 7 & & (3) & 148.17 & (17.18) & $0.51 \quad(0.86)$ & 143.84 & $(17.71)$ & $0.44(0.87)$ & 159.54 & (11.69) & $0.39(0.61)$ & & \\
\hline 8 & & (4) & 150.16 & (16.91) & $1.34(1.21)$ & 146.09 & (17.39) & $1.56(1.13)$ & 160.88 & $(11.57)$ & $0.83(1.04)$ & & \\
\hline 9 & 1972 & (1) & 147.68 & (17.17) & $-1.67(1.58)$ & 144.13 & (17.61) & $-1.35(1.46)$ & 157.22 & (11.83) & $-2.30(1.40)$ & & \\
\hline 10 & & (2) & 146.64 & (17.24) & $-0.70(0.77)$ & 143.17 & $(17.66)$ & $-0.67(0.76)$ & 155.94 & (11.90) & $-0.82(0.52)$ & & \\
\hline 11 & & (3) & 148.12 & $(17.00)$ & $1.00(1.02)$ & 145.07 & $(17.35)$ & 1.32 (1.19) & 156.99 & $(11.77)$ & $0.67(0.71)$ & & \\
\hline 12 & & (4) & 148.77 & $(16.88)$ & $0.44(0.73)$ & 146.01 & (17.19) & $0.65(0.73)$ & 157.34 & $(11.71)$ & $0.22(0.49)$ & & \\
\hline 13 & 1973 & (1) & 162.61 & $(15.42)$ & $8.89(1.62)$ & 160.02 & $(15.67)$ & $9.16(1.50)$ & 170.58 & $(10.79)$ & $8.08(1.43)$ & & \\
\hline 14 & & (2) & 164.94 & $(15.18)$ & $1.42(1.78)$ & 162.48 & $(15.41)$ & $1.53(1.70)$ & 171.75 & $(10.71)$ & $0.68(1.55)$ & & \\
\hline 15 & & (3) & 166.35 & $(15.00)$ & $0.85(1.40)$ & 163.85 & $(15.23)$ & $0.84(1.60)$ & 172.67 & (10.61) & $0.53(1.28)$ & & \\
\hline 16 & & (4) & 176.77 & (14.09) & $6.08(0.89)$ & 174.82 & (14.24) & $6.48(0.91)$ & 182.93 & $(9.97)$ & $5.77(0.86)$ & & \\
\hline 17 & 1974 & (1) & 179.99 & $(13.82)$ & $1.81(0.87)$ & 178.55 & $(13.92)$ & $2.11(0.93)$ & 185.81 & (9.79) & $1.56(0.69)$ & & \\
\hline 18 & & (2) & 174.87 & (14.19) & $-2.89(1.48)$ & 173.22 & $(14.32)$ & $-3.03(1.58)$ & 180.29 & $(10.07)$ & $-3.02(1.10)$ & & \\
\hline 19 & & (3) & 180.15 & $(13.75)$ & $2.98(1.46)$ & 178.32 & (13.89) & $2.90(1.25)$ & 186.54 & (9.67) & $3.41 \quad(1.58)$ & & \\
\hline 20 & & (4) & 160.70 & $(15.15)$ & $-11.43(0.79)$ & 158.74 & $(15.36)$ & $-11.63(0.74)$ & 166.66 & $(10.80)$ & $-11.27(0.73)$ & & \\
\hline 21 & 1975 & (1) & 163.74 & $(14.65)$ & $1.87(1.07)$ & 161.22 & $(14.92)$ & 1.55 (1.19) & 169.45 & $(10.59)$ & $1.66(1.14)$ & & \\
\hline 22 & & (2) & 164.73 & (14.32) & $0.60(0.70)$ & 162.15 & (14.60) & $0.57(0.76)$ & 170.15 & $(10.53)$ & $0.41(0.76)$ & & \\
\hline 23 & & (3) & 162.28 & $(14.36)$ & $-1.50(1.34)$ & 160.11 & $(14.63)$ & $-1.27(1.40)$ & 168.25 & $(10.63)$ & $-1.12(0.87)$ & & \\
\hline 24 & & (4) & 167.44 & $(13.71)$ & $3.13(0.84)$ & 165.11 & (13.98) & $3.08(0.83)$ & 174.56 & $(10.24)$ & $3.68(0.52)$ & & \\
\hline 25 & 1976 & (1) & 168.42 & $(13.40)$ & $0.58(0.69)$ & 166.21 & $(13.67)$ & $0.66(0.70)$ & 175.46 & $(10.18)$ & $0.51 \quad(0.52)$ & & \\
\hline 26 & & (2) & 167.96 & (13.15) & $-0.27(1.36)$ & 166.40 & $(13.37)$ & $0.12(1.55)$ & 174.07 & $(10.04)$ & $-0.80(1.21)$ & & \\
\hline 27 & & (3) & 169.16 & (12.83) & $0.71 \quad(0.87)$ & 167.93 & (13.03) & $0.91 \quad(0.87)$ & 174.58 & $(9.83)$ & $0.29(0.82)$ & & \\
\hline 28 & & (4) & 158.50 & $(13.46)$ & $-6.51(0.86)$ & 157.27 & $(13.67)$ & $-6.56(1.03)$ & 163.57 & $(10.31)$ & $-6.51(0.65)$ & & \\
\hline 29 & 1977 & (1) & 148.60 & (14.12) & $-6.45(0.91)$ & 147.30 & $(14.37)$ & $-6.55(1.00)$ & 153.23 & $(10.83)$ & $-6.53(0.77)$ & & \\
\hline 30 & & (2) & 148.71 & $(13.87)$ & $0.08(1.05)$ & 147.63 & $(14.12)$ & $0.23(0.94)$ & 152.65 & $(10.67)$ & $-0.38(1.12)$ & & \\
\hline 31 & & (3) & 147.11 & $(13.80)$ & $-1.08(0.78)$ & 146.17 & $(14.06)$ & $-0.99(0.73)$ & 150.52 & $(10.64)$ & $-1.41(0.73)$ & & \\
\hline 32 & & (4) & 145.67 & $(13.70)$ & $-0.99(1.54)$ & 145.00 & (13.96) & $-0.80(1.38)$ & 147.90 & $(10.61)$ & $-1.76(1.67)$ & & \\
\hline 33 & 1978 & (1) & 143.37 & (13.73) & $-1.59(0.96)$ & 142.32 & (14.05) & $-1.87(1.07)$ & 145.61 & $(10.63)$ & $-1.55(0.71)$ & & \\
\hline 34 & & (2) & 140.08 & $(13.71)$ & $-2.32(1.83)$ & 139.89 & (13.98) & $-1.72(1.75)$ & 140.89 & $(10.65)$ & $-3.30(2.04)$ & & \\
\hline 35 & & (3) & 135.07 & (13.89) & $-3.64(2.42)$ & 135.41 & $(14.18)$ & $-3.25(2.10)$ & 134.30 & (10.77) & $-4.79(2.79)$ & & \\
\hline
\end{tabular}


TABLE A2 (continued)

PRELIMINARY ESTIMATES OF REER INDEX

(Standard errors in parentheses)

\begin{tabular}{|c|c|c|c|c|c|c|c|c|c|c|c|c|}
\hline \multirow{3}{*}{$\begin{array}{l}\text { Observation } \\
\text { number } \\
\text { (1) }\end{array}$} & \multirow{3}{*}{$\begin{array}{l}\text { Year } \\
(2) \\
\end{array}$} & \multirow{3}{*}{ Quarter } & \multicolumn{10}{|c|}{ Weights } \\
\hline & & & \multicolumn{4}{|c|}{ Trade } & \multicolumn{2}{|c|}{ Import } & \multicolumn{2}{|c|}{ Export } & \multicolumn{2}{|c|}{ G7-GDP } \\
\hline & & & & $\begin{array}{l}\text { evel } \\
\text { (4) }\end{array}$ & Chat & $\begin{array}{l}\text { nge } \alpha_{t} \\
\text { (5) }\end{array}$ & $\begin{array}{l}\text { Level } \\
\text { (6) }\end{array}$ & $\begin{array}{l}\text { Change } \alpha_{t} \\
\text { (7) }\end{array}$ & $\begin{array}{l}\text { Level } \\
(8)\end{array}$ & 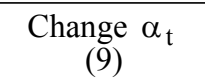 & $\begin{array}{l}\text { Level } \\
(10)\end{array}$ & $\underset{\text { (11) }}{\text { Change }} \alpha_{t}$ \\
\hline 36 & & (4) & 133.65 & $(13.84)$ & -1.06 & $(0.78)$ & $133.75(14.17)$ & $-1.24(0.83)$ & $133.07(10.70)$ & $-0.92(0.68)$ & & \\
\hline 37 & 1979 & (1) & 133.01 & (13.62) & -0.48 & (1.87) & $132.46(14.06)$ & $-0.97(1.65)$ & $133.70(10.36)$ & $0.47(2.06)$ & & \\
\hline 38 & & (2) & 132.53 & (13.38) & -0.36 & $(2.08)$ & $131.44(13.91)$ & $-0.77(1.88)$ & $134.66(9.98)$ & $0.71(2.25)$ & & \\
\hline 39 & & (3) & 132.30 & $(13.16)$ & -0.18 & $(1.54)$ & $130.44(13.78)$ & $-0.76(1.70)$ & $135.41 \quad(9.72)$ & $0.56(1.37)$ & & \\
\hline 40 & & (4) & 131.87 & $(12.91)$ & -0.32 & $(2.39)$ & $129.46(13.64)$ & $-0.75(2.09)$ & $136.45 \quad(9.28)$ & $0.76(2.70)$ & & \\
\hline 41 & 1980 & (1) & 130.60 & $(12.86)$ & -0.97 & (1.30) & $127.84(13.65)$ & $-1.26(1.25)$ & $135.95(9.15)$ & $-0.37(1.33)$ & $127.38(11.95)$ & \\
\hline 42 & & (2) & 130.35 & $(12.73)$ & -0.19 & (1.29) & $127.93(13.50)$ & 0.07 (1.19) & $135.03(9.04)$ & $-0.68(1.52)$ & $128.13(11.77)$ & $0.59(1.31)$ \\
\hline 43 & & (3) & 131.58 & $(12.52)$ & 0.94 & (1.06) & $129.29(13.28)$ & $1.06(1.00)$ & $135.71 \quad(8.91)$ & $0.50(1.02)$ & $130.22(11.57)$ & $1.62(3.02)$ \\
\hline 44 & & (4) & 132.03 & (12.36) & 0.34 & (1.23) & $130.39(13.06)$ & $0.85(1.28)$ & $135.53 \quad(8.79)$ & $-0.14(1.30)$ & $131.97(11.36)$ & $1.34(0.60)$ \\
\hline 45 & 1981 & (1) & 134.68 & $(12.04)$ & 1.99 & (1.10) & $133.52(12.68)$ & $2.37(1.20)$ & $137.89(8.56)$ & $1.73(1.05)$ & $135.89(11.19)$ & $2.93(1.22)$ \\
\hline 46 & & (2) & 137.77 & (11.71) & 2.27 & (1.80) & $136.58(12.34)$ & $2.26(1.78)$ & $141.79(8.27)$ & $2.79(1.56)$ & $138.62(10.73)$ & $1.98(3.21)$ \\
\hline 47 & & (3) & 144.03 & (11.11) & 4.44 & (2.16) & $143.07(11.68)$ & $4.64(2.31)$ & $148.66(7.81)$ & $4.73(1.74)$ & $143.39(10.28)$ & $3.39(3.32)$ \\
\hline 48 & & (4) & 141.87 & $(11.23)$ & -1.51 & $(0.88)$ & 140.65 & $-1.70(0.99)$ & $146.09(7.90)$ & $-1.75(0.70)$ & $141.04(10.24)$ & $-1.65(3.26)$ \\
\hline 49 & 1982 & (1) & 139.63 & $(11.35)$ & -1.59 & $(1.25)$ & 138.25 (11.99) & $-1.72(1.13)$ & $144.55(7.93)$ & $-1.06(1.24)$ & $138.45(10.39)$ & $-1.85(0.81)$ \\
\hline 50 & & (2) & 138.90 & $(11.37)$ & -0.53 & $(1.26)$ & $137.29(12.04)$ & $-0.69(1.15)$ & $144.52(7.88)$ & $-0.02(1.22)$ & $136.96(10.45)$ & $-1.08(0.83)$ \\
\hline 51 & & (3) & 136.01 & (11.55) & -2.10 & (1.63) & $134.30(12.26)$ & $-2.21(1.49)$ & $142.34(7.91)$ & $-1.52(1.62)$ & $133.73(10.67)$ & $-2.39(2.04)$ \\
\hline 52 & & (4) & 134.67 & $(11.32)$ & -1.00 & $(1.70)$ & 133.13 (11.99) & $-0.87(1.78)$ & $140.54(7.82)$ & $-1.28(0.66)$ & $131.75(10.31)$ & $-1.49(0.88)$ \\
\hline 53 & 1983 & (1) & 132.06 & $(11.22)$ & -1.95 & (2.63) & $130.97(11.83)$ & $-1.64(2.77)$ & $136.58(7.82)$ & $-2.86(1.57)$ & $129.69(10.35)$ & $-1.57(3.23)$ \\
\hline 54 & & (2) & 125.01 & $(11.78)$ & -5.48 & (1.67) & $123.82(12.43)$ & $-5.62(1.79)$ & $129.62(8.05)$ & $-5.23(0.74)$ & $122.51(10.72)$ & $-5.70(0.70)$ \\
\hline 55 & & (3) & 129.62 & $(10.99)$ & 3.62 & (1.07) & $128.26(11.80)$ & $3.52(0.92)$ & $134.40 \quad(7.57)$ & $3.62(1.05)$ & $126.63(10.16)$ & $3.31(1.31)$ \\
\hline 56 & & (4) & 134.26 & (10.26) & 3.52 & $(0.83)$ & 133.19 (11.13) & $3.78(0.72)$ & $138.59 \quad(7.18)$ & $3.07 \quad(0.62)$ & $131.60(9.53)$ & $3.85(0.78)$ \\
\hline 57 & 1984 & (1) & 137.76 & $(9.66)$ & 2.57 & $(0.81)$ & $136.79(10.63)$ & $2.66(0.49)$ & $141.84(6.86)$ & $2.32(0.78)$ & $135.37(9.12)$ & $2.83(0.64)$ \\
\hline 58 & & (2) & 134.29 & $(9.59)$ & -2.55 & $(0.72)$ & $133.43(10.70)$ & $-2.48(0.39)$ & $138.14 \quad(6.92)$ & $-2.64(0.61)$ & $132.07(9.09)$ & $-2.47(0.33)$ \\
\hline 59 & & (3) & 130.97 & $(9.51)$ & -2.50 & (1.87) & $130.00(10.82)$ & $-2.60(1.78)$ & $135.45(6.86)$ & $-1.97(1.84)$ & $127.11(9.12)$ & $-3.83(3.69)$ \\
\hline 60 & & (4) & 135.06 & $(8.92)$ & 3.08 & $(0.84)$ & $134.31(10.28)$ & $3.26(0.78)$ & $139.50 \quad(6.55)$ & $2.95(0.64)$ & $130.79(8.60)$ & $2.86(1.80)$ \\
\hline 61 & 1985 & (1) & 125.06 & $(9.29)$ & -7.70 & (1.47) & $124.36(10.92)$ & $-7.70(1.29)$ & $129.42 \quad(6.88)$ & $-7.50(1.50)$ & 120.47 (8.99) & $-8.22(3.14)$ \\
\hline 62 & & (2) & 110.10 & $(10.22)$ & -12.74 & (1.41) & 109.35 & $-12.86(1.23)$ & $114.15 \quad(7.67)$ & $-12.55(1.12)$ & 105.80 & $-12.98(2.30)$ \\
\hline 63 & & (3) & 112.80 & $(9.73)$ & 2.42 & (1.42) & $111.99(11.68)$ & $2.38(1.30)$ & $116.69(7.36)$ & $2.20(1.39)$ & $108.87(9.61)$ & $2.86(2.55)$ \\
\hline 64 & & (4) & 105.86 & $(10.06)$ & -6.35 & $(2.34)$ & 105.58 & $-5.89(2.18)$ & $108.68 \quad(7.59)$ & $-7.11(2.30)$ & $102.98(9.98)$ & $-5.56(4.20)$ \\
\hline 65 & 1986 & (1) & 105.89 & $(9.73)$ & 0.03 & $(1.71)$ & $105.88(11.78)$ & $0.28(1.58)$ & $108.53(7.41)$ & $-0.14(1.60)$ & $102.71(9.65)$ & $-0.27(3.47)$ \\
\hline 66 & & (2) & 104.75 & $(9.50)$ & -1.09 & (1.72) & $105.04(11.58)$ & $-0.80(1.56)$ & $106.72(7.34)$ & $-1.68(1.70)$ & $102.29(9.56)$ & $-0.41(2.47)$ \\
\hline 67 & & (3) & 90.27 & $(10.61)$ & -14.87 & (1.51) & $90.61(13.04)$ & $-14.78(1.35)$ & $91.99(8.34)$ & $-14.85(1.55)$ & $87.69(10.66)$ & $-15.40(2.35)$ \\
\hline 68 & & (4) & 97.05 & $(9.48)$ & 7.23 & (1.41) & $96.69(11.75)$ & $6.49(1.51)$ & $99.76(7.48)$ & $8.10(1.09)$ & $92.56(9.57)$ & $5.40(0.35)$ \\
\hline 69 & 1987 & (1) & 98.41 & $(9.12)$ & 1.40 & $(1.35)$ & $97.92(11.39)$ & $1.27(1.19)$ & 101.15 & $1.39(0.77)$ & $93.96(9.31)$ & $1.51(2.82)$ \\
\hline 70 & & (2) & 102.29 & $(8.56)$ & 3.86 & $(1.25)$ & $101.92(10.70)$ & $4.00(1.15)$ & $104.43(6.86)$ & $3.19(1.39)$ & $98.89(8.75)$ & $5.11(1.50)$ \\
\hline
\end{tabular}

(continued on next page) 
TABLE A2 (continued)

PRELIMINARY ESTIMATES OF REER INDEX

(Standard errors in parentheses)

\begin{tabular}{|c|c|c|c|c|c|c|c|c|c|c|c|c|}
\hline \multirow{2}{*}{\multicolumn{2}{|c|}{$\begin{array}{l}\text { Observation Year } \\
\text { number }\end{array}$}} & \multirow{3}{*}{ Quarter } & \multicolumn{10}{|c|}{ Weights } \\
\hline & & & \multicolumn{2}{|c|}{ Trade } & \multicolumn{3}{|c|}{ Import } & \multicolumn{3}{|c|}{ Export } & \multicolumn{2}{|c|}{ G7-GDP } \\
\hline (1) & (2) & & $\begin{array}{l}\text { Level } \\
\text { (4) }\end{array}$ & $\underset{(5)}{\text { Change }} \alpha_{t}$ & & $\begin{array}{l}\text { Level } \\
\text { (6) }\end{array}$ & $\underset{\text { (7) }}{\text { Change }} \alpha_{t}$ & $\begin{array}{r}\text { Lev } \\
(8)\end{array}$ & & $\underset{(9)}{\text { Change }} \alpha_{t}$ & $\begin{array}{l}\text { Level } \\
(10)\end{array}$ & $\underset{\text { (11) }}{\text { Change }} \alpha_{t}$ \\
\hline 71 & & (3) & $103.86(8.12)$ & $1.53(1.54)$ & 103.31 & $(10.19)$ & $1.36(1.15)$ & 106.14 & $(6.61)$ & $1.62(1.41)$ & $100.78(8.34)$ & $1.89(1.37)$ \\
\hline 72 & & (4) & $98.76(8.38)$ & $-5.03(1.30)$ & 98.35 & $(10.50)$ & $-4.92(1.21)$ & 101.00 & $(6.79)$ & $-4.96(1.12)$ & $96.21(8.52)$ & $-4.64(2.91)$ \\
\hline 73 & 1988 & (1) & $99.76(8.17)$ & $1.00(0.94)$ & 99.46 & (10.14) & $1.12(0.79)$ & 101.52 & $(6.64)$ & $0.52(0.75)$ & $97.88(8.38)$ & $1.73(1.22)$ \\
\hline 74 & & (2) & $107.76(7.48)$ & $7.72(0.88)$ & 107.55 & (9.12) & $7.82(0.62)$ & 109.27 & $(6.07)$ & $7.35(0.55)$ & $106.33(7.55)$ & $8.28(0.61)$ \\
\hline 75 & & (3) & $116.78(6.73)$ & $8.04 \quad(1.80)$ & 116.42 & (8.18) & 7.93 (1.61) & 118.10 & $(5.45)$ & $7.77(1.33)$ & $114.82(6.70)$ & $7.69(3.99)$ \\
\hline 76 & & (4) & $120.17(6.34)$ & $2.86(1.02)$ & 119.71 & (7.74) & $2.79(0.95)$ & 121.42 & $(5.15)$ & $2.78(1.07)$ & $117.97(6.40)$ & $2.70(2.17)$ \\
\hline 77 & 1989 & (1) & $124.19(5.96)$ & $3.29(0.94)$ & 123.68 & $(7.25)$ & $3.26(0.97)$ & 125.54 & $(4.85)$ & $3.33(1.01)$ & $121.51(6.00)$ & $2.96(1.73)$ \\
\hline 78 & & (2) & $117.47(6.07)$ & $-5.56(1.21)$ & 117.08 & $(7.34)$ & $-5.49(1.34)$ & 118.78 & $(4.92)$ & $-5.54(1.33)$ & $115.05(6.19)$ & $-5.47(2.42)$ \\
\hline 79 & & (3) & $116.98(5.89)$ & $-0.42 \quad(0.89)$ & 116.54 & $(7.07)$ & $-0.46(1.05)$ & 118.44 & $(4.78)$ & $-0.29(1.02)$ & $114.42(5.82)$ & $-0.54(0.74)$ \\
\hline 80 & & (4) & $119.80(5.59)$ & $2.38 \quad(0.56)$ & 119.00 & $(6.66)$ & $2.09(0.87)$ & 121.62 & $(4.57)$ & $2.65(0.53)$ & $116.24(5.61)$ & $1.57(0.76)$ \\
\hline 81 & 1990 & (1) & $117.68(5.39)$ & $-1.79 \quad(1.29)$ & 116.31 & $(6.38)$ & $-2.28(1.56)$ & 120.13 & $(4.39)$ & $-1.24(1.36)$ & $112.84(5.35)$ & $-2.96(0.88)$ \\
\hline 82 & & (2) & $119.66(5.05)$ & $1.67(1.11)$ & 117.95 & $(5.93)$ & $1.40(1.32)$ & 122.62 & $(4.11)$ & $2.05(1.21)$ & $113.95(5.05)$ & $0.98(0.44)$ \\
\hline 83 & & (3) & $121.55(4.80)$ & $1.57(0.99)$ & 119.76 & $(5.64)$ & $1.52(1.15)$ & 124.50 & $(3.92)$ & $1.52(0.93)$ & $116.13(4.76)$ & $1.89(2.47)$ \\
\hline 84 & & (4) & $113.34(4.67)$ & $-7.00 \quad(1.91)$ & 111.76 & (5.69) & $-6.91(1.72)$ & 115.73 & $(3.70)$ & $-7.30(2.08)$ & $108.62(4.59)$ & $-6.68(3.13)$ \\
\hline 85 & 1991 & (1) & $113.93(4.49)$ & $0.52(0.72)$ & 112.29 & (5.39) & $0.48(0.88)$ & 116.44 & $(3.57)$ & $0.60(0.73)$ & $108.81(4.46)$ & $0.17(1.54)$ \\
\hline 86 & & (2) & $116.96(4.19)$ & $2.62 \quad(1.10)$ & 115.82 & (4.93) & $3.09(1.43)$ & 119.04 & (3.38) & $2.21(0.82)$ & $112.72(4.19)$ & $3.53(4.03)$ \\
\hline 87 & & (3) & $119.19(3.96)$ & $1.89(0.45)$ & 117.86 & (4.63) & $1.75(0.41)$ & 121.35 & $(3.24)$ & $1.92(0.43)$ & $114.53(3.95)$ & $1.59(0.39)$ \\
\hline 88 & & (4) & $115.53(3.86)$ & $-3.12(1.03)$ & 114.04 & $(4.55)$ & $-3.29(1.08)$ & 117.70 & (3.13) & $-3.05(1.12)$ & $110.71(3.86)$ & $-3.39(2.58)$ \\
\hline 89 & 1992 & (1) & $110.60(3.88)$ & $-4.36(0.50)$ & 109.06 & $(4.52)$ & $-4.47(0.50)$ & 112.75 & (3.18) & $-4.30(0.50)$ & $105.78(3.80)$ & $-4.56(0.20)$ \\
\hline 90 & & (2) & $111.57(3.65)$ & $0.88(0.72)$ & 109.70 & $(4.24)$ & $0.59(0.68)$ & 113.96 & $(3.02)$ & $1.07(0.76)$ & $106.07(3.72)$ & $0.28(0.19)$ \\
\hline 91 & & (3) & $104.46(3.73)$ & $-6.59(0.74)$ & 102.49 & $(4.27)$ & $-6.80(1.10)$ & 106.89 & $(3.12)$ & $-6.41(0.61)$ & $98.93(3.66)$ & $-6.97(2.70)$ \\
\hline 92 & & (4) & $102.05(3.27)$ & $-2.33(1.69)$ & 100.67 & $(3.70)$ & $-1.79(1.84)$ & 103.76 & $(2.83)$ & $-2.97(1.41)$ & $97.58(3.23)$ & $-1.37(3.64)$ \\
\hline 93 & 1993 & (1) & $101.95(3.00)$ & $-0.09(1.01)$ & 100.74 & (3.37) & $0.07(1.00)$ & 103.31 & (2.68) & $-0.44(0.82)$ & $97.59(3.01)$ & $0.00(2.38)$ \\
\hline 94 & & (2) & $99.80(2.26)$ & $-2.14(1.81)$ & 98.83 & (2.81) & $-1.92(1.61)$ & 100.69 & $(1.85)$ & $-2.57(1.93)$ & $96.35(2.37)$ & $-1.28(2.16)$ \\
\hline 95 & & (3) & $95.95(1.88)$ & $-3.93(1.04)$ & 95.38 & $(2.50)$ & $-3.56(0.88)$ & 96.39 & (1.54) & $-4.36(1.00)$ & $93.48(2.07)$ & $-3.02(1.00)$ \\
\hline 96 & & (4) & $96.50(1.59)$ & $0.57(0.63)$ & 95.95 & $(2.10)$ & 0.60 & 96.97 & (1.28) & $0.61 \quad(0.69)$ & $94.17(1.72)$ & $0.73(1.28)$ \\
\hline 97 & 1994 & (1) & $101.86(1.30)$ & $5.41(0.47)$ & 101.43 & $(1.70)$ & $5.56(0.58)$ & 102.28 & (1.07) & $5.33(0.46)$ & $99.84(1.44)$ & $5.85(0.77)$ \\
\hline 98 & & (2) & $101.71(0.95)$ & $-0.15(0.74)$ & 101.41 & (1.37) & $-0.03(0.77)$ & 101.94 & $(0.77)$ & $-0.34(0.70)$ & 100.12 & $0.28(1.50)$ \\
\hline 99 & & (3) & $101.01(0.68)$ & $-0.69(0.55)$ & 100.81 & $(0.97)$ & $-0.59(0.83)$ & 101.10 & $(0.63)$ & $-0.82(0.40)$ & $99.98(0.83)$ & $-0.14(1.66)$ \\
\hline 100 & & (4) & $102.38(0.40)$ & $1.35(0.46)$ & 102.26 & $(0.56)$ & $1.42(0.66)$ & 102.48 & $(0.33)$ & $1.35(0.50)$ & $101.79(0.39)$ & $1.80(0.56)$ \\
\hline 101 & 1995 & (1) & $100.00(0.00)$ & $-2.35(0.40)$ & 100.00 & $(0.00)$ & $-2.23(0.57)$ & 100.00 & $(0.00)$ & $-2.45(0.34)$ & $100.00(0.00)$ & $-1.78(0.29)$ \\
\hline 102 & & (2) & $92.60(2.04)$ & $-7.69(2.20)$ & 93.07 & $(1.92)$ & $-7.18(2.07)$ & 91.96 & (2.09) & $-8.38(2.27)$ & $94.10(1.97)$ & $-6.08(2.92)$ \\
\hline 103 & & (3) & $97.74(3.13)$ & $5.41(2.28)$ & 97.95 & (3.11) & $5.11(2.35)$ & 97.59 & $(3.34)$ & $5.95(2.54)$ & $98.16(3.10)$ & $4.22(2.13)$ \\
\hline 104 & & (4) & $100.96(3.66)$ & $3.24(1.58)$ & 100.82 & (3.72) & $2.88(1.72)$ & 101.35 & $(3.91)$ & $3.77(1.72)$ & 100.55 & $2.41(1.42)$ \\
\hline 105 & 1996 & (1) & $103.42(3.99)$ & $2.41 \quad(1.14)$ & 103.24 & (4.14) & $2.37(1.28)$ & 103.98 & $(4.26)$ & $2.57(1.27)$ & $102.78(4.13)$ & $2.19(1.70)$ \\
\hline
\end{tabular}

(continued on next page) 
TABLE A2 (continued)

PRELIMINARY ESTIMATES OF REER INDEX

(Standard errors in parentheses)

\begin{tabular}{|c|c|c|c|c|c|c|c|c|c|c|}
\hline \multirow{2}{*}{\multicolumn{2}{|c|}{$\begin{array}{l}\text { Observation } \\
\text { number }\end{array}$}} & \multirow{2}{*}{ Quarter } & \multicolumn{8}{|c|}{ Weights } \\
\hline & & & \multicolumn{2}{|c|}{ Trade } & \multicolumn{2}{|c|}{ Import } & \multicolumn{2}{|c|}{ Export } & \multicolumn{2}{|c|}{ G7-GDP } \\
\hline (1) & (2) & (3) & $\begin{array}{l}\text { Level } \\
\text { (4) }\end{array}$ & $\underset{\text { (5) }}{\text { Change }} \alpha_{t}$ & $\begin{array}{l}\text { Level } \\
\text { (6) }\end{array}$ & $\underset{\text { (7) }}{\text { Change }} \alpha_{t}$ & $\begin{array}{l}\text { Level } \\
\text { (8) }\end{array}$ & $\begin{array}{c}\text { Change } \\
\text { (9) }\end{array}$ & $\begin{array}{l}\text { Level } \\
(10)\end{array}$ & $\begin{array}{l}\text { Change } \alpha_{t} \\
\text { (11) }\end{array}$ \\
\hline 106 & & (2) & $108.79(4.31)$ & $5.06(0.55)$ & 108.75 & $5.20(0.73)$ & $109.32(4.55)$ & $5.00(0.59)$ & 108.46 & $5.38(0.79)$ \\
\hline 107 & & (3) & $108.60(4.44)$ & $-0.18(0.56)$ & 108.35 (4.79) & $-0.37(0.78)$ & $109.36(4.64)$ & $0.04(0.61)$ & $107.91(4.63)$ & $-0.51(0.09)$ \\
\hline 108 & & (4) & $110.36(4.73)$ & $1.61(0.91)$ & $109.93(5.20)$ & $1.45(1.12)$ & $111.37(4.90)$ & $1.81(0.96)$ & $109.37(4.84)$ & $1.34(0.86)$ \\
\hline 109 & 1997 & (1) & 112.33 & $1.77(1.49)$ & $111.82(5.79)$ & $1.70(1.73)$ & $113.57(5.34)$ & $1.96(1.55)$ & $111.00(5.49)$ & $1.48(3.46)$ \\
\hline 110 & & (2) & $110.74(5.30)$ & $-1.43(0.84)$ & $110.39(5.96)$ & $-1.28(0.68)$ & $111.71(5.39)$ & $-1.65(0.85)$ & $109.83(5.54)$ & $-1.06(0.56)$ \\
\hline 111 & & (3) & $107.35(5.37)$ & $-3.10(1.00)$ & $106.89(6.03)$ & $-3.23(0.78)$ & $108.21(5.39)$ & $-3.18(1.02)$ & $105.92(5.59)$ & $-3.63(1.08)$ \\
\hline 112 & & (4) & $105.64(5.63)$ & $-1.61(1.65)$ & $103.54(6.27)$ & $-3.18(1.58)$ & $107.88(5.72)$ & -0.31 & $100.04(5.80)$ & $-5.71(0.55)$ \\
\hline 113 & 1998 & (1) & $106.30(6.00)$ & $0.62(1.73)$ & $102.96(6.50)$ & $-0.56(1.25)$ & $109.54(6.30)$ & $1.53(2.11)$ & 97.57 (6.23) & $-2.50(1.14)$ \\
\hline 114 & & (2) & $100.95(6.16)$ & $-5.17(1.78)$ & $97.96(6.66)$ & $-4.98(1.63)$ & $104.13(6.52)$ & $-5.07(2.19)$ & $92.67(6.50)$ & $-5.15(1.55)$ \\
\hline 115 & & (3) & $97.55(6.13)$ & $-3.43(0.91)$ & $94.43 \quad(6.70)$ & $-3.67(1.02)$ & $100.87(6.45)$ & $-3.18(1.00)$ & $88.67(6.47)$ & $-4.41(1.04)$ \\
\hline 116 & & (4) & $95.41(6.65)$ & $-2.22(2.67)$ & $92.96(7.12)$ & $-1.56(2.52)$ & $97.83(6.90)$ & $-3.06(2.79)$ & $88.60(6.90)$ & $-0.08(4.41)$ \\
\hline 117 & 1999 & (1) & $99.25(7.26)$ & $3.95(2.20)$ & $97.05(7.74)$ & $4.30(2.20)$ & $101.41(7.52)$ & 3.59 (2.29) & $91.19(7.53)$ & $2.88(0.55)$ \\
\hline 118 & & (2) & $104.27(7.71)$ & $4.93(0.86)$ & $102.08(8.25)$ & $5.06(1.05)$ & $106.38(7.95)$ & $4.79(0.74)$ & $95.92(7.91)$ & $5.06(1.49)$ \\
\hline 119 & & (3) & $103.32(7.79)$ & $-0.91(1.16)$ & 101.34 (8.36) & $-0.73(1.09)$ & $105.17(8.01)$ & $-1.14(1.30)$ & $95.19(8.12)$ & $-0.77(1.21)$ \\
\hline 120 & & (4) & $100.80(7.85)$ & $-2.47(1.49)$ & $99.22(8.45)$ & $-2.11(1.39)$ & $102.17(8.01)$ & $-2.90(1.64)$ & $93.15(8.12)$ & $-2.17(1.80)$ \\
\hline 121 & 2000 & (1) & $100.44(7.96)$ & $-0.36(0.92)$ & $98.98 \quad(8.63)$ & $-0.25(1.04)$ & $101.67(8.07)$ & $-0.49(0.90)$ & $93.22(8.18)$ & 0.08 (1.49) \\
\hline 122 & & (2) & $95.19(7.67)$ & $-5.36(0.86)$ & $93.97 \quad(8.39)$ & $-5.19(1.05)$ & $96.17(7.71)$ & $-5.56(0.70)$ & $88.39(7.97)$ & $-5.32(1.20)$ \\
\hline 123 & & (3) & $94.65(7.74)$ & $-0.58(0.68)$ & $93.41 \quad(8.52)$ & $-0.60(0.80)$ & $95.64(7.74)$ & $-0.55(0.63)$ & $87.43(8.01)$ & $-1.10(0.73)$ \\
\hline 124 & & (4) & $90.00(7.45)$ & $-5.03(0.73)$ & 88.67 (8.24) & $-5.21(0.87)$ & $91.14(7.43)$ & $-4.83(0.63)$ & 82.35 (7.69) & $-5.98(1.05)$ \\
\hline 125 & 2001 & (1) & 91.16 (7.98) & $1.28(2.00)$ & 89.15 (8.83) & $0.55(2.01)$ & $93.10(7.92)$ & $2.13(2.00)$ & 82.31 (8.18) & $-0.05(0.50)$ \\
\hline 126 & & (2) & $90.75(8.05)$ & $-0.46(0.76)$ & $88.67(8.95)$ & $-0.54(0.95)$ & $92.78(7.95)$ & $-0.34(0.59)$ & $81.37(8.23)$ & $-1.15(1.52)$ \\
\hline 127 & & (3) & $90.76(8.21)$ & $0.01(0.51)$ & $88.62 \quad(9.22)$ & $-0.06(0.67)$ & $92.86(8.04)$ & $0.09(0.42)$ & $81.23(8.55)$ & $-0.18(0.94)$ \\
\hline 128 & & (4) & $91.33(8.42)$ & $0.63(0.61)$ & $88.92(9.53)$ & $0.34(0.74)$ & $93.72(8.19)$ & $0.92(0.50)$ & $81.32(8.61)$ & $0.11 \quad(0.28)$ \\
\hline 129 & 2002 & (1) & $94.52(8.97)$ & $3.43(1.36)$ & $91.71(10.16)$ & $3.09(1.30)$ & $97.36(8.72)$ & $3.82(1.46)$ & & \\
\hline \multirow[t]{4}{*}{130} & & (2) & $97.61 \quad(9.44)$ & $3.22(0.81)$ & $94.86(10.80)$ & $3.38(0.96)$ & $100.37(9.09)$ & $3.04(0.73)$ & & \\
\hline & & & Mean & -0.34 & & -0.34 & & -0.37 & & -0.52 \\
\hline & & & Percentage of $\alpha_{t}$ & & & & & & & \\
\hline & & ignifica & it at the $5 \%$ level & 40 & & 40 & & 43 & & 45 \\
\hline
\end{tabular}

Note: The entries in columns 5, 7, 9 and 11 are to be divided by 100 . 
FIGURE A2

HISTOGRAMS OF PRELIMINARY ESTIMATES OF $\alpha_{t}$

A. Trade weights

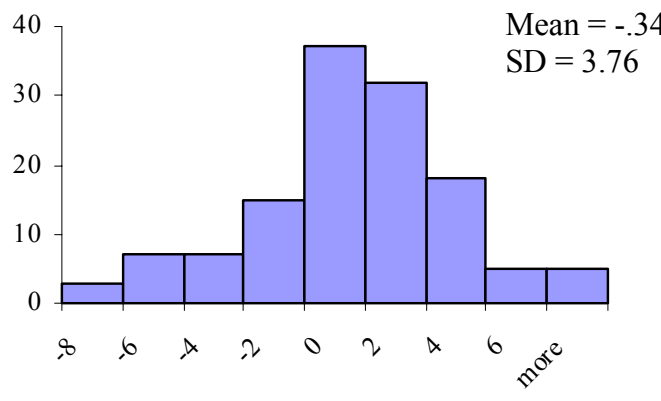

C. Export weights

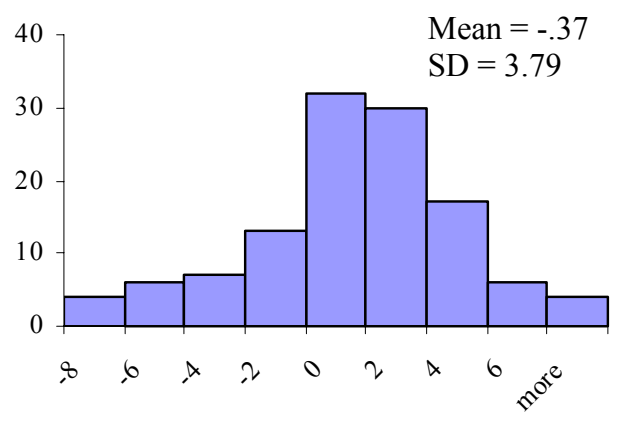

B. Import weights

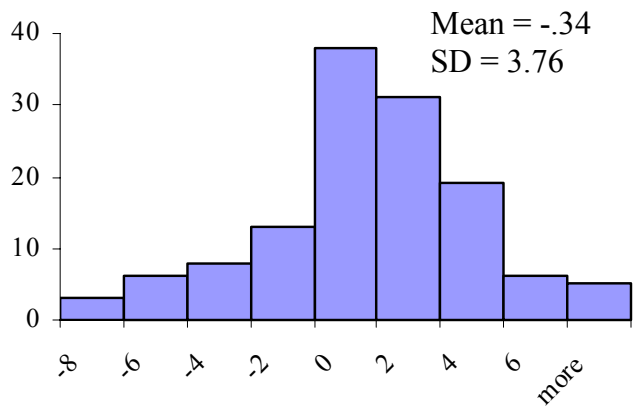

D. G7-GDP weights Mean $=-.52$

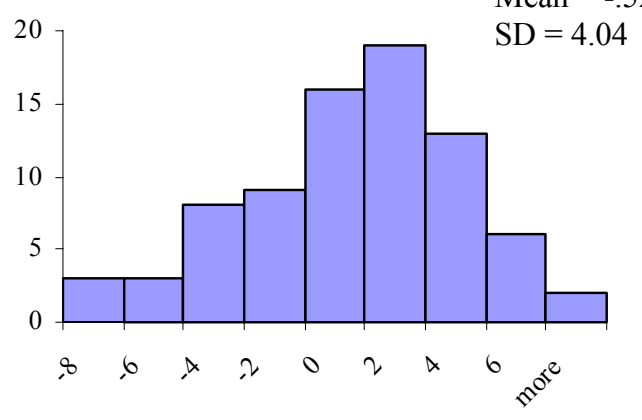

Note: All estimated $\alpha_{t}$ are to be divided by 100 .

FIGURE A3

HISTOGRAMS OF t-RATIOS OF PRELIMINARY ESTIMATES OF $\alpha_{t}$

A. Trade weights

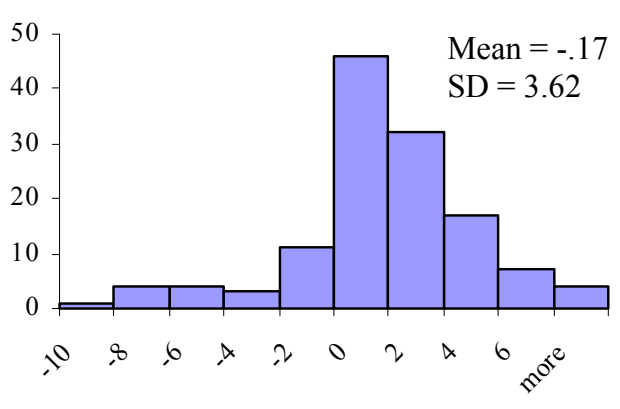

C. Export weights

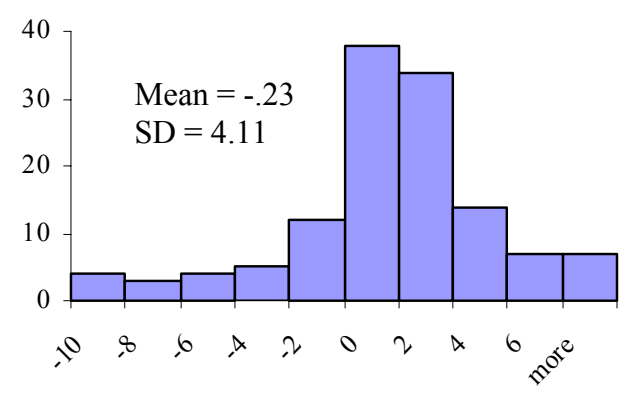

B. Import weights

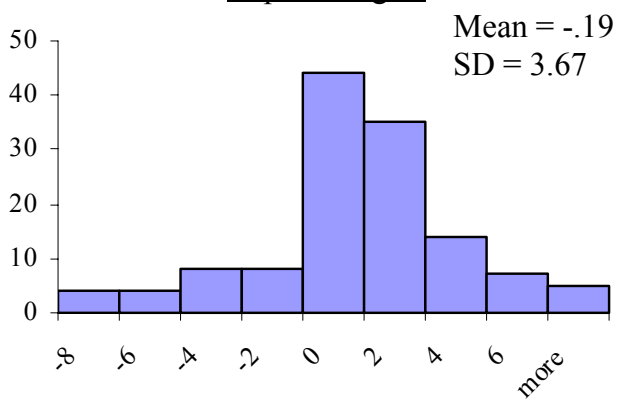

D. G7-GDP weights Mean $=-.31$

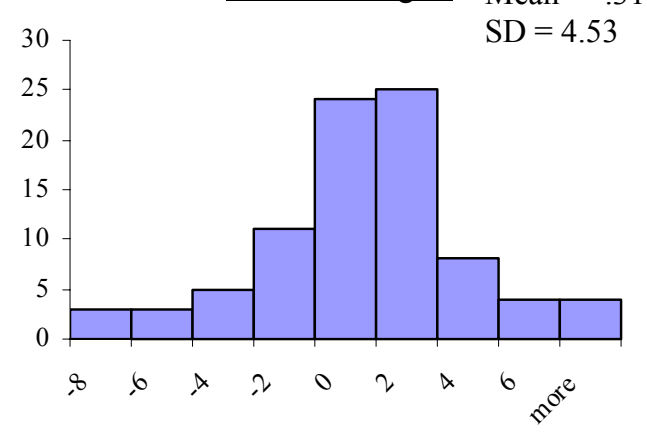


FIGURE A4

PRELIMINARY ESTIMATES OF REER INDEX AND CONFIDENCE BANDS: CHANGES

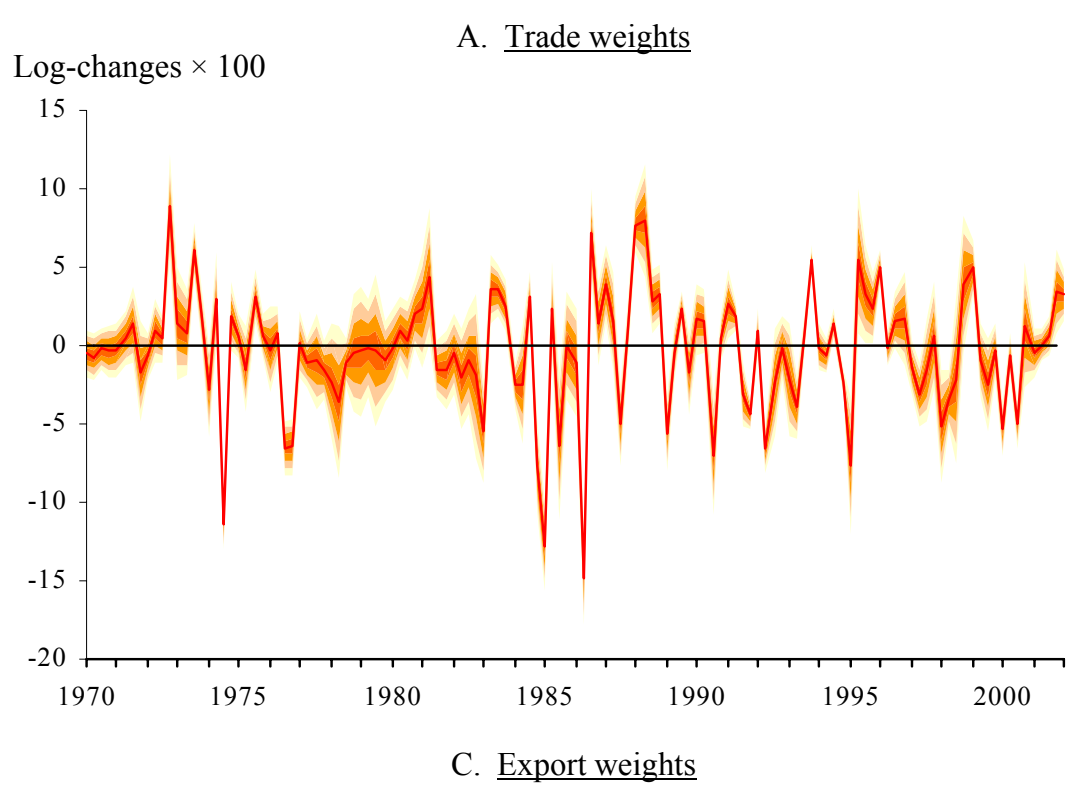

Log-changes $\times 100$
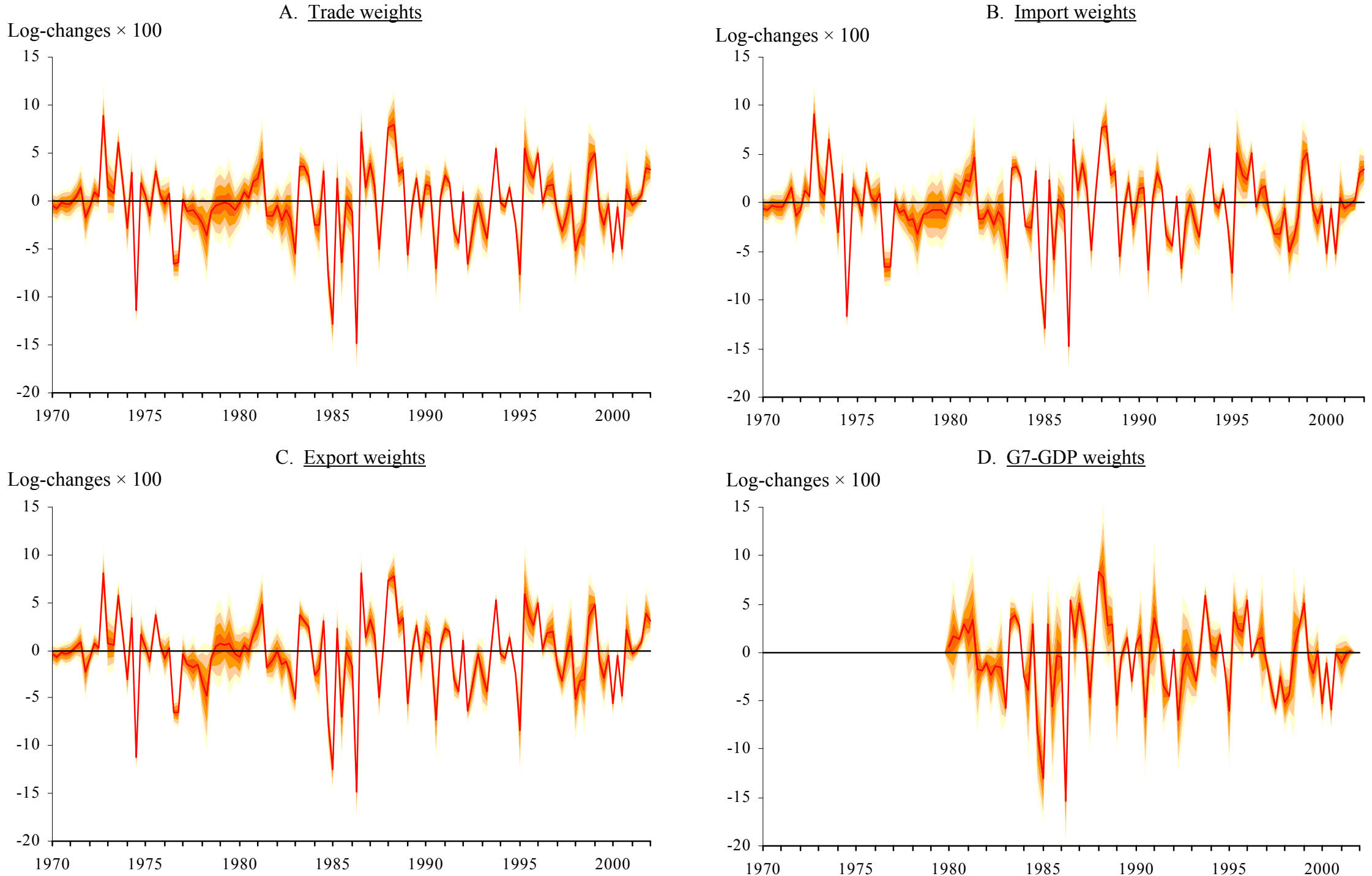

Log-changes $\times 100$

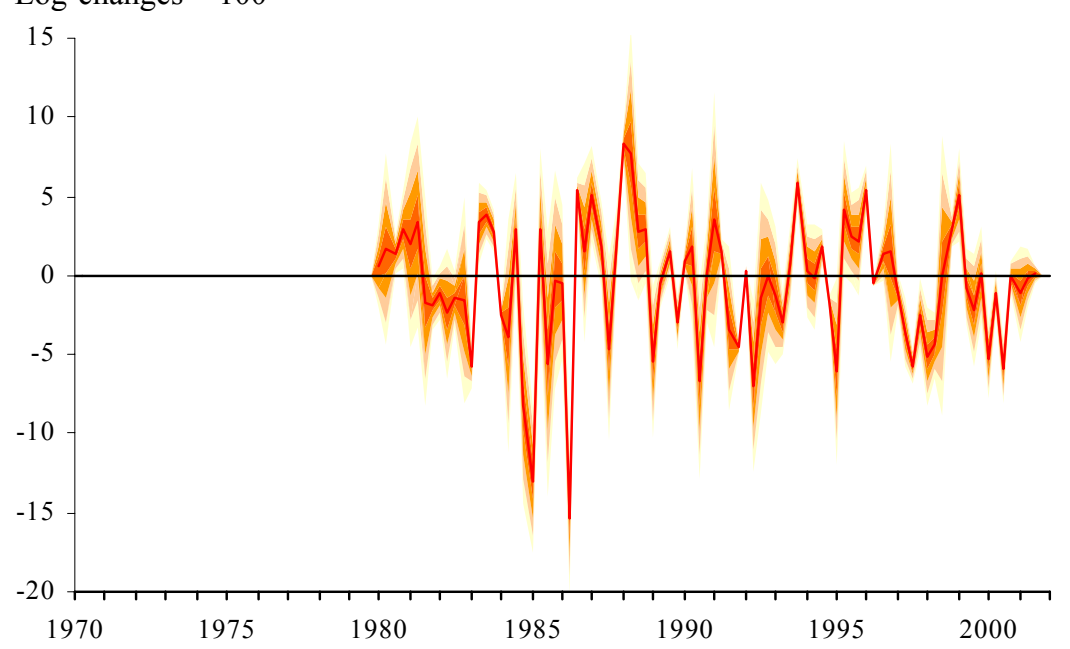

41 
FIGURE A5

PRELIMINARY ESTIMATES OF REER INDEX AND CONFIDENCE BANDS: LEVELS
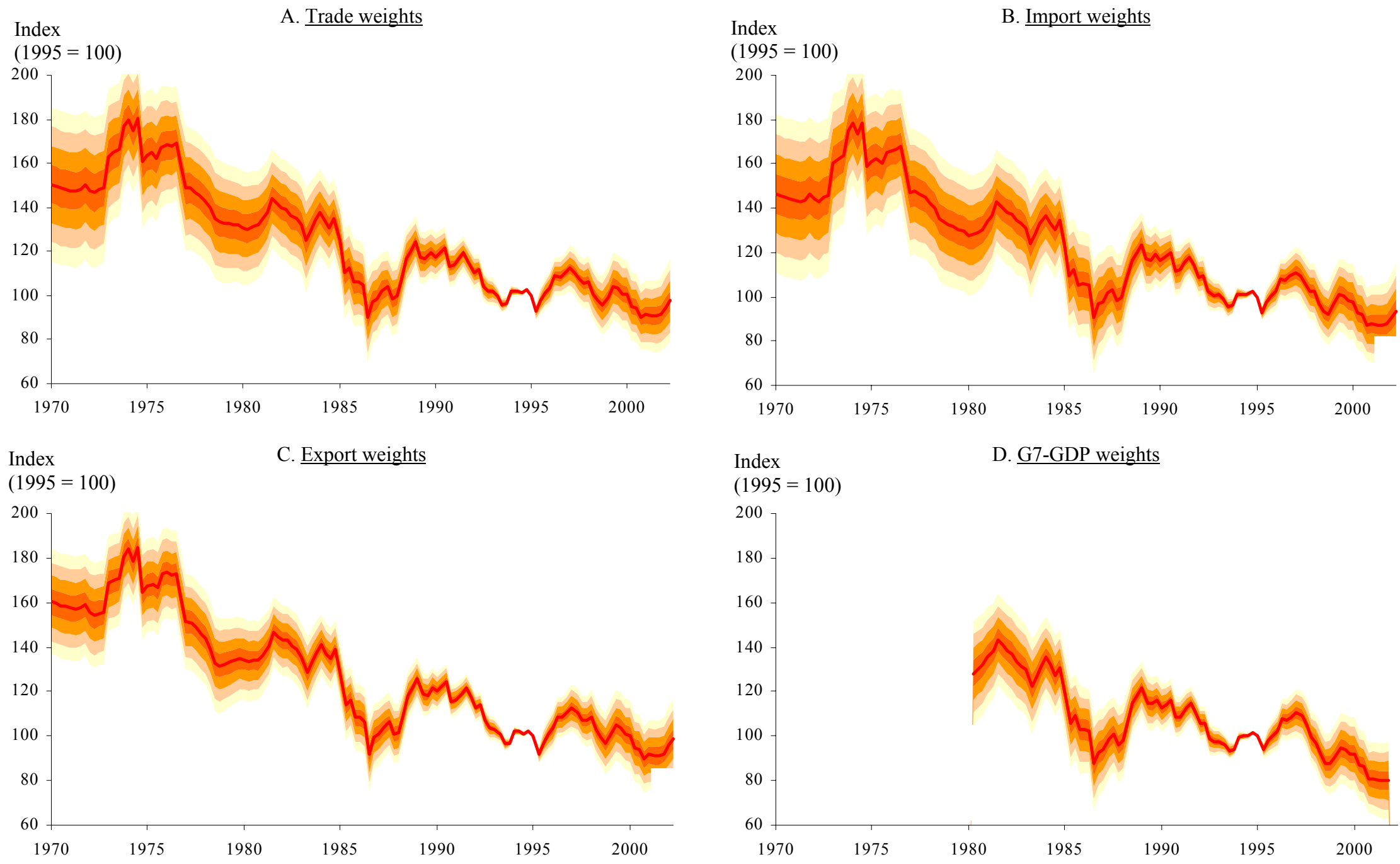

Index

D. G7-GDP weights

$(1995=100)$

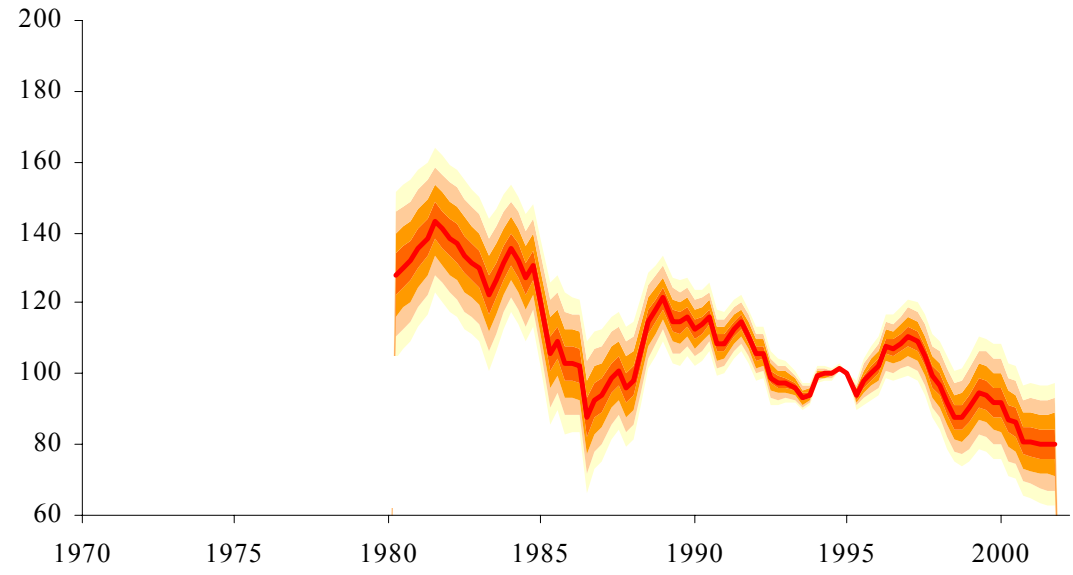


TABLE A3

PRELIMINARY ESTIMATES OF COUNTRY COMPONENTS OF MODEL (3.1) (Standard errors in parentheses)

\begin{tabular}{|c|c|c|c|c|c|c|c|c|}
\hline \multirow{2}{*}{ Country } & \multicolumn{7}{|c|}{ Sub-period } & \multirow[b]{2}{*}{ Mean } \\
\hline & 1 & 2 & 3 & 4 & 5 & & 6 & \\
\hline \multicolumn{9}{|c|}{ A. Trade weights } \\
\hline USA & $1.31(.72)$ & $-.34(.52)$ & $.05(1.54)$ & $.78(.78)$ & -.36 & $(.73)$ & $-.55(1.32)$ & $.18(.33)$ \\
\hline Germany & $-.55(.91)$ & $1.08(.79)$ & $.02(1.97)$ & $-.17(.86)$ & -.46 & $(.56)$ & $.58(.97)$ & $.05(.36)$ \\
\hline Japan & $-.91(.48)$ & $-.20(.46)$ & $-.43(1.32)$ & $-1.76(.54)$ & .01 & $(.39)$ & $.07(.75)$ & $-.54(.23)$ \\
\hline UK & $.33(.57)$ & $-.85(.76)$ & $.53(3.36)$ & $.28(.95)$ & -.59 & $(.63)$ & $.01 \quad(.56)$ & $-.13(.31)$ \\
\hline Switzerland & $-1.26(.75)$ & $-.19(.97)$ & $-.08(2.17)$ & & -.64 & $(.66)$ & $.22(.88)$ & $-.48(.41)$ \\
\hline New Zealand & $-.84(.65)$ & $.72(.73)$ & $.53(2.52)$ & $-1.07(1.34)$ & .74 & $(.47)$ & $-.06(1.04)$ & $.08(.34)$ \\
\hline Hong Kong & $-1.55(.75)$ & $.39(.75)$ & $.62(2.79)$ & $1.06(.90)$ & -2.04 & $(.54)$ & $.17(.68)$ & $-.49(.33)$ \\
\hline Singapore & $-.84(.97)$ & $.76(.70)$ & $-.04(2.00)$ & $1.72(.81)$ & -.69 & $(.38)$ & $.05(.59)$ & $.07(.29)$ \\
\hline Malaysia & $-.40(.80)$ & $.85(.70)$ & $-.10(1.88)$ & $2.48(.89)$ & 1.06 & $(.69)$ & $-.46(.66)$ & $.59(.34)$ \\
\hline France & $-.09(.83)$ & $.68(.80)$ & $.17(2.42)$ & $-.29(.82)$ & -.34 & $(.57)$ & $.53(.93)$ & $.06(.35)$ \\
\hline Canada & $.89(.74)$ & $.87(.79)$ & $-.18(2.26)$ & $.86(.88)$ & 1.08 & $(.53)$ & $-.43(.70)$ & $.62(.33)$ \\
\hline Italy & $.59(.68)$ & $.67(.82)$ & $-.18(2.21)$ & $-.58(.82)$ & -.13 & $(.72)$ & $.38(.90)$ & $.17(.36)$ \\
\hline Netherlands & $-.97(.70)$ & $.46(.86)$ & $.17(2.14)$ & $-.04(.89)$ & -.45 & $(.58)$ & $.26(.97)$ & $-.19(.35)$ \\
\hline Taiwan & $-.72(1.45)$ & $-.03(.75)$ & & $-.03(.97)$ & .24 & $(.49)$ & $-.01(.65)$ & $-.01(.34)$ \\
\hline Sweden & $.07(.65)$ & $.81(.78)$ & $1.04(4.77)$ & $-.60(.69)$ & .91 & $(.76)$ & $.41(.76)$ & $.31(.34)$ \\
\hline South Korea & & & $.24(1.97)$ & $.67(.94)$ & .96 & $(.89)$ & $-.62(.91)$ & $.33(.53)$ \\
\hline Thailand & & & & & .39 & $(.84)$ & $.21(.81)$ & $.30(.58)$ \\
\hline \multicolumn{9}{|l|}{ Indonesia } \\
\hline \multicolumn{9}{|l|}{ Saudi Arabia } \\
\hline Belgium-Lux. & $-.56(.79)$ & $1.35(.85)$ & $.15(2.03)$ & & -.31 & $(.61)$ & $.46(.83)$ & $.17(.39)$ \\
\hline India & $.31(.76)$ & $1.39(.77)$ & & & 1.69 & $(.74)$ & $-.20(.60)$ & $.74(.36)$ \\
\hline \multicolumn{9}{|l|}{ China } \\
\hline PNG & $-.61(.83)$ & $.78(.82)$ & $.10(1.82)$ & $12.24(.59)$ & 4.10( & $(1.54)$ & $4.85(9.47)$ & $4.44(.45)$ \\
\hline Philippines & & & & & .03 & $(.83)$ & $.00(1.07)$ & $.02(.66)$ \\
\hline South Africa & $.34(.49)$ & $.79(.60)$ & & & .30 & $(.69)$ & $1.35(1.65)$ & $.56(.35)$ \\
\hline UAE & & & & & -4.03 & $(.60)$ & $-.94(.69)$ & $-2.59(.45)$ \\
\hline Spain & & & & & -.43 & $(.30)$ & $.31(.96)$ & $-.25(.33)$ \\
\hline Euro-zone & & & & & & & $.54(.77)$ & $.54(.77)$ \\
\hline Vietnam & & & & & & & $-.65(.48)$ & $-.65(.48)$ \\
\hline \multicolumn{9}{|c|}{ B. Import weights } \\
\hline USA & $1.23(.72)$ & $-.32(.54)$ & $.03(1.61)$ & $.23(.42)$ & -.54 & $(.97)$ & & $.15(.31)$ \\
\hline Germany & $-.64(.86)$ & $1.09(.73)$ & $.01(2.08)$ & $-.50(.47)$ & .59 & $(.99)$ & & $.05(.36)$ \\
\hline Japan & $-.99 \quad(.53)$ & $-.19(.53)$ & $-.45(1.51)$ & $-1.09(.35)$ & .08 & $(.85)$ & & $-.66(.26)$ \\
\hline UK & $.24 \quad(.52)$ & $-.84(.67)$ & $.51(3.06)$ & $-.34(.52)$ & .02 & $(.65)$ & & $-.17(.31)$ \\
\hline Switzerland & $-1.34 \quad(.74)$ & $-.18(.94)$ & $-.09(2.34)$ & $-.74(.57)$ & .23 & $(.91)$ & & $-.46(.51)$ \\
\hline New Zealand & $-.92 \quad(.67)$ & $.73(.72)$ & $.51(2.64)$ & $.09(.58)$ & -.05( & (1.09) & & $-.01(.38)$ \\
\hline Hong Kong & $-1.64 \quad(.76)$ & $.40(.71)$ & $.60(2.85)$ & $-1.26(.51)$ & .18 & $(.77)$ & & $-.57(.35)$ \\
\hline Singapore & $-.92(1.00)$ & $.78(.68)$ & $-.06(2.15)$ & $.52(.42)$ & .06 & $(.69)$ & & $.22(.33)$ \\
\hline Malaysia & $-.48 \quad(.82)$ & $.87(.67)$ & $-.12(2.04)$ & $2.78(.62)$ & -.45 & $(.74)$ & & $.73(.36)$ \\
\hline France & $-.17 \quad(.84)$ & $.70(.78)$ & $.15(2.56)$ & $-.46(.48)$ & .54 & $(.96)$ & & $.06(.37)$ \\
\hline Canada & $.81 \quad(.74)$ & $.89(.77)$ & $-.20(2.34)$ & $1.72(.49)$ & -.42 & $(.80)$ & & $.80(.35)$ \\
\hline Italy & $.51 \quad(.67)$ & $.68(.78)$ & $-.20(2.39)$ & $-.45(.55)$ & .39 & $(.93)$ & & $.19(.37)$ \\
\hline Netherlands & $-1.05 \quad(.69)$ & $.47(.82)$ & $.16(2.28)$ & $-.41(.51)$ & .27 & (.99) & & $-.23(.37)$ \\
\hline Taiwan & $-.80(1.46)$ & $-.02(.74)$ & & $.29(.49)$ & .00 & $(.76)$ & & $.00(.37)$ \\
\hline Sweden & $-.01 \quad(.64)$ & $.83(.75)$ & $1.02(4.78)$ & $.58(.57)$ & .42 & $(.82)$ & & $.47(.37)$ \\
\hline South Korea & & & $.22(2.08)$ & $1.47(.73)$ & -.61( & (1.03) & & $.55(.62)$ \\
\hline Thailand & & & & $1.85(.69)$ & .22 & $(.87)$ & & $.22(.87)$ \\
\hline \multicolumn{9}{|l|}{ Indonesia } \\
\hline Saudi Arabia & & & & & & & & \\
\hline Belgium-Lux. & $-.64 \quad(.79)$ & $1.36(.82)$ & $.14(2.18)$ & $-.33(.51)$ & .47 & $(.87)$ & & $.36(.49)$ \\
\hline
\end{tabular}


TABLE A3 (continued)

PRELIMINARY ESTIMATES OF COUNTRY COMPONENTS OF MODEL (3.1)

(Standard errors in parentheses)

\begin{tabular}{|c|c|c|c|c|c|c|c|}
\hline \multirow{3}{*}{$\begin{array}{l}\text { Country } \\
\text { India }\end{array}$} & \multicolumn{6}{|c|}{ Sub-period } & \multirow{2}{*}{ Mean } \\
\hline & \multirow{2}{*}{$\frac{1}{.23(.74)}$} & \multirow{2}{*}{$\begin{array}{c}2 \\
1.41 \quad(.75)\end{array}$} & \multirow[t]{2}{*}{3} & \multirow{2}{*}{$\begin{array}{c}4 \\
2.95(.63)\end{array}$} & 5 & \multirow[t]{2}{*}{6} & \\
\hline & & & & & $-.19 \quad(.70)$ & & $.47 \quad(.42)$ \\
\hline \multicolumn{8}{|l|}{ China } \\
\hline PNG & $-.70(.85)$ & $.79(.81)$ & $.08(1.95)$ & $12.32(2.09)$ & $4.86(9.41)$ & & $1.89 \quad(.64)$ \\
\hline Philippines & & & & $1.32(.81)$ & $.01(1.13)$ & & $.01(1.13)$ \\
\hline South Africa & $.25(.49)$ & $.80(.58)$ & & $2.11(.88)$ & $1.36(1.72)$ & & $.62 \quad(.40)$ \\
\hline UAE & & & & $-6.31(.71)$ & $-.93 \quad(.77)$ & & $-.93 \quad(.77)$ \\
\hline Spain & & & & $-1.18 \quad(.34)$ & $.32 \quad(.98)$ & & $.32 \quad(.98)$ \\
\hline Euro-zone & & & & & $.55 \quad(.73)$ & & $.55 \quad(.73)$ \\
\hline \multirow[t]{2}{*}{ Vietnam } & & & & & $-.64 \quad(.60)$ & & $-.64 \quad(.60)$ \\
\hline & \multicolumn{6}{|c|}{ C. Export weights } & \\
\hline USA & $1.46 \quad(.76)$ & -.35 (.69) & $.52(1.17)$ & $.21(2.28)$ & $-.29(1.22)$ & $-.56(2.23)$ & $.27 \quad(.46)$ \\
\hline Germany & $-.29(.71)$ & $1.02(.86)$ & $-.05 \quad(.84)$ & $-.43(2.04)$ & $-.21 \quad(.56)$ & $.57(1.00)$ & $.10(.35)$ \\
\hline Japan & $-.87 \quad(.26)$ & $-.09(.34)$ & $-1.75 \quad(.45)$ & $.05 \quad(.70)$ & $-.15 \quad(.33)$ & $.06(.67)$ & $-.52(.16)$ \\
\hline UK & $.29(.46)$ & $-.71(.91)$ & $1.27(1.22)$ & $-.31(1.45)$ & $-.75 \quad(.63)$ & $.00(.53)$ & $-.06 \quad(.30)$ \\
\hline Switzerland & $-1.76 \quad(.64)$ & $.49(1.01)$ & & & $-.37 \quad(.65)$ & $.21(.91)$ & $-.50 \quad(.38)$ \\
\hline New Zealand & $.39 \quad(.66)$ & $-.38(.60)$ & $-.35 \quad(.95)$ & $-1.78(2.65)$ & $.49 \quad(.43)$ & $-.07(1.03)$ & $.00 \quad(.31)$ \\
\hline Hong Kong & $-1.23(.58)$ & $.22(.80)$ & $1.41(1.42)$ & $.11(1.41)$ & $-2.12 \quad(.52)$ & $.16(.64)$ & $-.58 \quad(.31)$ \\
\hline Singapore & $-.15 \quad(.74)$ & $.24(.69)$ & $1.59 \quad(.99)$ & $.19(1.39)$ & $-.64 \quad(.34)$ & $.04(.55)$ & $.01 \quad(.26)$ \\
\hline Malaysia & $.40 \quad(.61)$ & $.22(.66)$ & $1.30 \quad(.85)$ & $.17(1.28)$ & $1.39 \quad(.62)$ & $-.47(.64)$ & $.50 \quad(.30)$ \\
\hline France & $-.43 \quad(.66)$ & $1.24(.81)$ & $1.58 \quad(.96)$ & $-.41(1.82)$ & $-.09 \quad(.55)$ & $.52(.96)$ & $.38 \quad(.34)$ \\
\hline Canada & $1.00 \quad(.63)$ & $.97(.85)$ & $-.05 \quad(.85)$ & $-.11(1.46)$ & $.84 \quad(.52)$ & $-.44(.65)$ & $.44 \quad(.30)$ \\
\hline Italy & $1.16(.63)$ & $.26(.83)$ & $1.05 \quad(.93)$ & $-.38(1.99)$ & $.07 \quad(.70)$ & $.37(.92)$ & $.52(.36)$ \\
\hline Netherlands & $-.99(.54)$ & $.67(.90)$ & $-.58 \quad(.74)$ & $-.39(1.94)$ & $-.17 \quad(.57)$ & .25 (.99) & $-.28 \quad(.32)$ \\
\hline Taiwan & $-.28(1.11)$ & $-.34(.77)$ & $.14 \quad(.84)$ & $-.99(2.25)$ & $.21 \quad(.45)$ & $-.02(.58)$ & $-.07 \quad(.32)$ \\
\hline Sweden & $-.09 \quad(.52)$ & $1.19(.83)$ & $1.03 \quad(.94)$ & & $.88 \quad(.73)$ & $.40(.75)$ & $.59 \quad(.32)$ \\
\hline South Korea & & & $.76(1.12)$ & $-.34(1.32)$ & $.46 \quad(.79)$ & $-.63(.82)$ & $.06 \quad(.48)$ \\
\hline Thailand & & & & & $.43 \quad(.75)$ & $.20(.80)$ & $.32(.55)$ \\
\hline \multicolumn{8}{|l|}{ Indonesia } \\
\hline \multicolumn{8}{|l|}{ Saudi Arabia } \\
\hline Belgium-Lux. & $-.35 \quad(.62)$ & $1.37(.89)$ & $1.82 \quad(.73)$ & & $-.01 \quad(.59)$ & $.45(.85)$ & $.57 \quad(.32)$ \\
\hline India & $1.61 \quad(.65)$ & & & & $2.00 \quad(.69)$ & $-.21(.56)$ & $1.05(.36)$ \\
\hline \multicolumn{8}{|l|}{ China } \\
\hline PNG & $-.49 \quad(.64)$ & $.85(.90)$ & $3.85 \quad(.50)$ & $7.60(.77)$ & $4.73(1.44)$ & $4.84(9.52)$ & $3.17(.36)$ \\
\hline Philippines & & & & & $.07 \quad(.75)$ & $-.01(1.04)$ & $.04 \quad(.62)$ \\
\hline South Africa & $1.47 \quad(.28)$ & $-.21 \quad(.53)$ & & & $.75 \quad(.66)$ & $1.34(1.60)$ & $.90(.26)$ \\
\hline UAE & & & & & $-4.52 \quad(.63)$ & $-.95(.67)$ & $-2.79 \quad(.46)$ \\
\hline Spain & & & & & $-.47 \quad(.25)$ & $.30(.98)$ & $-.32(.28)$ \\
\hline Euro-zone & & & & & & $.53(.87)$ & $.53 \quad(.87)$ \\
\hline \multirow[t]{2}{*}{ Vietnam } & & & & & & $-.66(.41)$ & $-.66(.41)$ \\
\hline & \multicolumn{6}{|c|}{ D. G7-GDP weights } & \\
\hline USA & $-1.30(.77)$ & $-1.21 \quad(.53)$ & $1.55(.28)$ & $-1.37(.90)$ & & & $.00(.26)$ \\
\hline Germany & $3.38(1.36)$ & $1.49(.95)$ & $-1.54(.53)$ & $2.48(1.86)$ & & & $.59(.48)$ \\
\hline Japan & $-1.36(1.35)$ & $.11(.88)$ & $-2.74 \quad(.49)$ & $.03(1.76)$ & & & $-1.44(.45)$ \\
\hline UK & $.88(1.40)$ & $2.03(.95)$ & $-1.16(.54)$ & $.74(1.89)$ & & & $.24(.48)$ \\
\hline France & $2.51(1.40)$ & $2.73(.95)$ & $-1.37(.54)$ & $2.48(1.88)$ & & & $.84(.48)$ \\
\hline Canada & $-1.02(1.41)$ & $-1.31 \quad(.96)$ & $5.11(.55)$ & $.77(1.89)$ & & & $1.86(.49)$ \\
\hline Italy & $2.31(1.41)$ & $.30(.96)$ & $-1.06(.55)$ & $1.92(1.90)$ & & & $.25(.49)$ \\
\hline
\end{tabular}

Notes: 1. See Table A1 for the sub-periods.

2. The standard error of the mean, given in the last column, is calculated in the same way as in Table 9. 
FIGURE A6

PRELIMINARY ESTIMATES IN SUB-PEIORDS OF COUNTRY COMPONENTS

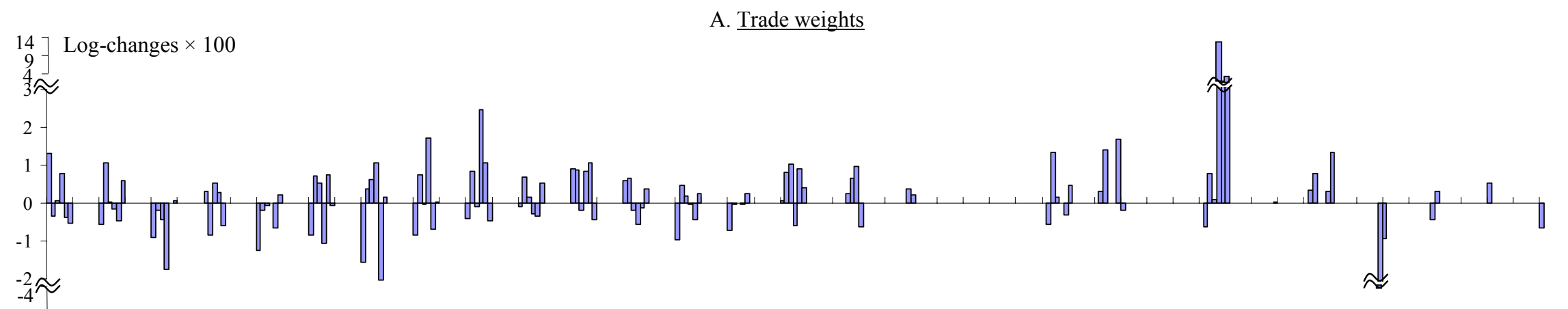

$$
\text { B. Import weights }
$$

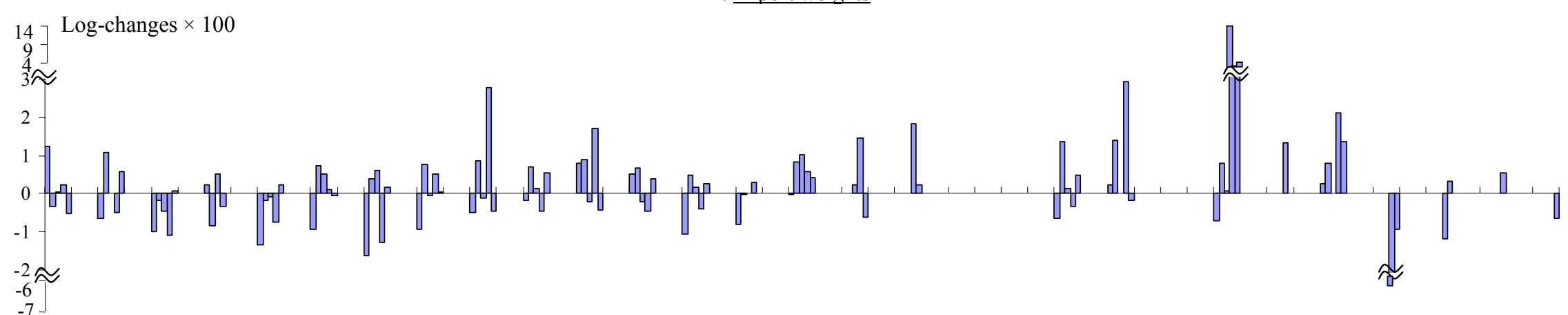

\section{Export weights}

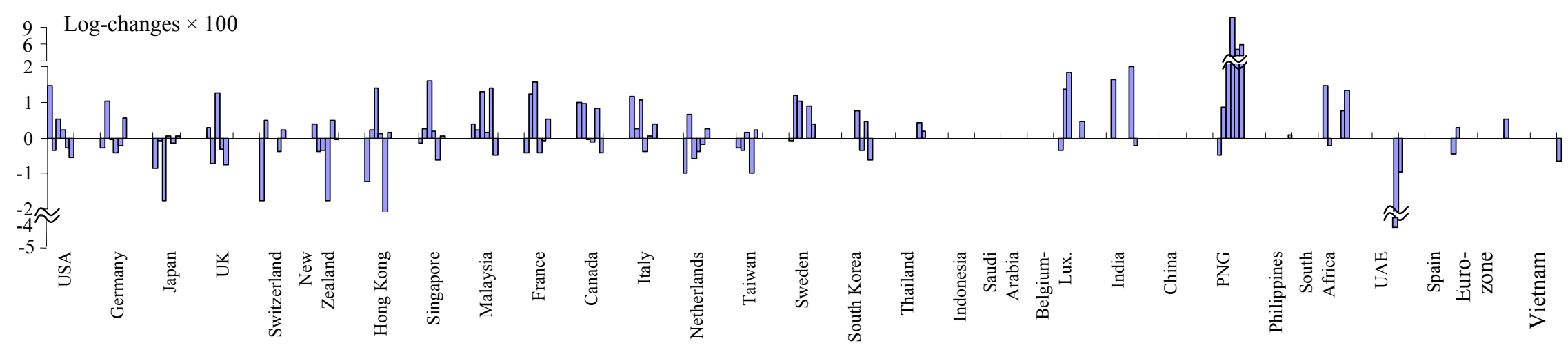


FIGURE A6 (continued)

PRELIMINARY ESTIMATES IN SUB-PEIORDS OF COUNTRY COMPONENTS

D. G7-GDP weights

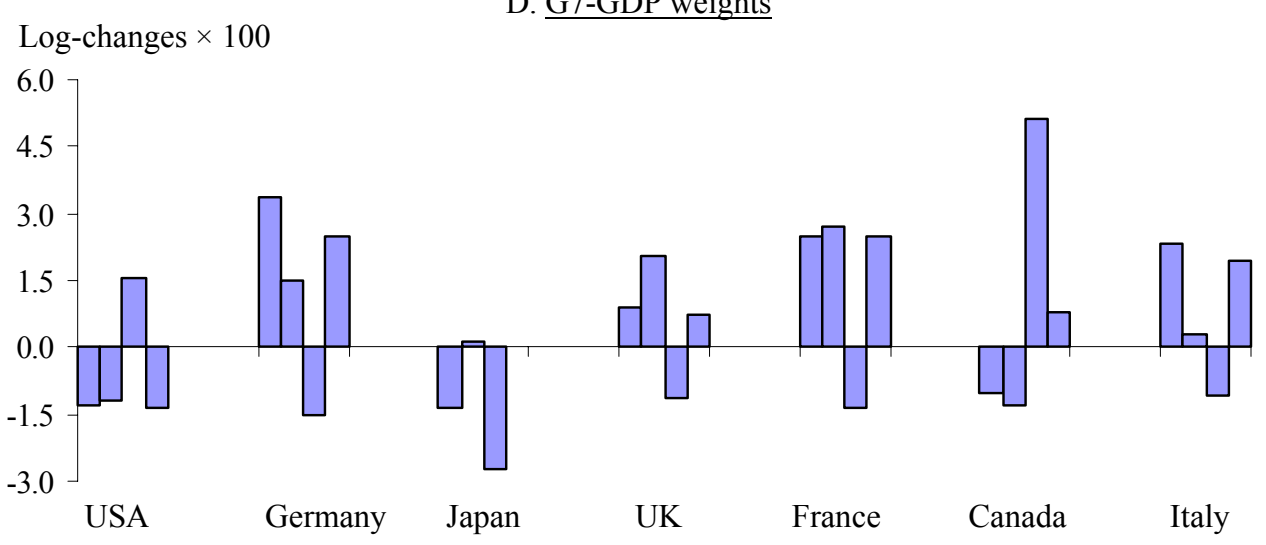

Note: The four, five or six columns for a given country in a given panel refer to the estimated values of $\beta_{c}$ for that country in the four, five or six sub-periods. 
FIGURE A7

AVERAGES OF PRELIMINARY ESTIMATES OF COUNTRY COMPONENTS

A. Trade weights

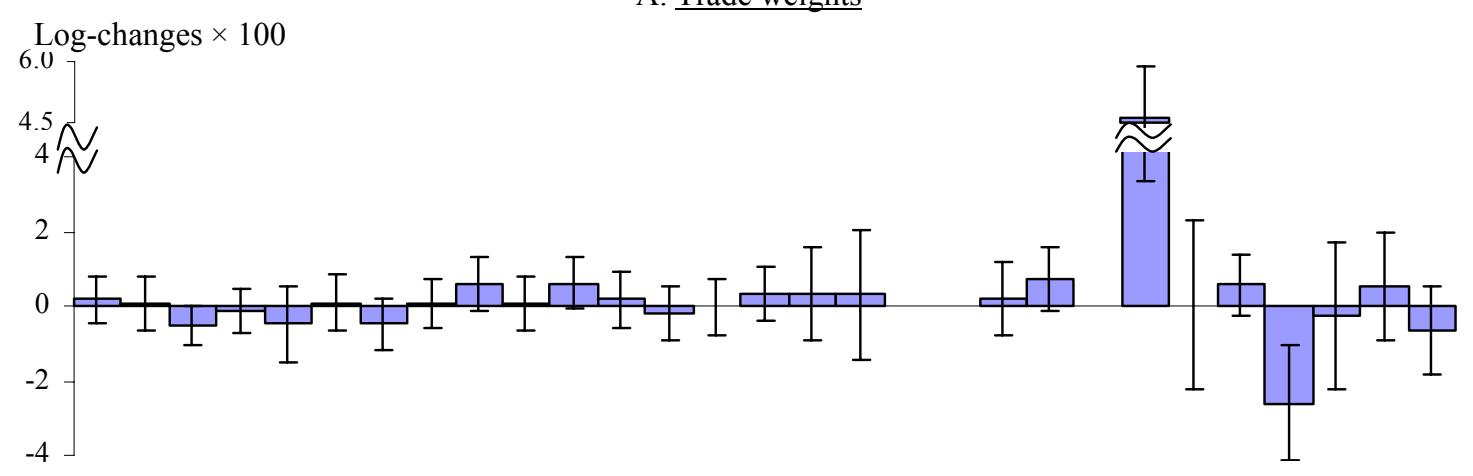

B. Import weights

Log-changes $\times 100$

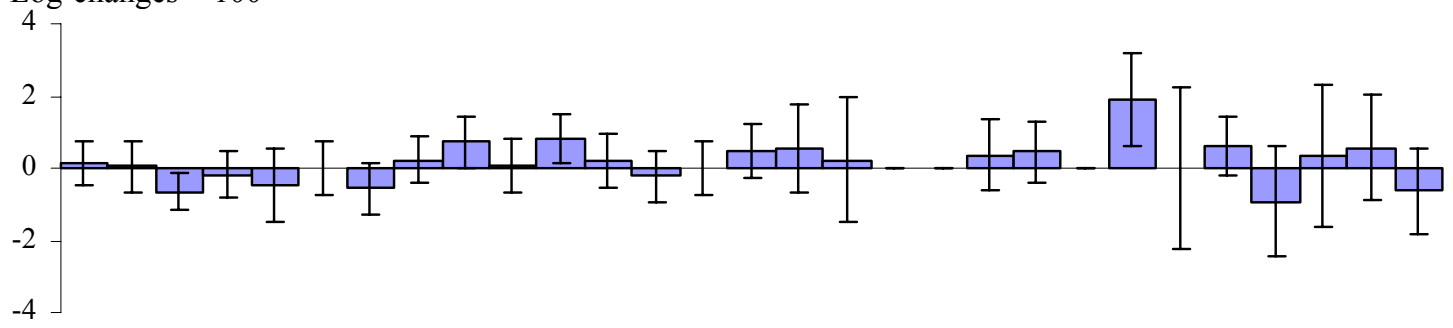

Log-changes $\times 100$

C. Export weights

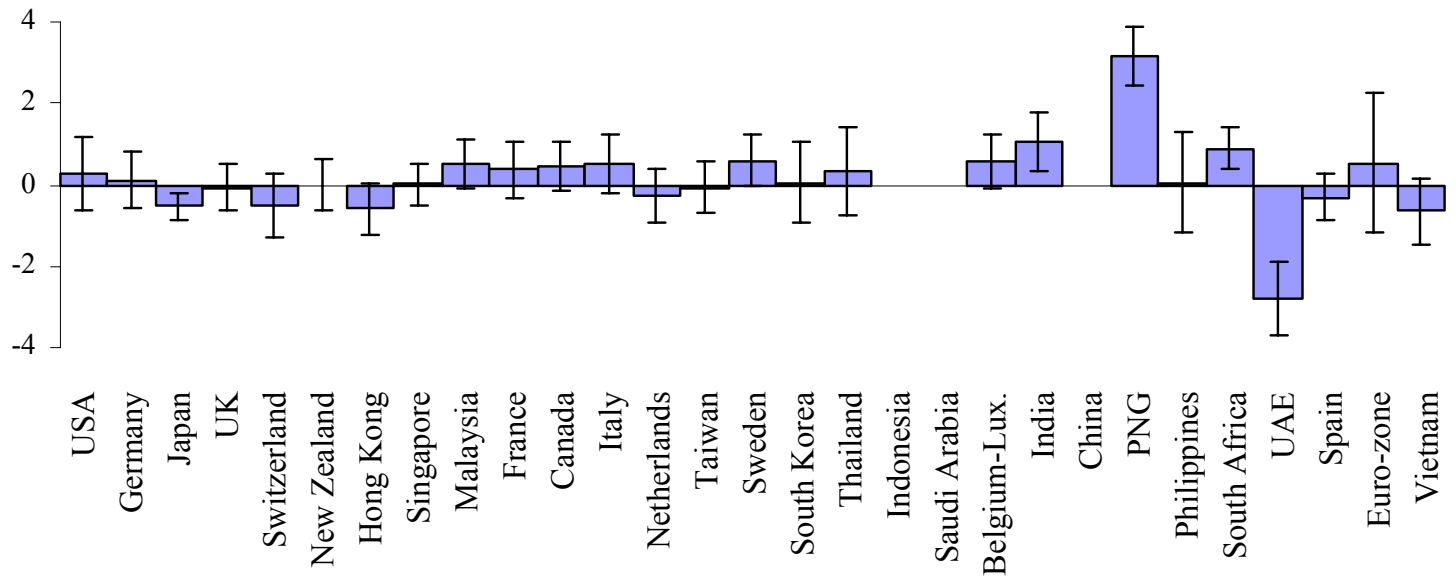

Log-changes $\times 100$

D. G7-GDP weights

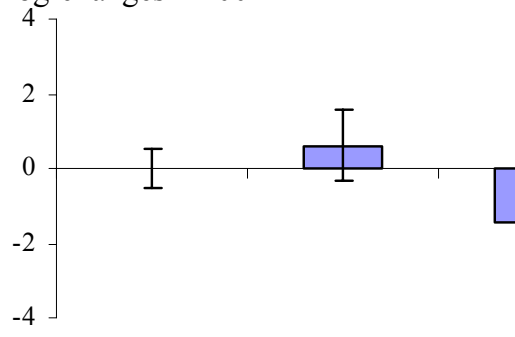

USA Germany Japan UK France Canada Italy

Note: This figure presents for each country (i) the mean (over the sub-periods) of the preliminary estimates of $\beta_{\mathrm{c}}$, which is represented by height of the relevant column; and (ii) the associated two-standard-error band, which is represented by the length of the corresponding vertical line. 


\section{APPENDIX 4 \\ DIVISIA MOMEMTS OF EXCHANGE RATES AND INCOMES}

This appendix analyses the interrelationships between real exchange rates and real incomes across countries by applying the methodology of Divisia moments. This approach was introduced in the context of consumption economics by Theil (1967, Chap. 5).

Consider the $n$ real exchange rate log-changes from quarter $t-1$ to $t, \operatorname{Dr}_{1 t}, \ldots, \mathrm{Dr}_{\mathrm{nt}}$. If $\mathrm{w}_{\mathrm{c}}$ is the weight applicable to country $\mathrm{c}$, the weighted (or Divisia) mean of these exchange rate changes is $\mathrm{DR}_{\mathrm{t}}=\sum_{\mathrm{c}=1}^{\mathrm{n}} \mathrm{w}_{\mathrm{c}} \mathrm{Dr}_{\mathrm{ct}}$, while the corresponding second-order moment is the Divisia variance $\mathrm{V}_{\mathrm{rt}}=\sum_{\mathrm{c}=1}^{\mathrm{n}} \mathrm{w}_{\mathrm{c}}\left(\mathrm{Dr}_{\mathrm{ct}}-\mathrm{DR}_{\mathrm{t}}\right)^{2}$, which measures the extend to which exchange rates change disproportionately. Next, let $\mathrm{Dy}_{1 \mathrm{t}}, \ldots, \mathrm{Dy}_{\mathrm{nt}}$ be the log-changes in real GDP per capita in the $\mathrm{n}$ countries, with Divisia moments $\quad \mathrm{DY}_{\mathrm{t}}=\sum_{\mathrm{c}=1}^{\mathrm{n}} \mathrm{w}_{\mathrm{c}} \mathrm{Dy}_{\mathrm{ct}}, \mathrm{V}_{\mathrm{yt}}=\sum_{\mathrm{c}=1}^{\mathrm{n}} \mathrm{w}_{\mathrm{c}}\left(\mathrm{Dy}_{\mathrm{ct}}-\mathrm{DY} \mathrm{Y}_{\mathrm{t}}\right)^{2}$. This $\mathrm{DY} \mathrm{Y}_{\mathrm{t}}$ is the average growth in per capita GDP for the $\mathrm{n}$ countries, while $\mathrm{V}_{\mathrm{yt}}$ measures the dispersion of growth.

The productivity-bias hypothesis associated with Balassa (1964) and Samuelson (1964) states that because of faster productivity growth in the production of traded goods in comparison to that in nontraded goods, the currencies of rich countries tend to be overvalued, while those for poor countries are undervalued. In terms of our framework which is formulated in terms of changes over time, this means that if country $\mathrm{c}$ is growing rapidly, then the real value of its currency appreciates relative to the average of all rates, so that $\mathrm{Dr}_{\mathrm{ct}}-\mathrm{DR}_{\mathrm{t}}<0$. Conversely, if $\mathrm{c}$ is not growing rapidly, $\mathrm{Dr}_{\mathrm{ct}}-\mathrm{DR}_{\mathrm{t}}>0$. We interpret the term "growing rapidly" as meaning that country $\mathrm{c}$ grows faster than average, $D y_{c t}-D Y_{t}>0$, so that "not growing rapidly" means $D y_{c t}-D Y_{t}<0$. It is then possible to summarise the average interaction between exchange rates and incomes over the $n$ countries by a weighted covariance with weights reflecting the relative importance of countries. We do this with the Divisia exchange-rate-income covariance

$$
\mathrm{V}_{\mathrm{ryt}}=\sum_{\mathrm{c}=1}^{\mathrm{n}} \mathrm{w}_{\mathrm{c}}\left(\mathrm{Dr}_{\mathrm{ct}}-\mathrm{DR}_{\mathrm{t}}\right)\left(\mathrm{Dy}_{\mathrm{ct}}-\mathrm{DY}_{\mathrm{t}}\right)
$$

The productivity-bias hypothesis implies that $\mathrm{V}_{\text {ryt }}$ is negative.

Next, to present an uncluttered, clear picture, we eliminate the time dimension by averaging and define for any variable $\mathrm{x}_{\mathrm{ct}}$ its average over time $\mathrm{x}_{\mathrm{c} \bullet}=(1 / \mathrm{T}) \sum_{\mathrm{t}=1}^{\mathrm{T}} \mathrm{x}_{\mathrm{ct}}$. If the weighted 
covariance of equation (A4.1) is negative, then when we plot $\sqrt{\mathrm{w}_{\mathrm{c}}}\left(\mathrm{Dr}_{\mathrm{c} \bullet}-\mathrm{DR}\right.$.) against $\sqrt{\mathrm{w}_{\mathrm{c}}}\left(\mathrm{Dy}_{\mathrm{c} \bullet}-\mathrm{DY}.\right)$ for $\mathrm{c}=1, \ldots, \mathrm{n}$ countries, the points should be scattered around a downwardsloping line. Figure A8 gives the results using the data described in Appendix 1 pertaining to $\mathrm{n}=26$ countries, and GDP from the Penn World Table (Summers and Heston, 1991) for the various weights and sub-periods described in the text. As can be seen, most of the regression lines are downward sloping, as expected. This is especially the case for the first (1970-1974) and last (19992002) sub-periods. Positive correlations are found for sub-period 3 when trade, import and export weighting schemes are used, and for sub-period 2 with G7-GDP weights. Referring back to Table A1, we find that these positive correlations refer to the mid-1980s when the US dollar was rapidly appreciating against most currencies. During this time even the currencies of fast-growing countries depreciated, so that many countries are located in the first quadrant in the relevant graphs in Figure A8.

The last column of Figure A8 presents the same graphs when the observations are pooled over all sub-periods. It can be seen that the correlations for the trade, import and export weights are in the range of -0.07 to -0.13 . For the G7-GDP weights, as the correlation in sub-period 2 is a large positive value, we consider the seven observations of this sub-period to be outliers. Pooling the remaining 21 observations yields a correlation of -0.14 (see the last graph in the last column of Figure A8).

To summarise, the evidence from the covariation of exchange rates and incomes is generally supportive of the productivity-bias hypothesis. 
FIGURE A8

RELATIVE CHANGES IN EXCHANGE RATES AND INCOMES

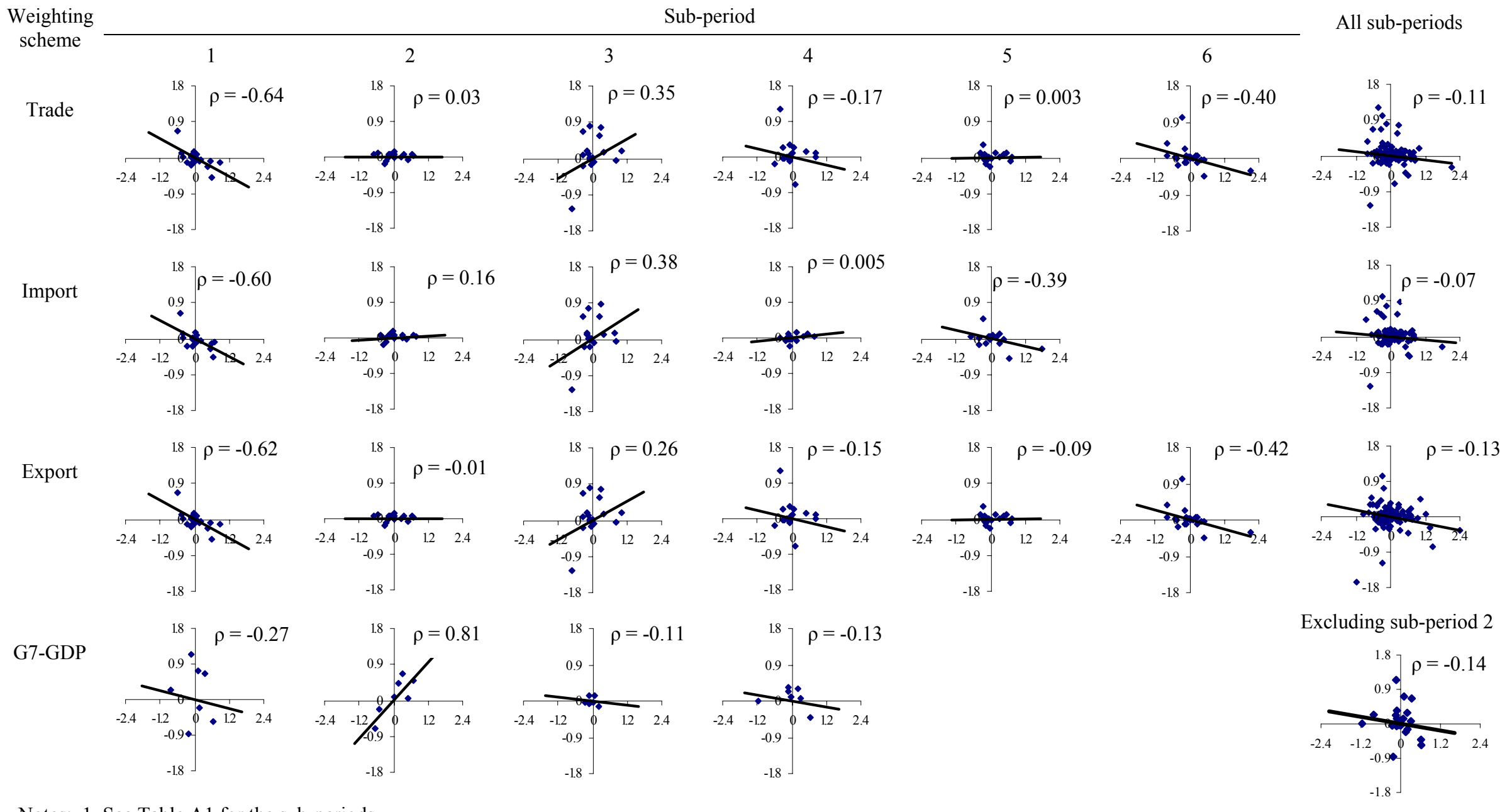

Notes: 1 . See Table A1 for the sub-periods.

2. The variable on each vertical axis is $\sqrt{\mathrm{w}_{\mathrm{c}}}\left(\mathrm{Dr}_{\mathrm{c} \bullet}-\mathrm{DR}_{\bullet}\right) \times 100$, while that on the horizontal axis is $\sqrt{\mathrm{w}_{\mathrm{c}}}\left(\mathrm{Dy}_{\mathrm{c} \bullet}-\mathrm{DY}_{\bullet}\right) \times 100$.

3. The correlation $\rho$ is computed as $\rho=V_{r y} / \sqrt{V_{r} V_{y}}$, where $V_{r y}=\sum_{c} w_{c}\left(D_{c} \bullet-D R \bullet\right)\left(D_{c} \bullet-D Y_{\bullet}\right), V_{r}=\sum_{c} w_{c}\left(D r_{c} \bullet-D R \bullet\right)^{2}$, and $V_{y}=\sum_{c} w_{c}\left(D y_{c} \bullet-D D_{\bullet}\right)^{2}$. 


\section{APPENDIX 5}

FINAL ESTIMATES OF MODEL (6.2)

FOR FOUR SETS OF WEIGHTS

This section provides the final estimation results for model (6.2) with the four sets of weights. These results correspond to those of Section 6 .

Table A4, which corresponds to Table 8, gives four the estimated REER indexes in levels and changes. It can be seen again that the four sets of results are fairly similar. In addition, the point estimates are the same as their preliminary counterparts displayed in Table A2. But as the standard errors of the estimated changes are smaller, there is an improvement in precision.

The counterparts of panels $\mathrm{A}$ and $\mathrm{B}$ of Figure 4 are split into two figures -- Figure A9 presents the histograms of the $\alpha_{t}$-estimates and Figure A10 their t-ratios. Figure A11, corresponding to Figure 5, shows the four versions of the fan chart of the changes in the index. Figure A12 contains the fan charts of the indexes in levels, which correspond to Figure 6.

Table A5 presents the estimates of country-specific parameters $\beta_{c}$ for the three groups of countries. For the four sets of weights, the $\beta_{\mathrm{c}}$-estimates for fast-growing countries are all negative, those for slow-growing countries are all positive and those for the other countries are mostly insignificant. 
TABLE A4

FINAL ESTIMATES OF MODEL (6.2)

(Standard errors in parentheses)

\begin{tabular}{|c|c|c|c|c|c|c|c|c|c|c|}
\hline \multirow{2}{*}{\multicolumn{3}{|c|}{$\begin{array}{l}\text { Observation Year Quarter } \\
\text { number }\end{array}$}} & \multicolumn{8}{|c|}{ Weights } \\
\hline & & & \multicolumn{2}{|c|}{ Trade } & \multicolumn{2}{|c|}{ Import } & \multicolumn{2}{|c|}{ Export } & \multicolumn{2}{|c|}{ G7-GDP } \\
\hline (1) & (2) & (3) & $\begin{array}{l}\text { Level } \\
\text { (4) }\end{array}$ & $\underset{\text { (5) }}{\text { Change }} \alpha_{t}$ & $\begin{array}{l}\text { Level } \\
(6)\end{array}$ & $\underset{\text { (7) }}{\text { Change }} \alpha_{t}$ & $\begin{array}{l}\text { Level } \\
\text { (8) }\end{array}$ & 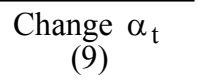 & $\begin{array}{l}\text { Level } \\
(10)\end{array}$ & Change $\alpha_{t}$ \\
\hline 1 & 1970 & (1) & $150.46(7.58)$ & & $146.63(7.67)$ & & $162.08(7.32)$ & & & \\
\hline 2 & & (2) & $149.72(7.61)$ & $-0.50(0.45)$ & $145.83(7.70)$ & $-0.54(0.45)$ & $161.40(7.35)$ & $-0.42(0.38)$ & & \\
\hline 3 & & (3) & $148.66(7.66)$ & $-0.71(0.37)$ & $144.78(7.76)$ & $-0.72(0.32)$ & $160.27(7.40)$ & $-0.70(0.39)$ & & \\
\hline 4 & & (4) & $148.32(7.67)$ & $-0.23(0.34)$ & $144.51(7.77)$ & $-0.19(0.37)$ & $159.81(7.42)$ & $-0.29(0.29)$ & & \\
\hline 5 & 1971 & (1) & $147.80(7.69)$ & $-0.35(0.40)$ & $143.87(7.79)$ & $-0.44(0.43)$ & $159.28(7.44)$ & $-0.33(0.38)$ & & \\
\hline 6 & & (2) & $147.41(7.71)$ & $-0.27(0.44)$ & $143.21(7.82)$ & $-0.46(0.54)$ & $158.92(7.45)$ & $-0.22(0.34)$ & & \\
\hline 7 & & (3) & $148.17(7.66)$ & $0.51 \quad(0.33)$ & $143.84(7.78)$ & $0.44(0.40)$ & $159.54(7.42)$ & $0.39(0.29)$ & & \\
\hline 8 & & (4) & $150.16(7.54)$ & $1.34(0.83)$ & $146.09(7.64)$ & $1.56(0.76)$ & $160.88(7.34)$ & $0.83(0.86)$ & & \\
\hline 9 & 1972 & (1) & $147.68(7.62)$ & $-1.67(1.27)$ & $144.13(7.71)$ & $-1.35(1.17)$ & $157.22(7.47)$ & $-2.30(1.25)$ & & \\
\hline 10 & & (2) & $146.64(7.68)$ & $-0.70(0.20)$ & $143.17(7.76)$ & $-0.67(0.24)$ & $155.94(7.53)$ & $-0.82(0.16)$ & & \\
\hline 11 & & (3) & $148.12(7.58)$ & $1.00(0.73)$ & $145.07(7.63)$ & $1.32(0.93)$ & $156.99(7.47)$ & $0.67 \quad(0.57)$ & & \\
\hline 12 & & (4) & $148.77(7.55)$ & $0.44(0.27)$ & $146.01(7.58)$ & $0.65(0.31)$ & $157.34(7.45)$ & $0.22(0.22)$ & & \\
\hline 13 & 1973 & (1) & $162.61(6.86)$ & $8.89(1.30)$ & $160.02(6.88)$ & $9.16(1.20)$ & $170.58(6.83)$ & $8.08(1.25)$ & & \\
\hline 14 & & (2) & $164.94(6.71)$ & $1.42(1.51)$ & $162.48(6.72)$ & $1.53(1.46)$ & $171.75(6.74)$ & $0.68(1.39)$ & & \\
\hline 15 & & (3) & $166.35(6.62)$ & $0.85(0.95)$ & $163.85(6.62)$ & $0.84(1.20)$ & $172.67(6.68)$ & $0.53(1.01)$ & & \\
\hline 16 & & (4) & $176.77(6.22)$ & $6.08(0.68)$ & $174.82(6.19)$ & $6.48(0.76)$ & $182.93(6.29)$ & $5.77(0.74)$ & & \\
\hline 17 & 1974 & (1) & $179.99(6.10)$ & $1.81(0.65)$ & $178.55(6.04)$ & $2.11(0.76)$ & $185.81(6.19)$ & $1.56(0.58)$ & & \\
\hline 18 & & (2) & $174.87(6.24)$ & $-2.89(1.15)$ & $173.22(6.18)$ & $-3.03(1.34)$ & $180.29(6.36)$ & $-3.02(0.88)$ & & \\
\hline 19 & & (3) & $180.15(6.00)$ & $2.98(1.48)$ & $178.32(5.96)$ & $2.90(1.27)$ & $186.54(6.09)$ & $3.41(1.56)$ & & \\
\hline 20 & & (4) & $160.70(6.72)$ & $-11.43(0.53)$ & $158.74(6.69)$ & $-11.63(0.49)$ & $166.66(6.80)$ & $-11.27(0.59)$ & & \\
\hline 21 & 1975 & (1) & $163.74(6.56)$ & $1.87(1.07)$ & $161.22(6.54)$ & $1.55(1.25)$ & $169.45(6.67)$ & $1.66(0.90)$ & & \\
\hline 22 & & (2) & $164.73(6.52)$ & $0.60(0.52)$ & $162.15(6.49)$ & $0.57(0.64)$ & $170.15(6.63)$ & $0.41 \quad(0.59)$ & & \\
\hline 23 & & (3) & $162.28(6.57)$ & $-1.50(1.21)$ & $160.11(6.53)$ & $-1.27(1.24)$ & $168.25(6.68)$ & $-1.12(1.05)$ & & \\
\hline 24 & & (4) & $167.44(6.36)$ & $3.13(0.54)$ & $165.11(6.32)$ & $3.08(0.49)$ & $174.56(6.43)$ & $3.68(0.63)$ & & \\
\hline 25 & 1976 & (1) & $168.42(6.32)$ & $0.58 \quad(0.38)$ & $166.21(6.28)$ & $0.66(0.39)$ & $175.46(6.39)$ & $0.51 \quad(0.35)$ & & \\
\hline 26 & & (2) & $167.96(6.30)$ & $-0.27(1.12)$ & $166.40(6.22)$ & 0.12 (1.29) & $174.07(6.41)$ & $-0.80(1.09)$ & & \\
\hline 27 & & (3) & $169.16(6.25)$ & $0.71 \quad(0.64)$ & $167.93(6.15)$ & $0.91 \quad(0.61)$ & $174.58(6.38)$ & $0.29(0.72)$ & & \\
\hline 28 & & (4) & $158.50(6.66)$ & $-6.51(0.51)$ & $157.27(6.55)$ & $-6.56(0.73)$ & $163.57(6.80)$ & $-6.51(0.43)$ & & \\
\hline 29 & 1977 & (1) & $148.60(7.08)$ & $-6.45(0.86)$ & $147.30(6.96)$ & $-6.55(1.00)$ & $153.23(7.25)$ & $-6.53(0.73)$ & & \\
\hline 30 & & (2) & $148.71(7.04)$ & $0.08(0.96)$ & $147.63(6.92)$ & $0.23(0.87)$ & $152.65(7.24)$ & $-0.38(1.09)$ & & \\
\hline 31 & & (3) & $147.11(7.11)$ & $-1.08(0.60)$ & $146.17(6.98)$ & $-0.99(0.56)$ & $150.52(7.33)$ & $-1.41(0.65)$ & & \\
\hline 32 & & (4) & $145.67(7.10)$ & $-0.99(1.53)$ & $145.00(6.97)$ & $-0.80(1.39)$ & $147.90(7.37)$ & $-1.76(1.69)$ & & \\
\hline 33 & 1978 & (1) & 143.37 (7.19) & $-1.59(0.95)$ & $142.32(7.06)$ & $-1.87(1.12)$ & $145.61(7.47)$ & $-1.55(0.72)$ & & \\
\hline 34 & & (2) & $140.08(7.26)$ & $-2.32(1.68)$ & $139.89(7.10)$ & $-1.72(1.56)$ & $140.89(7.59)$ & $-3.30(1.97)$ & & \\
\hline 35 & & (3) & $135.07(7.31)$ & $-3.64(2.43)$ & $135.41(7.16)$ & $-3.25(2.12)$ & $134.30(7.69)$ & $-4.79(2.80)$ & & \\
\hline
\end{tabular}


TABLE A4 (continued)

FINAL ESTIMATES OF MODEL (6.2)

(Standard errors in parentheses)

\begin{tabular}{|c|c|c|c|c|c|c|c|c|c|c|c|c|c|}
\hline \multirow{2}{*}{\multicolumn{3}{|c|}{$\begin{array}{l}\text { Observation Year Quarter } \\
\text { number }\end{array}$}} & \multicolumn{11}{|c|}{ Weights } \\
\hline & & & \multicolumn{4}{|c|}{ Trade } & \multicolumn{3}{|c|}{ Import } & \multicolumn{2}{|c|}{ Export } & \multicolumn{2}{|c|}{ G7-GDP } \\
\hline (1) & (2) & (3) & $\begin{array}{l}\text { Leve } \\
\text { (4) }\end{array}$ & & \multicolumn{2}{|c|}{$\underset{(5)}{\text { Change }} \alpha_{t}$} & \multicolumn{2}{|c|}{$\begin{array}{l}\text { Level } \\
(6)\end{array}$} & \multirow{2}{*}{$\begin{array}{c}\text { Change } \alpha_{t} \\
(7) \\
-1.24(0.62)\end{array}$} & \multirow{2}{*}{$\begin{array}{c}\begin{array}{c}\text { Level } \\
(8)\end{array} \\
133.07(7.75)\end{array}$} & \multirow{2}{*}{$\begin{array}{c}\begin{array}{c}\text { Change } \alpha_{t} \\
(9)\end{array} \\
-0.92(0.51)\end{array}$} & \multirow[t]{2}{*}{$\begin{array}{l}\text { Level } \\
(10)\end{array}$} & $\underset{(11)}{\text { Change }} \alpha_{t}$ \\
\hline 36 & & (4) & 133.65 & $(7.38)$ & -1.06 & $(0.51)$ & 133.75 & $(7.24)$ & & & & & \\
\hline 37 & 1979 & (1) & 133.01 & $(7.30)$ & -0.48 & (1.68) & 132.46 & $(7.22)$ & $-0.97(1.47)$ & $133.70(7.58)$ & $0.47(1.94)$ & & \\
\hline 38 & & (2) & 132.53 & (7.19) & -0.36 & (1.91) & 131.44 & $(7.16)$ & $-0.77(1.72)$ & $134.66(7.36)$ & $0.71(2.13)$ & & \\
\hline 39 & & (3) & 132.30 & (7.12) & -0.18 & (1.43) & 130.44 & $(7.10)$ & $-0.76(1.66)$ & $135.41(7.25)$ & $0.56(1.26)$ & & \\
\hline 40 & & (4) & 131.87 & $(6.95)$ & -0.32 & (2.19) & 129.46 & $(7.01)$ & $-0.75(1.88)$ & $136.45(6.95)$ & $0.76(2.57)$ & & \\
\hline 41 & 1980 & (1) & 130.60 & $(6.96)$ & -0.97 & (1.11) & 127.84 & $(7.04)$ & $-1.26(1.10)$ & $135.95(6.92)$ & $-0.37(1.20)$ & $127.38(8.33)$ & \\
\hline 42 & & (2) & 130.35 & $(6.91)$ & -0.19 & (1.19) & 127.93 & $(6.98)$ & 0.07 (1.09) & $135.03(6.88)$ & $-0.68(1.45)$ & $128.13(8.26)$ & $0.59(0.86)$ \\
\hline 43 & & (3) & 131.58 & $(6.80)$ & 0.94 & $(1.07)$ & 129.29 & $(6.87)$ & $1.06(1.03)$ & $135.71(6.80)$ & $0.50(1.05)$ & $130.22(8.08)$ & $1.62(1.15)$ \\
\hline 44 & & (4) & 132.03 & $(6.73)$ & 0.34 & $(1.06)$ & 130.39 & $(6.75)$ & $0.85(1.10)$ & $135.53(6.76)$ & $-0.14(1.19)$ & $131.97(7.92)$ & $1.34(1.19)$ \\
\hline 45 & 1981 & (1) & 134.68 & $(6.56)$ & 1.99 & $(0.91)$ & 133.52 & $(6.55)$ & $2.37(1.00)$ & $137.89(6.61)$ & $1.73(0.91)$ & $135.89(7.63)$ & $2.93(1.35)$ \\
\hline 46 & & (2) & 137.77 & $(6.29)$ & 2.27 & $(1.72)$ & 136.58 & (6.29) & $2.26(1.68)$ & $141.79(6.34)$ & $2.79(1.49)$ & $138.62(7.32)$ & $1.98(2.14)$ \\
\hline 47 & & (3) & 144.03 & $(5.84)$ & 4.44 & $(2.09)$ & 143.07 & $(5.80)$ & $4.64(2.21)$ & $148.66(5.94)$ & $4.73(1.69)$ & $143.39(6.91)$ & $3.39(2.17)$ \\
\hline 48 & & (4) & 141.87 & $(5.91)$ & -1.51 & $(0.79)$ & 140.65 & $(5.86)$ & $-1.70(0.94)$ & $146.09(6.02)$ & $-1.75(0.67)$ & $141.04(6.94)$ & $-1.65(1.49)$ \\
\hline 49 & 1982 & (1) & 139.63 & $(5.95)$ & -1.59 & (1.04) & 138.25 & (5.93) & $-1.72(0.90)$ & $144.55(6.04)$ & $-1.06(1.10)$ & $138.45(7.03)$ & $-1.85(1.03)$ \\
\hline 50 & & (2) & 138.90 & $(5.94)$ & -0.53 & $(1.06)$ & 137.29 & $(5.93)$ & $-0.69(0.93)$ & $144.52(6.00)$ & $-0.02(1.08)$ & $136.96(7.07)$ & $-1.08(1.02)$ \\
\hline 51 & & (3) & 136.01 & $(5.96)$ & -2.10 & (1.48) & 134.30 & $(5.98)$ & $-2.21(1.32)$ & $142.34(5.99)$ & $-1.52(1.52)$ & $133.73(7.13)$ & $-2.39(1.67)$ \\
\hline 52 & & (4) & 134.67 & $(6.01)$ & -1.00 & $(0.46)$ & 133.13 & $(6.02)$ & $-0.87(0.52)$ & $140.54(6.06)$ & $-1.28(0.40)$ & $131.75(7.24)$ & $-1.49(0.34)$ \\
\hline 53 & 1983 & (1) & 132.06 & $(5.96)$ & -1.95 & (1.93) & 130.97 & $(5.94)$ & $-1.64(1.93)$ & $136.58(6.06)$ & $-2.86(1.95)$ & $129.69(7.23)$ & $-1.57(1.71)$ \\
\hline 54 & & (2) & 125.01 & $(6.28)$ & -5.48 & $(0.47)$ & 123.82 & $(6.27)$ & $-5.62(0.51)$ & $129.62(6.37)$ & $-5.23(0.50)$ & $122.51(7.63)$ & $-5.70(0.79)$ \\
\hline 55 & & (3) & 129.62 & $(6.00)$ & 3.62 & $(1.12)$ & 128.26 & $(6.02)$ & $3.52(0.88)$ & $134.40(6.12)$ & $3.62(0.66)$ & $126.63(7.32)$ & 3.31 (1.21) \\
\hline 56 & & (4) & 134.26 & $(5.77)$ & 3.52 & $(0.63)$ & 133.19 & $(5.76)$ & $3.78(0.79)$ & $138.59(5.90)$ & $3.07(0.90)$ & $131.60(7.02)$ & $3.85(0.68)$ \\
\hline 57 & 1984 & (1) & 137.76 & $(5.61)$ & 2.57 & $(0.44)$ & 136.79 & $(5.61)$ & $2.66(0.31)$ & $141.84(5.76)$ & $2.32(0.33)$ & $135.37(6.82)$ & $2.83(0.34)$ \\
\hline 58 & & (2) & 134.29 & $(5.75)$ & -2.55 & $(0.33)$ & 133.43 & $(5.75)$ & $-2.48(0.26)$ & $138.14(5.91)$ & $-2.64(0.24)$ & 132.07 (6.99) & $-2.47(0.24)$ \\
\hline 59 & & (3) & 130.97 & $(5.69)$ & -2.50 & $(2.03)$ & 130.00 & $(5.73)$ & $-2.60(1.79)$ & $135.45(5.91)$ & $-1.97(1.58)$ & $127.11(7.09)$ & $-3.83(1.99)$ \\
\hline 60 & & (4) & 135.06 & $(5.48)$ & 3.08 & $(0.86)$ & 134.31 & $(5.52)$ & $3.26(0.84)$ & $139.50(5.73)$ & $2.95(0.49)$ & 130.79 (6.85) & $2.86(1.00)$ \\
\hline 61 & 1985 & (1) & 125.06 & $(5.79)$ & -7.70 & $(1.55)$ & 124.36 & $(5.87)$ & $-7.70(1.27)$ & $129.42(6.11)$ & $-7.50(1.08)$ & $120.47(7.31)$ & $-8.22(1.67)$ \\
\hline 62 & & (2) & 110.10 & $(6.50)$ & -12.74 & $(1.08)$ & 109.35 & $(6.59)$ & $-12.86(1.13)$ & $114.15(6.88)$ & $-12.55(0.91)$ & $105.80(8.20)$ & $-12.98(1.47)$ \\
\hline 63 & & (3) & 112.80 & $(6.27)$ & 2.42 & (1.09) & 111.99 & $(6.35)$ & $2.38(1.22)$ & $116.69(6.64)$ & 2.20 & $108.87(7.85)$ & $2.86(1.52)$ \\
\hline 64 & & (4) & 105.86 & $(6.35)$ & -6.35 & $(2.22)$ & 105.58 & $(6.38)$ & $-5.89(2.28)$ & $108.68(6.66)$ & $-7.11(2.74)$ & $102.98(7.88)$ & $-5.56(2.66)$ \\
\hline 65 & 1986 & (1) & 105.89 & $(6.19)$ & 0.03 & $(1.51)$ & 105.88 & $(6.16)$ & $0.28(1.65)$ & $108.53(6.42)$ & $-0.14(1.97)$ & $102.71(7.63)$ & $-0.27(2.14)$ \\
\hline 66 & & (2) & 104.75 & $(6.07)$ & -1.09 & $(1.56)$ & 105.04 & $(6.01)$ & $-0.80(1.65)$ & $106.72(6.22)$ & $-1.68(2.08)$ & $102.29(7.47)$ & $-0.41(1.74)$ \\
\hline 67 & & (3) & 90.27 & $(6.88)$ & -14.87 & $(1.36)$ & 90.61 & $(6.78)$ & $-14.78(1.44)$ & $91.99(6.89)$ & $-14.85(1.98)$ & $87.69(8.52)$ & -15.40 \\
\hline 68 & & (4) & 97.05 & $(6.04)$ & 7.23 & $(2.07)$ & 96.69 & $(6.17)$ & $6.49(1.48)$ & $99.76(5.89)$ & $8.10(2.38)$ & $92.56(8.01)$ & $5.40(0.91)$ \\
\hline 69 & 1987 & (1) & 98.41 & $(5.87)$ & 1.40 & $(0.96)$ & 97.92 & $(6.00)$ & $1.27(1.06)$ & 101.15 & $1.39(0.78)$ & $93.96(7.70)$ & $1.51(1.63)$ \\
\hline 70 & & (2) & 102.29 & $(5.57)$ & 3.86 & $(0.98)$ & 101.92 & $(5.64)$ & $4.00(1.17)$ & $104.43(5.32)$ & $3.19(1.74)$ & $98.89(7.22)$ & $5.11(1.19)$ \\
\hline
\end{tabular}


TABLE A4 (continued)

FINAL ESTIMATES OF MODEL (6.2)

(Standard errors in parentheses)

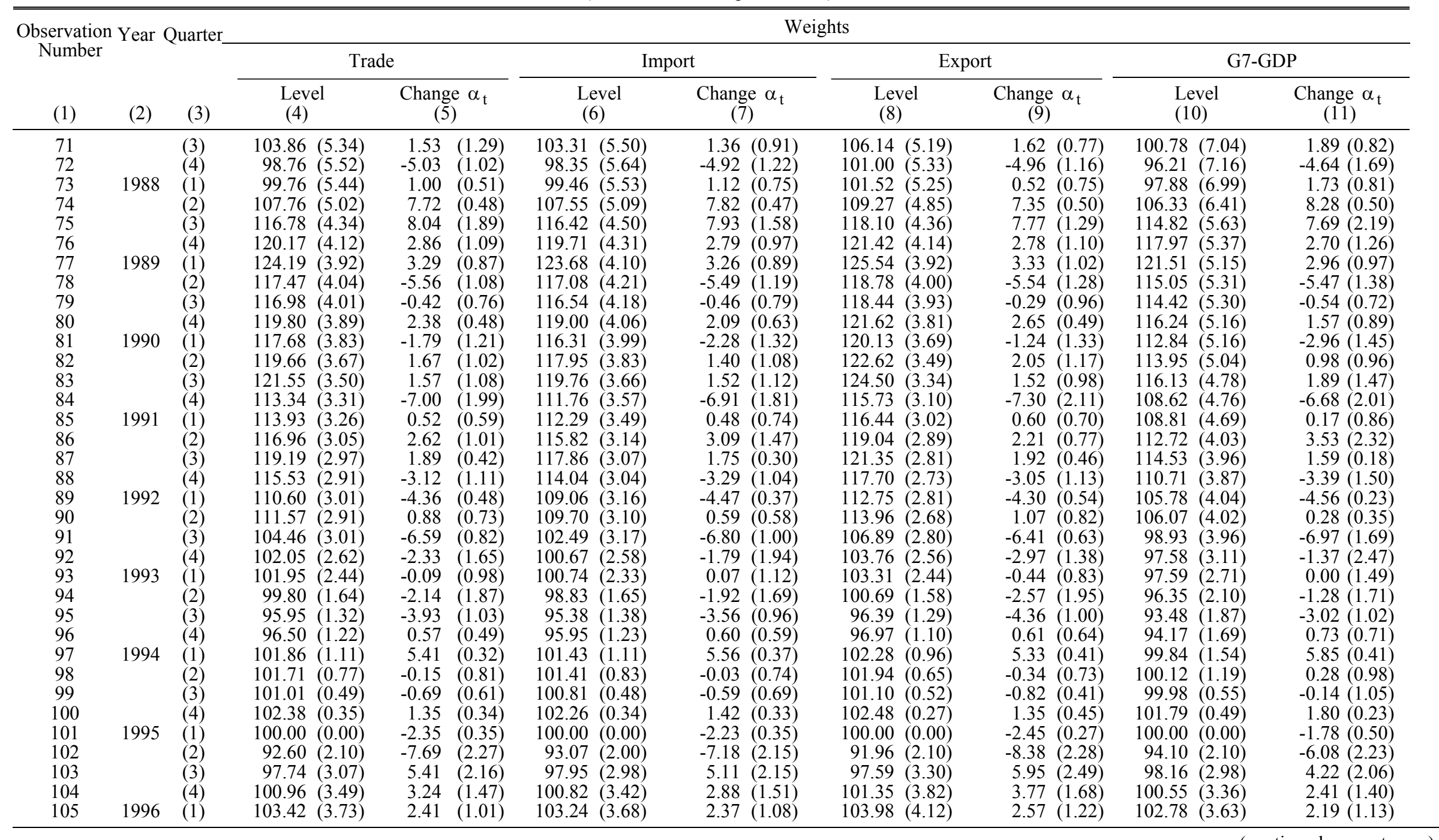


TABLE A4 (continued)

FINAL ESTIMATES OF MODEL (6.2)

(Standard errors in parentheses)

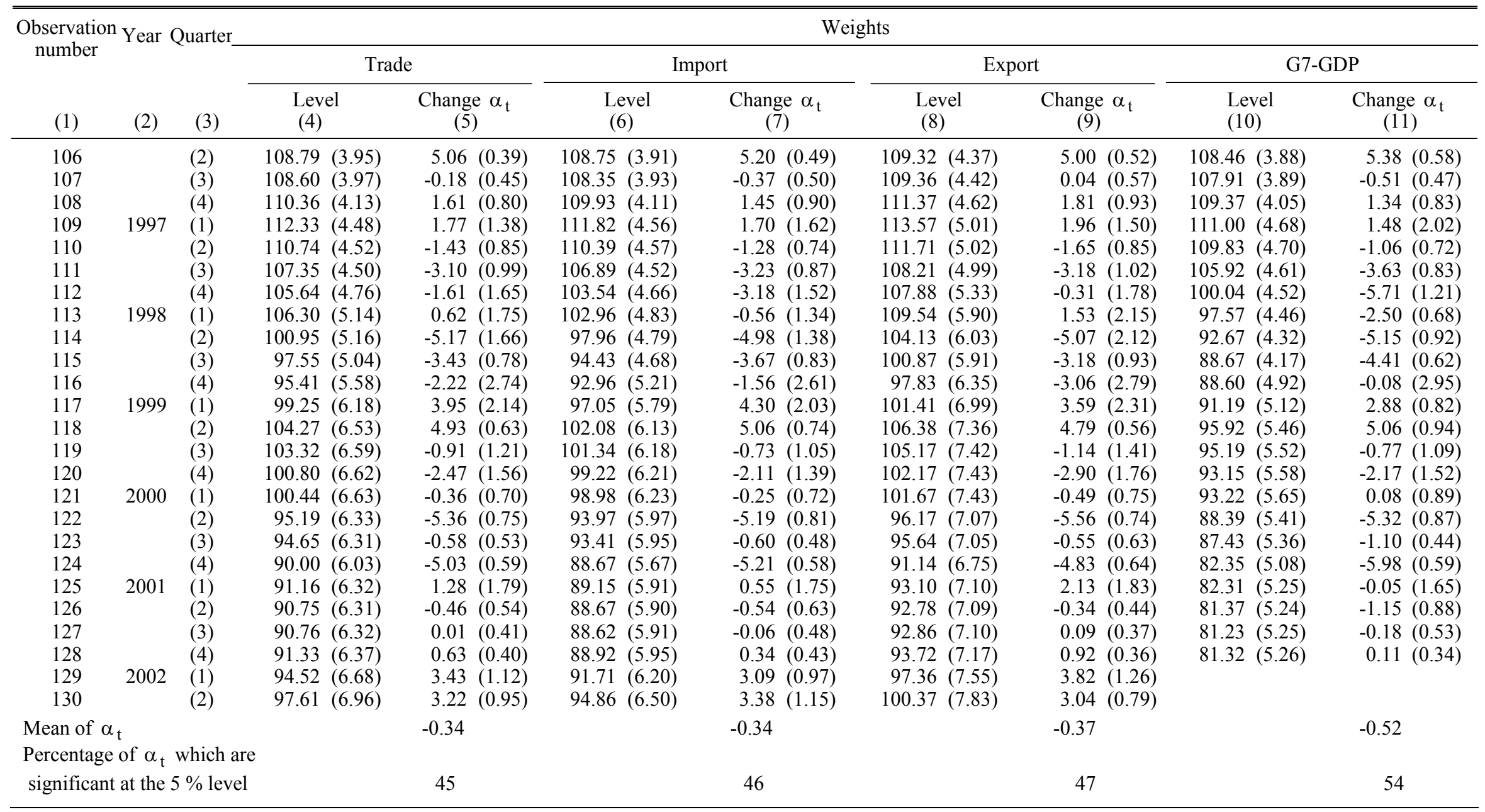

Notes: 1. This table corresponds to Table 8 .

2. The entries in columns 5, 7, 9 and 11 are to be divided by 100 . 
FIGURE A9

HISTOGRAMS OF ESTIMATES OF $\alpha_{t} \times 100$
A. Trade weights
B. Import weights
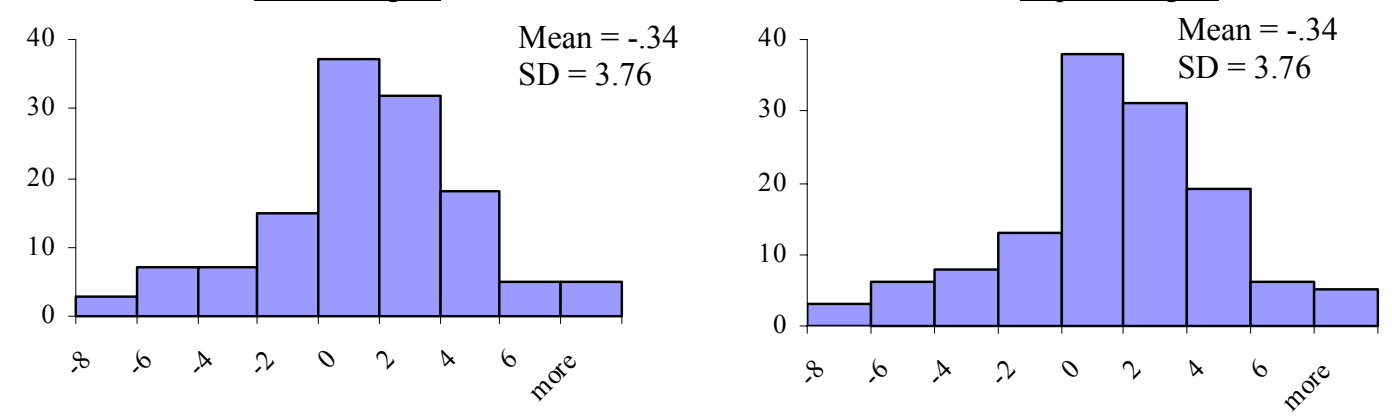

C. Export weights

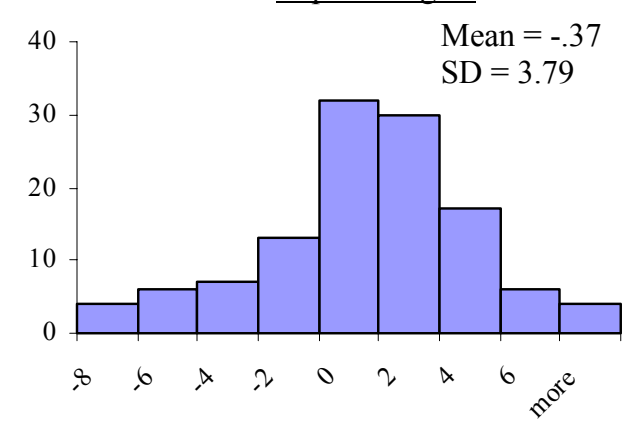

D. G7-GDP weights

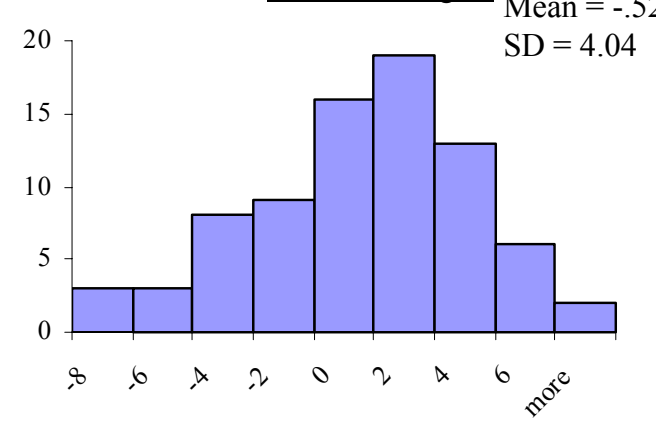

Notes: 1. This figure corresponds to Panel A of Figure 4.

2. All estimated $\alpha_{t}$ are to be divided by 100 .

FIGURE A10

HISTOGRAMS OF t-RATIOS OF $\alpha_{t}$
A. Trade weights
B. Import weights
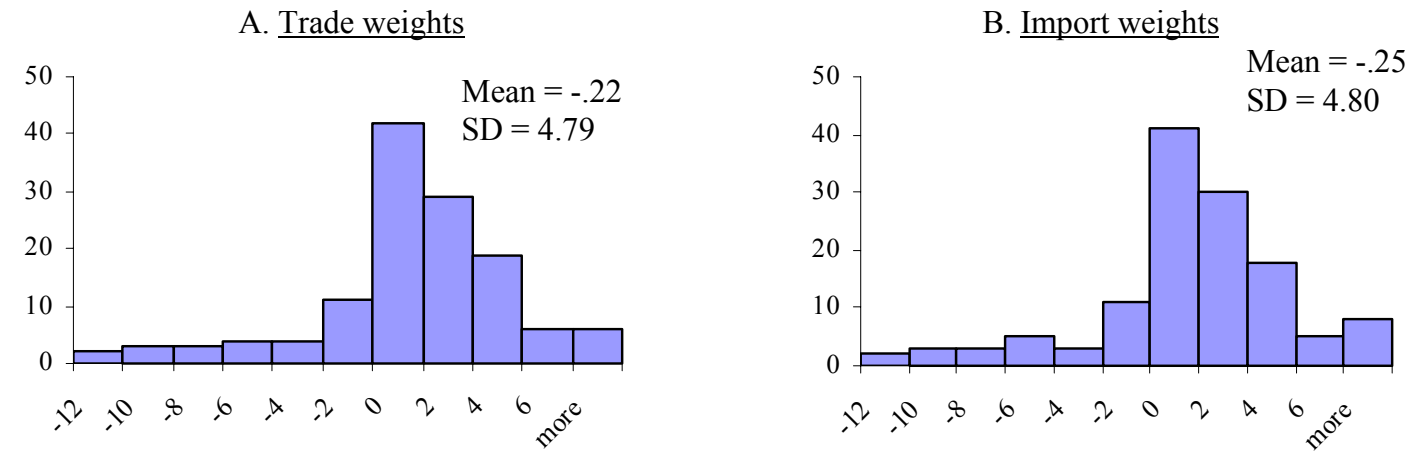

\section{Export weights}
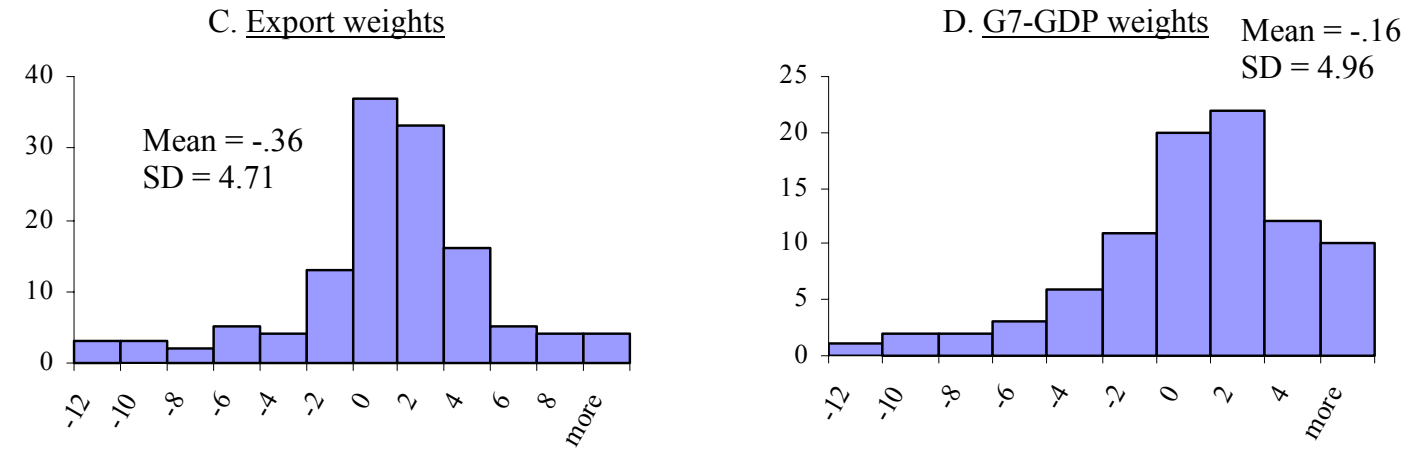

Note: This figure corresponds to Panel B of Figure 4. 
FIGURE A11
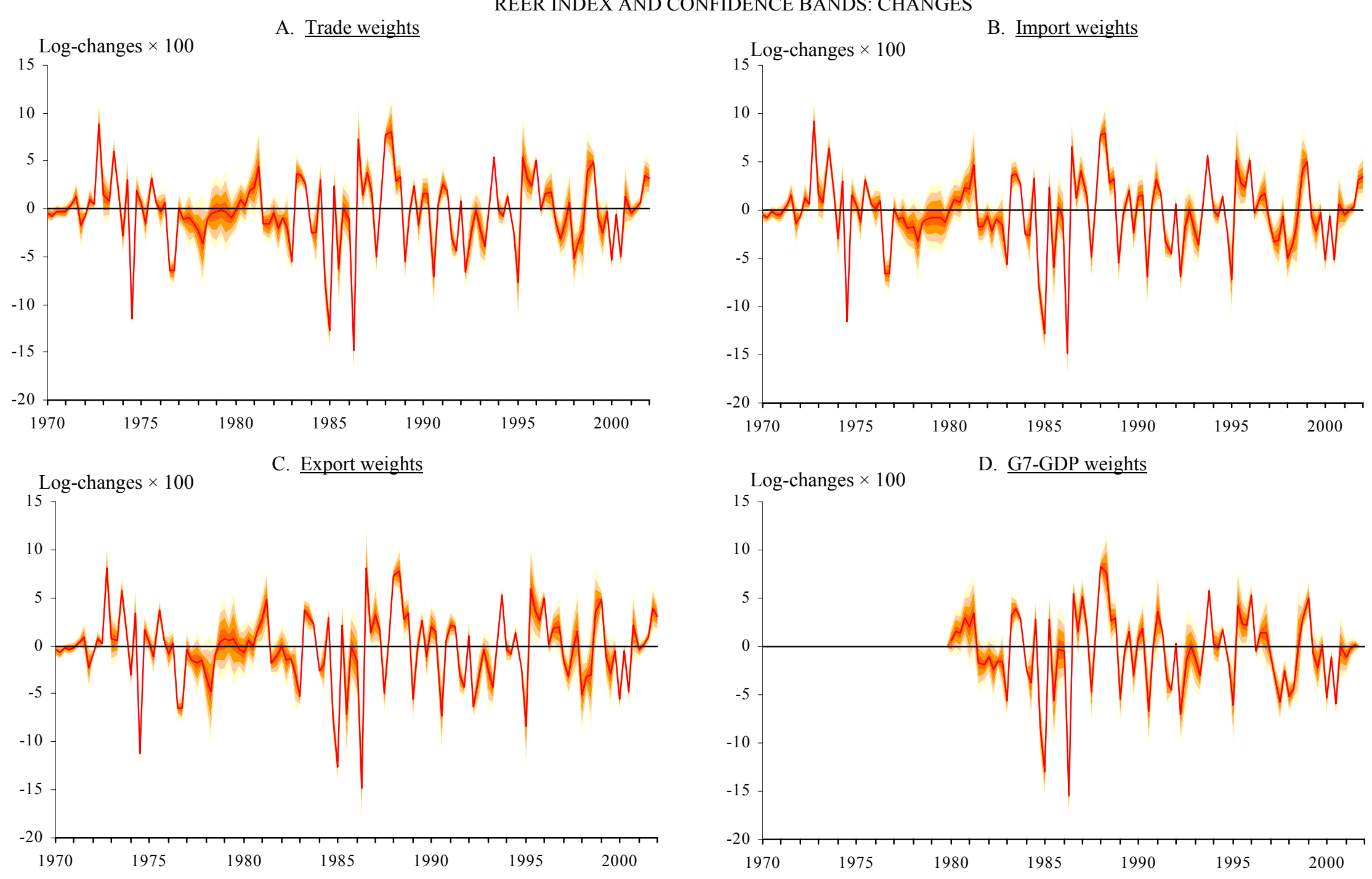

Note: This figure corresponds to Figure 5. 
FIGURE A12

REER INDEX AND CONFIDENCE BANDS: LEVELS
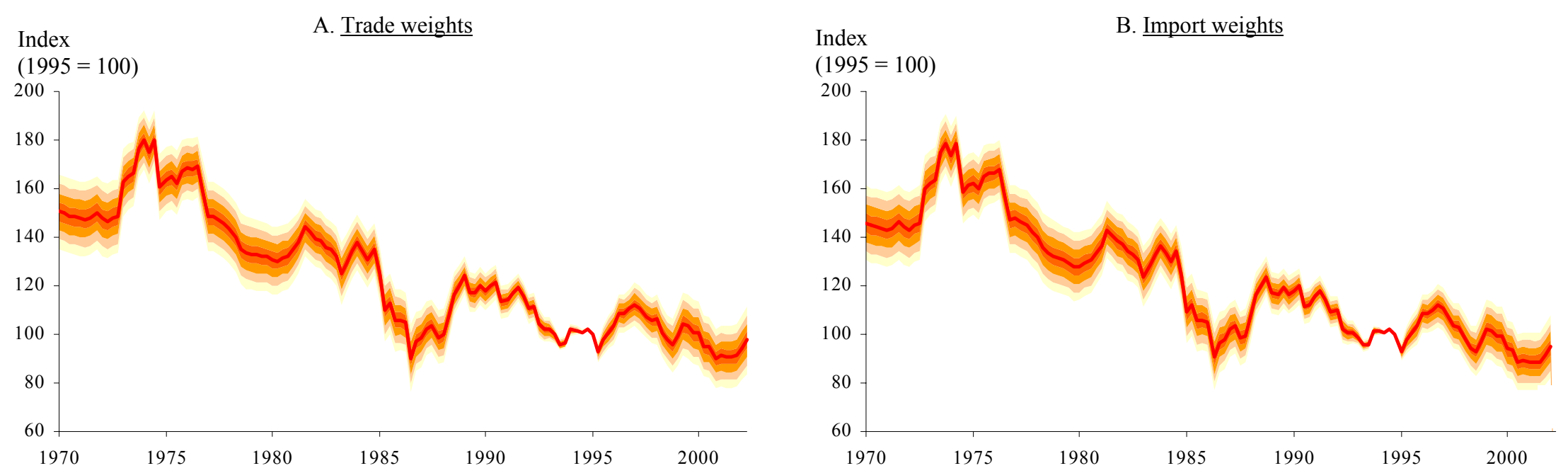

Index

C. Export weights

$(1995=100)$

Index $(1995=100)$

D. G7-GDP weights

200

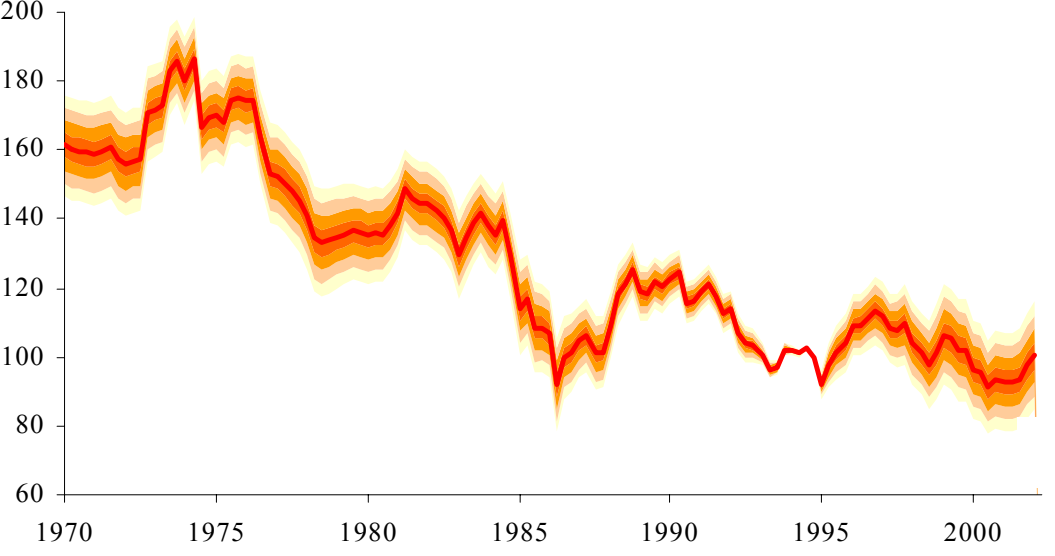

200

180

160

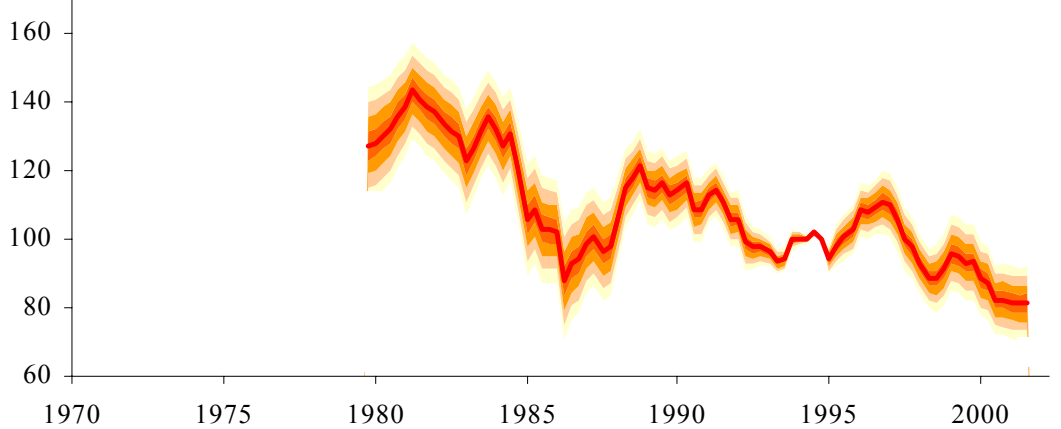

Note: This figure corresponds to Figure 6. 
TABLE A5

ESTIMATES OF COUNTRY-GROUP COMPONENTS OF REER CHANGES

(Standard errors in parentheses)

\begin{tabular}{|c|c|c|c|c|c|c|c|c|}
\hline \multicolumn{2}{|c|}{ Country group with } & \multicolumn{6}{|c|}{ Sub-period } & \multirow{2}{*}{ Mean } \\
\hline $\begin{array}{l}\text { GDP } \\
\text { growth }\end{array}$ & $\begin{array}{l}\text { Exchange-rate } \\
\text { change }\end{array}$ & 1 & 2 & 3 & 4 & 5 & 6 & \\
\hline \multicolumn{9}{|c|}{ A. Trade weights } \\
\hline Fast & Appreciation & $-0.87(0.24)$ & $-0.12(0.46)$ & $-0.35(0.89)$ & $-1.19(0.45)$ & $-0.37(0.28)$ & $-0.81(0.34)$ & $-0.65(0.15)$ \\
\hline Slow & Depreciation & $0.92(0.22)$ & $0.46(0.29)$ & $1.67(0.92)$ & $0.98(0.41)$ & $0.24(0.28)$ & $0.63(0.28)$ & $0.70(0.13)$ \\
\hline \multicolumn{2}{|c|}{ All other } & $-0.57(0.37)$ & $-0.08(0.20)$ & $-0.40(0.26)$ & $0.04(0.34)$ & $-0.12(0.18)$ & $-0.18(0.37)$ & $-0.20(0.11)$ \\
\hline \multicolumn{9}{|c|}{ B. Import weights } \\
\hline Fast & Appreciation & $-0.99(0.28)$ & $-0.11(0.52)$ & $-0.41(1.02)$ & $-0.49(0.41)$ & $-0.87(0.33)$ & & $-0.67(0.19)$ \\
\hline Slow & Depreciation & $0.80(0.22)$ & $0.53(0.29)$ & $1.34(0.94)$ & $0.27(0.20)$ & $0.65(0.26)$ & & $0.60(0.13)$ \\
\hline \multicolumn{2}{|c|}{ All other } & $-0.32(0.33)$ & $-0.17(0.19)$ & $-0.33(0.27)$ & $-0.14(0.12)$ & $-0.18(0.39)$ & & $-0.21(0.10)$ \\
\hline \multicolumn{9}{|c|}{ C. Export weights } \\
\hline Fast & Appreciation & $-0.63(0.17)$ & $-0.06(0.40)$ & - & $-2.34(1.25)$ & $-0.34(0.30)$ & $-0.75(0.37)$ & $-0.59(0.15)$ \\
\hline Slow & Depreciation & $0.75(0.19)$ & $0.70(0.37)$ & $1.93(0.68)$ & $1.49(0.59)$ & $0.55(0.32)$ & $0.61(0.33)$ & $0.85(0.14)$ \\
\hline \multicolumn{2}{|c|}{ All other } & $-0.25(0.34)$ & $-0.19(0.29)$ & $-0.33(0.12)$ & $-2.00(0.90)$ & $-0.08(0.07)$ & $-0.13(0.36)$ & $-0.24(0.07)$ \\
\hline \multicolumn{9}{|c|}{ D. G7-GDP weights } \\
\hline Fast & Appreciation & $-1.29(0.93)$ & - & $-0.29(0.34)$ & $-0.60(0.30)$ & & & $-0.57(0.24)$ \\
\hline Slow & Depreciation & $2.41(1.09)$ & - & $0.64(0.38)$ & $0.47(0.37)$ & & & $0.83(0.28)$ \\
\hline \multicolumn{2}{|c|}{ All other } & $-0.30(0.45)$ & - & $0.06(0.12)$ & $0.80(0.52)$ & & & $0.11(0.14)$ \\
\hline
\end{tabular}

Notes: 1. This table corresponds to Table 9.

2. See Table A1 for sub-periods.

3. The standard error of the mean, given in the last column, is calculated in the same way as in Table 9.

4. According to criteria (6.1), in sub-period 3 based on export weights, there are no fast-growing countries with appreciating currencies. In sub-period 2 based on GDP weights, all countries are classified as "all other", so that all $\beta_{\mathrm{c}}$ are indeterminant. 


\section{REFERENCES}

Balassa, B. (1964). “The Purchasing-Power Parity Doctrine: A Reappraisal.” Journal of Political Economy 72: 584-96.

Balk, B. M. (1995). “Axiomatic Price Index Theory: A Survey.” International Statistical Review 63: 69-93.

Breusch, T and A. Pagan (1979). "A Simple Test for Heteroscedasticity and Random Coefficient Variation." Econometrica 79: 1287-94.

Britton, E., P. Fisher and J. Whitley (1998), "The Inflation Report Projections: Understanding the Fan Chart," Bank of England Quarterly Bulletin 38: 30-37.

Chesher, A. and I. Jewitt (1987). "The Bias of the Heteroscedastic Consistent Covariance Matrix Estimator." Econometrica 55: 129-42.

Clements, K. W. and H. Y. Izan (1987). "The Measurement of Inflation: A Stochastic Approach." Journal of Business and Economic Statistics 5: 339-50.

Clements, K. W., H. Y. Izan and E. A. Selvanathan (2005). "Stochastic Index Numbers: A Review." Economics Program Discussion Paper No. 05.08, The University of Western Australia.

Cribari-Neto, F. and S. G. Zarkos (1999). "Bootstrap Methods for Heteroscedastic Regression Models: Evidence on Estimation and Testing." Econometric Reviews 18: 211-28.

Crompton, P. (2000). "Extending the Stochastic Approach to Index Numbers." Applied Economics Letters 7: 367-71.

Cumby, R. E. (1996). "Forecasting Exchange Rates and Relative Prices with the Hamburger Standard: Is What You Want What You Get with McParity?” NBER Working Paper 5676.

Davidson, R. and E. Flachaire (2001). "The Wild Bootstrap, Tamed at Last." Queen's Institute for Economic Research, Discussion Paper 1000.

Diewert, W. E. (1981). "The Economic Theory of Index Numbers.” In A. Deaton (ed) Essays in the Theory and Measurement of Consumer Behaviour (in Honour of Richard Stone). New York: Cambridge University Press. Pp. 163-208.

Diewert, W. E. (1995). “On the Stochastic Approach to Index Numbers.” Discussion Paper 95-31, Department of Economics, The University of British Columbia.

Diewert, W. E. (2002). "Weighted Country Product Dummy Variable Regressions and Index Number Formulae.” Discussion Paper 02-12, Department of Economics, The University of British Columbia.

Dwyer, J. and P. Lowe (1993). "Alternative Concepts of the Real Exchange Rate: A Reconciliation." Research Discussion Paper 1993-09, Reserve Bank of Australia.

Ellis, L. (2001). "Measuring the Real Exchange Rate: Pitfalls and Practicalities." Research Discussion Paper 2001-04, Reserve Bank of Australia.

Edwards, S. (1989). Real Exchange Rates, Devaluation, and Adjustment: Exchange Rate Policy in Developing Countries. Massachusetts: The MIT Press.

Fisher, I. (1922). The Making of Index Numbers. Boston: Houghton Muffin.

Flachaire, E. (2001). "Bootstrapping the Heteroscedasticity Consistent Covariance Matrix Estimator." Unpublished paper, University Paris Panthéon-Sorbonne.

Flachaire, E. (2003). Bootstrapping Heteroscedastic Regression Models.” Unpublished paper, University Paris Panthéon-Sorbonne.

Frenkel, J. A. (1978). "Purchasing Power Parity: Doctrinal Perspective and Evidence from the 1920s." Journal of International Economics 8: 169-91.

Frenkel, J. A. (1981). "The Collapse of Purchasing Power Parities during the 1970s." European Economic Review 27: 553-70. 
Froot, K. A. and K. Rogoff (1995). "Perspectives on PPP and Long-Run Real Exchange Rates." In G. Grossman, and K. Rogoff (eds) Handbook of International Economics. Amsterdam: North-Holland Press. Pp. 1647-88.

Godfrey, L.G. and C.D. Orme (2002). "Significance Levels of Heteroscedasticity-Robust Tests for Specification and Misspecification: Some Results on the Use of the Wild Bootstrap." Unpublished paper, University of York.

Harberger, A. (1986): "Economic Adjustment and the Real Exchange Rate." In S. Edwards and L. Ahamed (eds), Economic Adjustment and Exchange Rates in Developing Countries. Chicago: The University of Chicago Press.

Harberger, A. (2004): “The Real Exchange Rate: Issues of Concept and Measurement." Paper prepared for a Conference in Honour of Michael Mussa, International Monetary Fund.

Hinkle, L. and P. Montiel (1999) (eds) Exchange Rate Misalignment. Oxford: Oxford University Press and the World Bank.

Imbs, J., H. Mumtaz, M. O. Ravn and H. Rey (2002). "PPP Strikes Back: Aggregation and the Real Exchange Rate." NBER Working Paper 9372.

Lan, Y. (2004). "Equilibrium Exchange Rates and Currency Forecasts: A Big Mac Perspective." Unpublished Paper, The University of Western Australia.

Long, J. S. and L. H. Ervin (2000). "Using Heteroscedasticity Consistent Standard Errors in Linear Regression Models." The American Statistician 54: 217-24.

MacKinnon, J. G. and H. J. White (1985). "Some Heteroscedasticity Consistent Covariance Matrix Estimators with Improved Finite Sample Properties.” Journal of Econometrics 21: 53-70.

Michael, P., A. R. Nobay and D. A. Peel (1997). "Transaction Costs for Nonlinear Adjustment in Real Exchange Rates: An Empirical Investigation.” Journal of Political Economy 105: 862-79.

Ong, L. L. (2003). The Big Mac Index: Applications of Purchasing Power Parity. Hampshire, UK: Palgrave Macmillan.

Rogoff, K. (1996). "The Purchasing Power Parity Puzzle." Journal of Economic Literature 34: 647-68.

Samuelson, P. A. (1964). "Theoretical Notes on Trade Problems." Review of Economics and Statistics 46: 145-54.

Sarno, L. and M. P. Taylor (2002). "Purchasing Power Parity and the Real Exchange Rate." Chapter 3 in L. Sarno and M. P. Taylor The Economics of Exchange Rates. Cambridge: Cambridge University Press.

Selvanathan, E. A. and D. S. Prasada Rao (1994). Index Numbers: A Stochastic Approach. London: Macmillan.

Selvanathan, E. A. and S. Selvanathan (2004). "Modelling the Commodity Prices in the OECD Countries: A Stochastic Approach." Economic Modelling 21: 233-47.

Summers, R. and A. Heston (1991). "The Penn World Table (Mark 5): An Expanded Set of International Comparisons, 1950-1988." Quarterly Journal of Economics 106: 327-68.

Taylor, A.M. (2001). "Potential Pitfalls for the Purchasing-Power-Parity Puzzle? Sampling and Specification Biases in Mean-Reversion Tests of the Law of One Price." Econometrica: 47398.

Taylor, A. and M. P. Taylor (2004). “The Purchasing Power Parity Debate.” Journal of Economic Perspectives 18: 135-58.

Theil, H. (1967). Economics and Information Theory. Amsterdam: North-Holland.

Wallis, K. F. (1999), “Asymmetric Density Forecasts of Inflation and the Bank of England's Fan Chart." National Institute Economic Review 167: 106-12.

White, H. J. (1980). "A Heteroscedasticity-Consistent Covariance Matrix Estimator and a Direct Test for Heteroscedasticity." Econometrica 48: 817-38. 